Facultad de Ciencias Médicas.

Universidad Nacional de La Plata.

Tesis Doctoral

\title{
Estudio de la expresión del VEGF y su relación con la proliferación celular durante la regeneración hepática en ratones jóvenes.
}

Lic. Ayelen Fernández Blanco

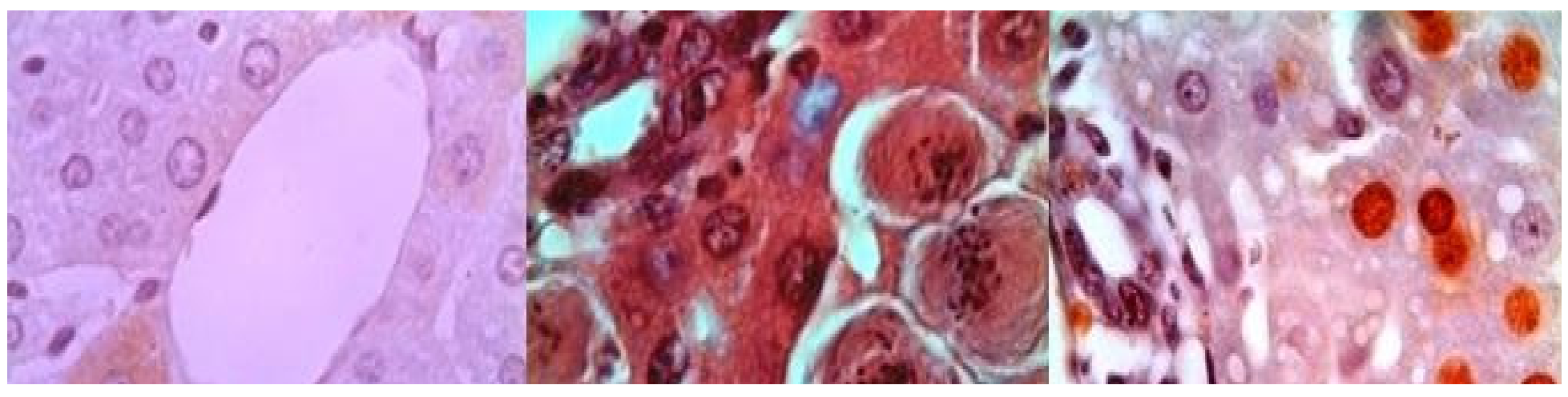




\title{
Estudio de la expresión del VEGF y su relación con la proliferación celular durante la regeneración hepática en ratones jóvenes.
}

\author{
Lic. Ayelen Fernández Blanco \\ Tesis Doctoral
}

\author{
De la Facultad de Ciencias Médicas, \\ Departamento de Ciencias Morfológicas, \\ Cátedra "A" de Citología, Histología y Embriología, \\ para optar al título de Doctora en Ciencias de la Salud.
}

Directora: Prof. Dra. Ana Lía Errecalde Co-Directora: Prof. Dra. Ana María Inda

La Plata

2015 
A mis amores Violeta, Valentin y Guille. 


\section{Agradecimientos}

A Ana Lía, por confiar en mí y haber abierto la puerta de la Cátedra para que hiciera Histología y permitirme trabajar en lo que más me gusta. Por escucharme, comprenderme y apoyarme siempre. Por acompañar mi crecimiento. Por sus consejos.

A Ana María, por haberme acompañado con las correcciones, la lectura critica y esas charlas de almuerzo. Gracias a ambas.

A los Profesores Dr. Carlos Martín, por facilitarme material fotográfico, bibliográfico y todo cuanto requería. Al Dr. Félix Corrons, por sus observaciones. A Marcela, por brindarme ayuda.

A mis hijos amados, Violeta y Valentin, por enseñarme a ser madre y darme el disfrute de sus abrazos y besos todos los días.

A Guille, mi amado esposo. El más leal compañero. Por sus consejos prácticos y humanos. Por mirarme y conocerme.

A mis queridos padres. Por transitar conmigo todas las etapas de mi vida con amor, aliento y alegrías. Por inculcarme la simpleza y el diálogo.

A mi amada hermana, Valeria. Por ser tan bella, sencilla $y$ escucharme. Por comprenderme. 
A mi compañera y amiga Adriana, por tantas charlas, momentos $y$ risas.

A mis amigas. A Laura por guiarme con sus palabras, por apoyarme y escucharme. A Cecilia, por alentarme y contagiarme la energía en todo momento.

A Mariela, que tantas veces me sacó de un apuro y por su ayuda en la edición de la tesis. A Angélica, por los mates cebados. A Walter y Vladimir, por acudir cuando lo necesitaba. A los técnicos de histología, especialmente a Maite. A Susana, por enseñarme el manejo del Bioterio y transmitirme su pasión. A Aylén por su buen humor y alegría.

A Marcos, Rocío y Barbi, por los momentos compartidos.

A todos mis compañeros de la Cátedra que de alguna manera formaron parte de esta tesis. 


\section{ÍNDICE}

\section{ABREVIATURAS}

RESUMEN

INTRODUCCION

1

1 Ciclo celular

1.1 Definiciones

$1.2 \quad$ Fases

1.3 Puntos de restricción

1.4 Control del ciclo celular

1.4.1 Ciclinas

1.4.2 Quinasas dependientes de ciclinas (Cdks)

1.4.3 Ciclinas inhibidoras de Cdks (CKIs)

1.4.4 Proteína P53

1.4.5 Ruta pRb /E2F

1.4.6 Factores de crecimiento

1.5 Ciclo celular en animales hepatectomizados y tumorales

1.6 Tipos de ciclos celulares

2 Ritmos biológicos

$2.1 \quad$ Ritmos biológicos

2.2 Ritmos circadianos

2.3 Ritmos circadianos en la expresión del VEGF, síntesis de ADN y actividad mitótica

3 Angiogénesis

3.1 Definición 18

3.2 Mecanismos de vascularización 19

3.3 Factores angiogénicos 20

3.3.1 Factor de crecimiento del endotelio vascular (VEGF) 20

$\begin{array}{lll}3.3 .1 .1 & \text { Estructura } & 21\end{array}$

3.3.1.2 Tipos de VEGF 22

3.3.1.3 Receptores 25

4 Unidad funcional hepática 27

$\begin{array}{lll}4.1 & \text { Tipos } & 27\end{array}$

5 Zonación metabólica 28

5.1 Mecanismos posibles de la zonación hepática 30 
5.2 Zonación hepática de la expresión del VEGF, de la síntesis de ADN y de la actividad mitótica 31

6 Crecimiento 31

7 Regeneración hepática 33

7.1 Capacidad regenerante del hígado 33

$\begin{array}{lll}7.2 & \text { Fases de la regeneración hepática } & 34\end{array}$

$\begin{array}{lll}7.3 & \text { Regeneración hepática y angiogénesis. } & 37\end{array}$

$\begin{array}{lll}7.4 & \text { Regeneración hepática en humanos } & 38\end{array}$

7.5 Expresión del VEGF, síntesis de ADN y actividad mitótica $\begin{array}{ll}\text { durante la regeneración hepática } & 38\end{array}$

8 Modelos experimentales de la regeneración hepática.

La hepatectomía parcial 39

9 Efecto de la portación de un tumor y de la hepatectomía parcial en la proliferación celular hepaocítica y en la expresión del VEGF 41

HIPÓTESIS $\quad 43$

OBJETIVOS

MATERIALES Y MÉTODOS $\quad 45$

1 Animales 45

1.1 Estandarización para análisis de periodicidad 46

$\begin{array}{lll}1.2 & \text { Tumor ES2 } & 47\end{array}$

$\begin{array}{lll}1.3 & \text { Injerto del tumor } & 48\end{array}$

1.4 Receptores de tumor $\quad 48$

1.5 Técnica quirúrgica. Técnica de Hepatectomía parcial 49

1.6 Administración de colchicina 50

1.7 Sacrificio de los animales y recolección de las muestras 51

2 Técnica Histológica.

Coloración con Hematoxilina de Meyer - Eosina. 52

3 Técnicas inmunohistoquímicas 53

3.1 Técnica inmunohistoquímica para Bromodeoxiuridina 53

3.2 Técnica inmunohistoquímica para VEGF 54

4 Cuantificación y clasificación de los datos 56

4.1 Método de recuento y determinación de la población de hepatocitos 56

$\begin{array}{lll}4.2 & \text { Método de registro } & 57\end{array}$

4.3 Determinación de los índices de marcación 57

5. Análisis estadístico de los datos 58 
DISEÑO EXPERIMENTAL $\quad 60$

Experimento I $\quad 60$

Experimento II 61

Experimentolll 62

RESULTADOS 63

DISCUSIÓN $\quad 67$

CONCLUSIONES PARCIALES $\quad 77$

CONCLUSIÓN GENERAL $\quad 78$

REFERENCIAS BIBLIOGRÁFICAS $\quad 79$

$\begin{array}{ll}\text { TABLAS } & 107\end{array}$

BECAS Y FINANCIAMIENTO 124

PUBLICACIONES 125 


\section{ABREVIATURAS}

$\begin{array}{ll}\text { ADNs } & \text { síntesis de ADN } \\ \text { AM } & \text { actividad mitótica } \\ \text { Int } & \text { Intactos } \\ \text { Hep } & \text { hepatectomizados } \\ \text { PortHep } & \text { portadores-hepatectomizados } \\ \text { HPP } & \text { hepatocitos periportales } \\ \text { HPV } & \text { hepatocitos perivenulares } \\ \text { BrdU } & \text { bromodeoxiuridina } \\ \text { HP } & \text { hepatectomía parcial }\end{array}$




\section{RESUMEN}

\section{ESTUDIO DE LA EXPRESIÓN DEL VEGF Y SU RELACIÓN CON LA PROLIFERACIÓN CELULAR DURANTE LA REGENERACIÓN HEPÁTICA EN RATONES JÓVENES.}

El hígado se caracteriza por su capacidad de regenerase tras un daño químico, viral o por remoción quirúrgica. Luego de realizada una hepatectomía parcial al $70 \%$, el tejido hepático remanente crece, fenómeno manifestado entre otros indicadores, por el aumento de la síntesis de ADN (ADNs) y de la actividad mitótica (AM) de los hepatocitos. Además, el crecimiento del tejido hepático debe ser acompañado por una nueva vasculatura, que aporte fundamentalmente oxígeno y nutrientes a todas las células neoformadas. La angiogénesis es el proceso responsable de que se formen estos vasos y el factor de crecimiento más importante que a su vez la estimula, se denomina Factor de Crecimiento del Endotelio Vascular (VEGF). Por otra parte, la presencia de células tumorales en el organismo puede provocar alteraciones en el ciclo celular normal y en el crecimiento, a través de la modificación en la temporalidad e intensidad de la ADNs y de la AM de los hepatocitos. Debido a que el fenómeno de regeneración hepática y la angiogénesis están íntimamente relacionadas es que se propuso analizar la evolución de los índices de la expresión del VEGF, de la ADNs y de la AM a lo largo de un periodo circadiano en los hepatocitos de los ratones machos jóvenes hepatectomizados portadores y no portadores de un tumor maligno y establecer la posible relación temporal entre dichas variables. Para ello, se utilizaron 169 ratones de la cepa $\mathrm{C} 3 \mathrm{H} / \mathrm{S}$ de 28 días, endocriados y estandarizados para el análisis de la periodicidad a los que se los dividió en los siguientes grupos experimentales: Intactos (grupo I), Hepatectomizados (grupo II) y PortadoresHepatectomizados (grupo III). A los 21 días, los animales del grupo III fueron injertados con el tumor espontáneo ES2. Al cumplir los 28 días, se realizó una hepatectomía parcial de los animales de los grupos II y III, los cuales se sacrificaron en lotes $(n=6)$ a las 12/26, 16/30, 20/34, 00/38, 04/42 y 08/46 hora del día/hora posthepatectomía, mientras que los animales Intactos se sacrificaron 
cada 4 horas y hasta completar un periodo circadiano. En todos los experimentos se tomaron muestras de la porción triangular derecha del hígado la cual fue procesada con la técnica histológica de rutina e inmunohistoquímica para el VEGF y BrdU. A partir del registro de las células, se estableció un índice porcentual para la expresión del VEGF, de la ADNs y de la AM de los hepatocitos de las zonas periportal y perivenular del lobulillo hepático. Luego se calculó la media aritmética \pm error estándar de cada lote, grupo y zona. Las medias fueron comparadas empleando los test estadísticos de Student, ANOVA y el postest de Comparaciones Múltiples de Tukey-Kramer. Los resultados muestran que el pico de la $\mathrm{AM}$ en los ratones hepatectomizados portadores y no portadores se presenta a las $08 / 46 \mathrm{HD} / \mathrm{HPH}$. La ADNs y la expresión del VEGF se adelantan y los valores de expresión del VEGF se incrementan en los ratones portadores. Finalmente, podemos concluir, que la cronobiología de los eventos de la proliferación celular en los ratones intactos y hepatectomizados sitúa los valores más altos de expresión de VEGF antes del pico de la síntesis de ADN. Sin embargo, al coexistir un tumor maligno en los ratones hepatectomizados, dicha cronobiología se ve modificada de modo tal que primero se manifiesta el pico de ADNs, luego el de expresión del VEGF y finalmente, el de AM.

Palabras claves: hígado, bromodeoxiuridina, VEGF, actividad mitótica, angiogénesis. 


\section{INTRODUCCIÓN}

La división celular y el crecimiento son la base de la vida biológica. Así como los componentes celulares deben ser duplicados durante la mitosis antes de que sean distribuidos entre las células hijas, también debió desarrollarse durante la evolución un preciso control que llevase a la duplicación y la segregación del genoma y que permitiera la progresión a través del ciclo celular (Uhlmann et al., 2011). Esto fue asegurado por la sucesión de etapas de G1, S, G2 y M que debe atravesar la célula durante el ciclo celular y que van a tener características particulares dependiendo de la célula que se trate (van den Heuvel, 2005). Así, existen algunas células diferenciadas que entran en un estado de quiescencia llamado G0 (células musculares esqueléticas), otras que continúan dividiéndose toda la vida (células hematopoyéticas), y otras que se dividen sólo para reparar una lesión o para compensar la pérdida de células por apoptosis (piel). Todas estas particularidades celulares tampoco se pueden explicar sin un mecanismo que controle la división celular (Viallard et al., 2001; Tarn and Lai, 2011). Sin embargo, también es imprescindible, que estos mecanismos puedan ser frenados cuando un organismo u órgano alcanza la masa óptima o cuando existen anomalías en los patrones de crecimiento normales (O’Farrell, 2011). Todas estas regulaciones del ciclo están principalmente a cargo de las ciclinas y de las quinasas dependientes de ciclinas (Viallard et al., 2001).

Por otro lado, la mayoría de las células de los metazoarios adultos ha abandonado el ciclo celular y permanecen quiescentes hasta que una injuria produce pérdida de células y éstas deben ser reemplazadas, o un cambio oncogénico conduce a una proliferación patológica. El estado de G0, presente tanto en organismos unicelulares como pluricelulares, tiene como una de sus finalidades detener el crecimiento celular de los organismos. Las señales de crecimiento sistémico operan en todos los órganos y tejidos y detienen el crecimiento cuando éste alcanza el tamaño adecuado (O’Farrell, 2011).

Tradicionalmente se considera a los hepatocitos del hígado normal como células quiescentes que responden mínimamente a mitógenos in vitro, así es como Michalopoulos (2011) considera a los hepatocitos adultos como células totalmente diferenciadas con limitada capacidad proliferativa. Este concepto se 
apoyó en el hecho de que en cultivos celulares los hepatocitos no podían experimentar más de uno o dos ciclos de división. Sin embargo, diversos estudios han dado evidencia experimental de la capacidad replicativa ilimitada de los hepatocitos, tanto mediante la inyección de factores de crecimiento como el TNF, en los que se vio que se inducía la replicación en un $40 \%$ más que en los normales; a través de la proliferación posthepatectomía; o mediante sistemas de cultivo en los cuales los hepatocitos proliferan teniendo un fenotipo diferenciado (Michalopoulus and DeFrances, 1997; Michalopoulos, 2011; Fausto and Campbell, 2003).

El estudio de la regeneración hepática que sigue a una hepatectomía parcial (HP) ha sido utilizado como modelo en la investigación básica, para evaluar el efecto sobre la misma de un tumor injertado, ya que representa el primer tratamiento para los tumores hepáticos 0 , incluso, para evaluar su efecto en la proliferación de las células hepáticas de ratones normales o portadores de un tumor (Wood and Hrushesky, 1996; García et al., 2009; García et al., 2010; Martin et al., 2000).

Por otra parte, el desarrollo de un lecho vascular mediante la angiogénesis es esencial para la reparación de un tejido, para las funciones reproductivas en el adulto y para la patogénesis de una serie de desórdenes como los tumores (Ferrara, 2004). Existe una relación estrecha entre la regeneración hepática y la angiogénesis. Ésta es estimulada por uno de los factores angiogénicos más potentes, el factor de crecimiento del endotelio vascular (VEGF) (Dogrul et al., 2010). Es producido por una gran variedad de células normales y transformadas entre las que se encuentran las células hepáticas regenerantes (Ferrara and Davis-Smyth, 1997; Dogrul et al., 2010). Además, la angiogénesis es un requisito fundamental para el desarrollo tumoral ya que éste debe ser abastecido por oxígeno y nutrientes sin los cuales, no podría crecer lo suficientemente y sus células morirían (Folkman, 1990; Folkman, 1995).

Se sabe que la extensión y momento en que ocurre la regeneración hepática varía dependiendo de los ritmos circadianos y de la especie de roedor utilizada (Fausto et al., 2006). En ratones parcialmente hepatectomizados, bajo condiciones estandarizadas de luz y de oscuridad, la regeneración hepática involucra un ritmo circadiano de la expresión del VEGF, de la síntesis de ADN y 
de la actividad mitótica, (García et al., 2009; Andrini et al., 2011). Además, en ratas parcialmente hepatectomizadas, hay una diferencia zonal en la incorporación de BrdU de los hepatocitos entre la zona perivenular y periportal (Othake et al., 2004).

\section{CICLO CELULAR}

\subsection{Definiciones}

Tres son los procesos que actúan de una manera integrada y coordinada para regular el crecimiento celular y la homeostasis tisular: el ciclo celular, la apoptosis y la diferenciación celular (Golias et al., 2004).

El ciclo celular es la secuencia de eventos durante el cual una célula en crecimiento replica todos sus componentes y se divide en dos células hijas, de manera que cada una de ellas recibe la información y maquinaria necesaria para repetir el proceso (Morgan, 2007). Otros autores han definido al ciclo celular como una serie de eventos repetitivos y ordenados mediante los cuales los animales completan cada división celular para que de una única célula cigoto se llegue a un individuo adulto (van den Heuvel, 2005).

\subsection{Fases}

Los eucariotas, desde las levaduras hasta el hombre, poseen ciclos celulares similares con 4 etapas o fases, Gap-1 (G1), Síntesis (S), Gap-2 (G2) y Mitosis. La prolongación de las fase G1 se conoce como Gap-0 (G0) o fase de reposo (Diallo and Prigent, 2011). Sin embargo, dependiendo los autores, el ciclo celular también se ha dividido en una interfase (fase de no división aparente o reposo) y otra de división o mitosis. La interfase comprende las etapas G1, S y G2 (Alberts et al., 2006). La mitosis se designa como M, Gap-1 proviene del inglés (intervalo 1), Gap-0 (intervalo 0), S por la etapa de duplicación del ADN, y Gap-2 (intervalo 2). La mayoría de las células diferenciadas adultas, las cuales no se dividen, se encuentran en la fase G1 o en estado de quiescencia (Viallard et al., 2001). 
Las fases G1 y G2 permiten ganar tiempo para que la célula crezca y duplique las organelas citoplasmáticas. Si la duración de la interfase se limitase al tiempo necesario para la replicación del ADN, la célula no tendría tiempo de duplicar su masa antes de dividirse e iría disminuyendo su tamaño cada vez más. Esto ocurre en circunstancias especiales de algunos embriones animales en los cuales con las sucesivas divisiones de clivaje (tras la fecundación), el ovocito va originado células más pequeñas. En estos casos las fases G1 y G2 están acortadas (Alberts et al., 2006).

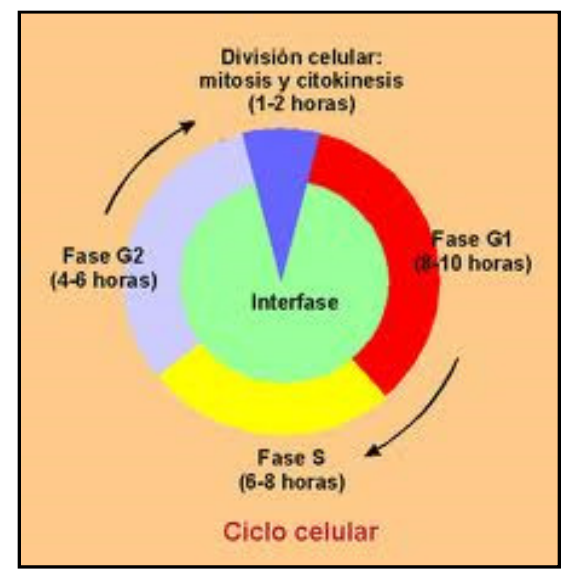

Fig. 1 Fases del ciclo celular mitótico de una célula proliferante.

\section{Descripción de las fases}

- fase M: durante la profase los cromosomas replicados inician su condensación y comienza a formarse el huso mitótico bipolar, que captura los cromosomas replicados y los alinea en la placa ecuatorial durante la metafase. Durante la anafase las cromátides hermanas son separadas hacia polos opuestos. En la telofase, la célula se divide para formar dos células hijas, cada una conteniendo una copia de cada cromosoma. Se completa en aproximadamente 30 minutos (Tyson et al., 2002; Lodish et al., 2005).

- fase $\mathbf{G}_{1}$ : esta fase se caracteriza por un aumento de la síntesis de proteínas y del ritmo metabólico. La célula recibe información del entorno 
extracelular y determina si se dividirá o no. Estudios realizados en levaduras y cultivos celulares de mamíferos permitieron reconocer como reguladores llave de esta fase a las ciclinas y quinasas dependientes de ciclina (Cdk). Los complejos ciclina-Cdk determinan el progreso de la célula a través de la fase $\mathrm{G}_{1}$ (Moeller and Sheaff, 2006; Tarn and Lai, 2011). Tiene una duración aproximada de entre 6 a12 h (Lodish et al., 2005).

- fase G0 o quiescente: las células de los mamíferos pueden abandonar reversiblemente el ciclo celular en respuesta a cambios del medio como la escasez de nutrientes 0 de factores de crecimiento, cambios en la adhesión celular e incremento en la densidad celular durante la etapa temprana de la fase G1. A esta estado/fase se la denomina quiescente o G0 (Oki et al., 2014).

- fase S: cada doble molécula de ADN (cromosoma) es replicada para formar un par de cromátides hermanas idénticas. (Barik et al., 2010). Esta fase dura aproximadamente $6 \mathrm{~h}$ (Murray and Hunt, 1993).

- fase $\mathbf{G}_{2}$ : es la fase que media entre la fase $S$ y la $M$. Se caracteriza por un crecimiento rápido de la célula y la síntesis de proteínas. Puede faltar en algunos ciclos como en embriones jóvenes de Xenopus y en algunos cánceres (Alberts et al., 2006; Liskay, 1977). En esta fase se encuentran listos la mayoría de los reguladores mitóticos para actuar durante la mitosis (Pérez de Castro et al., 2007). Dura, aproximadamente, 6 h (Murray and Hunt, 1993).

Señales externas a las células e información intrínseca determinan si las células se dividirán. En general, las señales externas afectan esta decisión solamente si las células se comprometen a atravesar el ciclo en su totalidad, lo que ocurre dentro de la fase $\mathrm{G}_{1}$, y se denomina Start (en levaduras) o punto de restricción (en mamíferos) (van den Heuvel, 2005). Durante G1, la célula debe decidir si continúa progresando a lo largo del ciclo celular y se dividirá, o si sale del ciclo para entrar en G0. La progresión a través del ciclo celular es controlada por la maquinaria intrínseca del ciclo celular (Shankland and Wolf, 2000). 


\subsection{Puntos de restricción}

El punto de restricción (R) (Pardee, 1989) o checkpoint es una vía bioquímica que se encarga de la dependencia de un proceso con respecto a otro. Son puntos de decisión de los mecanismos de control que operan e impiden la progresión dentro del ciclo celular si las etapas precedentes no fueron completas o si hay algún defecto en el ADN. Hay muchos $R$ pero los dos más críticos son aquellos que ocurren, casi al final de G1 (antes de la entrada en la fase S) y el que ocurre cerca del final de G2 (antes de la mitosis). De esta manera, una célula que se encuentra en $\mathrm{G} 1$, debe controlar su tamaño, la presencia de nutrientes y la integridad de su ADN antes de iniciar el proceso de la síntesis de ADN.

En G2 existe un punto de restricción (G2/M) que actúa en el caso de que el ADN no se haya duplicado, impidiendo a la célula entrar en mitosis (van den Heuvel, 2005).

Otro punto de restricción, fundamental para el ordenamiento de las etapas del ciclo celular típico, es el que ocurre dentro de la mitosis, llamado punto de restricción mitótico o comúnmente SAC (del el inglés spindle assembly checkpoint). Debe su nombre a que controla la transición desde la metafase a la anafase. Un cromosoma que no se halle correctamente orientado en el huso mitótico retrasa la progresión hacia la anafase, dando tiempo para reparar una defectuosa fijación al huso, la cual es crucial para la correcta segregación de los cromosomas (Uhlmann et al., 2011). Este punto de control resulta esencial en mamíferos, ya que sin él las células ingresan prematuramente a la anafase, provocando una segregación cromosómica incorrecta y la muerte celular consiguiente (Dobles et al., 2000).

\subsection{Control del ciclo celular}

El control de la progresión del ciclo celular está a cargo de muchos mecanismos reguladores. Dentro de los mismos incluimos a proteínas y complejos de proteínas: las ciclinas, las quinasas dependientes de ciclina (Cdks), los inhibidores de Cdks (CKI) y los productos de los genes supresores de tumor 
p53 y pRb (ruta pRb/E2F). Además, existen dos grandes grupos de factores involucrados en el control del ciclo: extracelulares (señales del ambiente, como los factores de crecimiento) e intracelulares (oncogenes y anti-oncogenes). Estas familias representan la maquinaria regulatoria básica responsable de la transición de la catálisis ciclo-celular y de los pasajes a través de los puntos de restricción (Golias et al., 2004).

Los factores de crecimiento son necesarios para la activación de las proteínas reguladoras que controlan la transición a través del punto de restricción de G1. Una vez que las células pasaron dicho punto, pueden continuar con el ciclo celular, aun en ausencia de mitógenos (Pardee, 1989).

Los componentes básicos de esta maquinaria que controlan el ciclo celular se conservan en todos los eucariotas. Consecuentemente, estudios genéticos realizados en las levaduras, bioquímicos en huevos de rana y cultivos tisulares en células de mamíferos, han contribuido conjuntamente a un conocimiento molecular sustancial acerca de la regulación del ciclo celular (van den Heuvel, 2005).

\subsubsection{Ciclinas}

Grupo proteico del sistema de control celular que no ejercen actividad enzimática por sí mismas sino a través de su unión a las quinasas dependientes de ciclina (Cdks), formando los complejos activos ciclina-Cdks. Estos complejos regulan las diferentes fases del ciclo celular (Alberts et al., 2006).

La denominación de "ciclina" se utilizó ya que se vio que las concentraciones de estas proteínas fluctuaban a lo largo del ciclo celular. Sin embargo, muchos de sus miembros no oscilan (Lim and Kaldis, 2013). Todas las variantes quedan definidas por una región común denominada ciclina box que sirve para unir las Cdk (Gopinathan et al., 2011).

Las ciclinas se pueden clasificar en 2 tipos de acuerdo al momento del ciclo en que actúan:

- ciclinas start o G1, son las que tienen su pico de expresión en esta fase del ciclo celular (ciclinas C, D1, D2 y D3) o en la transición G1/S (ciclina E). 
- ciclinas mitóticas, son las que actúan en la transición G2/M (ciclinas A y E) con su pico de expresión máximo en G2/M) (Viallard et al., 2001).

\section{Ciclinas start}

Ciclina C

Los niveles de ciclina $C$ son elevados en células humanas detenidas en G0. Se observó que la actividad asociada de una quinasa puede promover la salida de G0 de las células de mamíferos. La ciclina C forma complejos en las células con la proteína del retinoblastoma. Hasta ahora, la única quinasa asociada a la ciclina $C$ es la Cdk8. El complejo Cdk8-ciclina $C$ es un importante regulador de la transcripción de la polimerasa II y para el control transcripcional (Akoulitchev et al., 2000).

Ciclinas D

La función primaria de la ciclina $D$ es la de estimular la progresión en $G_{1}$. El factor disparador para la progresión a la fase $S$ es una señal mitogénica, como los factores de crecimiento. En respuesta a una activación de este tipo, las células sintetizan ciclina D, la que forma una holoenzima con las proteinquinasas Cdk4 y Cdk6.

La ciclina $D$ es la subunidad reguladora, mientras que las Cdks son las subunidades catalíticas (Stamatakos et al., 2010). Así, se constituye el complejo Cdks-ciclina D. El complejo activo fosforila la proteína pRB y la conduce a su inactivación. De esta manera, la pRB inactivada se separa de los factores transcripcionales E2F y los genes requeridos para la fase $S$ son transcriptos (Stamatakos et al., 2010; Viallard et al., 2001). 


\section{Ciclinas mitóticas}

Ciclinas E

La ciclina $E$ es una proteína nuclear que se expresa de manera máxima a finales de G1. Se une a la Cdk2 llevando a la fosforilación de los sustratos requeridos para una adecuada replicación, duplicación de centrosomas y la biosíntesis de histonas. La ciclina $\mathrm{E}$ y la Cdk2 pueden fosforilar e inactivar la pRB (Viallard et al., 2001).

Ciclina A

La ciclina A se une a la Cdk2 y el complejo formado tiene como principal rol asegurar la progresión a través de la fase $S$ del ciclo celular. También es activada durante la fase G2 para regular el tiempo de progresión de la mitosis (De Boer et al., 2008).

Las ciclinas A y B se unen a la Cdk1 y dichos complejos activos también son indispensables para la progresión del ciclo celular. Además, ambas regulan la entrada a la mitosis (Malumbres and Barbacid, 2005).

\subsubsection{Quinasas dependientes de ciclinas (Cdks)}

El mecanismo de control del ciclo celular ocurre mediante la activación e inactivación cíclica de proteínas y de los complejos que forman y así, éste regula el inicio de la replicación de ADN, la mitosis y la citocinesis. La fosforilación seguida de la desfosforilación es el proceso más utilizado por las células para conseguir la estimulación o inhibición de una proteína que actúa en el ciclo celular. De esta manera, las reacciones de fosforilación que controlan el ciclo celular son llevadas a cabo por un conjunto específico de proteínas (proteinquinasas). Éstas tienen la propiedad de enzima y transfieren un grupo fosfato de una molécula de ATP a una cadena lateral de aminoácidos de la proteína diana. Como poseen actividad enzimática cuando están unidas a las 
ciclinas, se las denomina, quinasas dependientes de ciclina o Cdks (Alberts et al., 2006).

Las Cdks se identificaron originalmente como quinasas que son esenciales para la activación de la mitosis y la replicación del ADN, pero ahora se sabe que también tienen un papel en muchos otros procesos celulares (Fisher et al., 2012). De las veinte Cdk que han sido, hasta ahora, identificadas en humanos, la Cdk1 es la única que es esencial para el ciclo celular en todas las células eucariotas (Malumbres et al., 2009); además, es suficiente para garantizar la ordenada replicación del ADN y la segregación cromosómica (Hochegger et al., 2007; Hochegger et al, 2008; Krasinska et al, 2008; Santamaría et al, 2007).

Tabla 1: Ciclinas y Cdks que operan en distintos momentos del ciclo celular en organismos eucariotas.

\begin{tabular}{|l|l|l|}
\hline Complejo Ciclina-Cdk & Ciclina & Cdk \\
\hline$G_{1}$-Cdk & ciclina $D^{*}$ & Cdk4, Cdk6 \\
\hline$G_{1} /$ S-Cdk & ciclina E & Cdk2 \\
\hline S-Cdk & ciclina A & Cdk2 \\
\hline M-Cdk & ciclina B & Cdk1 ${ }^{* *}$ \\
\hline
\end{tabular}

*Hay tres ciclinas D en los mamíferos: D1, D2, y D3. ${ }^{* *}$ Cdk1 es el mismo que Cdc2 en la levadura de fisión y Cdc28 de la levadura en gemación (Alberts et al., 2006).

Con sus diferencias, la regulación del ciclo celular mediante la activación y desactivación de las Cdks ocurre en todos los eucariotas. Por otro lado, recientes estudios demuestran que tanto las ciclinas, como las Cdks o las ciclinas inhibidoras de ciclinas pueden tener funciones aun sin formar complejos y así 
actuar en una gran variedad de roles independientes respecto del ciclo celular (Lim and Kaldis, 2013).

\subsubsection{Ciclinas inhibidoras de Cdks (CKIs)}

Hay ciclinas que en lugar de promover la actividad de las Cdks, las restringen. A éstas se las llama ciclinas inhibidoras de Cdks (CKI) y regulan negativamente (por retroalimentación negativa) la progresión del ciclo celular por inhibición del complejo ciclina-Cdk (Sherr and Roberts, 1995). Juegan un papel importante en la detención del ciclo celular en la fase G1 en respuesta a una variedad de estímulos, que van desde la privación del factor de crecimiento al daño del ADN, estrés celular, la diferenciación, y la senescencia (Duronio and Xiong, 2013).

Las CKIs se subdividen en dos tipos de acuerdo a su estructura y especifidad con las Cdks. La familia Ink4 que engloba a las p16, p15, p18 y a la p19; la familia de las Cip/Kip, que incluye a las p21, p27 y a la p57 (Lim and Kaldis, 2013). Estas dos familias de CKIs inhiben Cdks a través de diferentes mecanismos y evolucionaron para satisfacer la creciente necesidad de integrar numerosas señales diferentes antiproliferativas que puede detener a las células en la fase G1 (Duronio and Xiong, 2013).

\subsubsection{Proteína P53}

La proteína citoplasmática P53 (se denomina así debido a que su peso molecular es de $53 \mathrm{kDa}$ ), no solo sobreregula la expresión de los genes envueltos en la detención del ciclo celular (ej., p21) y en la apoptosis (ej., Bax, Apaf1), sino que también reprime la transcripción de las polimerasas I y III, pudiendo interferir entonces con la biogénesis de los ribosomas y el crecimiento celular (Pfeuty et al., 2008). Esta proteína es sintetizada por las células y es codificada por el gen p53, perteneciendo a la categoría de genes supresores de tumores. Sus niveles nucleares aumentan considerablemente en respuesta a una gran variedad de señales de estrés (ej. Daño del ADN, hipoxia, falta de nutrientes, contacto célulascélula, señales oncogénicas, deformación celular). En los mamíferos la proteína 
citoplasmática P53 tiene como uno de los roles más importantes detener a la célula en G1, después de un daño genotóxico, para que el ADN sea reparado antes de su duplicación y de la consiguiente división celular. Ello lo logra mediante la inhibición de cientos de genes (Reed and Quelle, 2015; Vousden and Prives, 2009). En respuesta a un daño masivo en el ADN y que no se puede reparar, dispara la ruta hacia la muerte celular por apoptosis. Esta capacidad se debe a la activación de la transcripción de la p21, inhibidora de las Cdk que controlan la entrada en fase S (Sherr, 1996). La p53 también puede causar que las células detengan el crecimiento de forma permanente y existen evidencias convincentes de que in vivo estas células "senescentes" secretan factores que conducen a la regresión del tumor (Xue et al., 2007). A través de estos mecanismos, la p53 ayuda a mantener la estabilidad genómica dentro de un organismo, lo que justifica su tan celebrado apodo de "guardián del genoma" (Lane, 1992).

\subsubsection{Ruta pRb/E2F}

Otro regulador del ciclo celular es el gen localizado en el cromosoma 13q14, codificando para la proteína del retinoblastoma $(p R b)$. Su presencia es crítica para la transición G1/S (van den Heuvel, 2005).

Su rol es posible gracias a la asociación con factores de transcripción, principalmente con los E2F (van den Heuvel, 2005).

La ciclina $D$ es capaz de formar complejos heterodiméricos con la proteína pRb. (Golias et al, 2004).

\subsubsection{Factores de crecimiento}

Mientras que las ciclinas actúan durante la fase de iniciación del hígado en regeneración para que se produzca la entrada de los hepatocitos quiescentes a G1, su continuidad a través del mismo está a cargo de los factores de crecimiento, los cuales anulan el punto de restricción al final de G1. El pasaje de G1 a la fase $S$ está asociado a la fosforilación de la pRb, el incremento en la expresión de la p107 (miembro de la familia de la Rb) y de la ciclinas D, E y A, y la formación de los complejos ciclina D-cdk4 y ciclina E-cdk2 (Fausto et al., 2006). 
Dentro de las funciones que poseen los factores de crecimiento se incluyen la regulación de la proliferación celular, la movilidad y la muerte celular (Cross and Dexter, 1991). Además, son necesarios para la activación de las proteínas reguladoras que controlan la transición a través del punto de restricción de G1. Una vez que las células pasaron dicho punto, pueden continuar con el ciclo celular, aun en ausencia de mitógenos (Pardee, 1989).

Dentro de los factores de crecimiento existen los de competencia que actúan en el pasaje de $\mathrm{G}_{0}$ a $\mathrm{G}_{1}$ del ciclo celular (ej., PDGF) y de progresión que desencadenan la transición entre las etapas $G_{1}$ y $S$ (ej., EGF, IGF). Ningún factor de crecimiento actúa después de que la célula pasó el punto de restricción y comienza a sintetizar ADN (Kojima and Nagasawa, 2007).

\subsection{Ciclo celular en animales hepatectomizados y tumorales}

En la regeneración hepática post-hepatectomía, intervienen tanto el TGF-a, que actúa por vía autocrina, como el EGF que es producido por las glándulas de Brunner y llega al órgano a través de la vena porta (Michalopoulos, 2010).

En la hepatectomía parcial (HP) la transición desde $\mathrm{G}_{0}$ a $\mathrm{G}_{1}$ y la progresión desde $G_{1}$ parecen estar gobernadas, en parte, por cambios en la matriz extracelular y por citoquinas incluyendo el factor de crecimiento tumoral-a (TGFa) y la interleuquina-6 (IL-6). A su vez, la inducción de la proteína ciclina D1 en los hepatocitos requiere de factores de crecimiento y se corresponde temporalmente con el pasaje a través del punto de restricción de G1 a las 40- 44 h. También es conocido que la regulación del complejo ciclina-quinasa de las fases $G_{1}$ y $S$ es similar en los hepatocitos del hígado en regeneración y en otros tipos celulares (Loyer et al., 1996; Albrecht et al., 1995).

La regulación por parte del reloj biológico circadiano se mantiene durante todo el proceso de regeneración hepática, incluso cuando la mayoría de los hepatocitos están atravesando el ciclo celular. Si bien las señales temporales humorales y nerviosas participan en la regulación del ciclo celular, la presencia de vías celulares del reloj circadiano hacia el sistema del ciclo celular, indican una fuerte correlación entre la hora de expresión del gen clock con la hora de los eventos del ciclo celular durante la regeneración hepática (Matsuo et al., 2003). 
Por otro lado, se sabe que en los tumores, por ejemplo, una proliferación celular descontrolada se debe a alteraciones del ciclo celular que involucran reguladores de la progresión de $\mathrm{G}_{1}$ y de la transición $\mathrm{G}_{2} / \mathrm{S}$ como los componentes de la vía $\mathrm{p} 16^{\mathrm{INK} 4 \mathrm{~A}}-\mathrm{Cdk4-pRB}$. Estas alteraciones incluyen la sobreexpresión de ciclinas (mayoritariamente D y E) y de las Cdk4 y Cdk6; inhibidores de ciclinas (mayoritariamente $\mathrm{p} 16^{\mathrm{ink} 4 \mathrm{~A}}, \mathrm{p} 15^{\mathrm{INK} 4 \mathrm{~B}}$ y $\mathrm{p} 27^{\mathrm{KIP} 1}$ ) o sustratos Cdk como la pRB que resultan inhibidos (Massague, 2004; Malumbres and Barbacid, 2001). Existen, además, los reguladores mitóticos como la Cdk1 que, presentes sobre todo al final de $G_{2}$, se encuentran preparados para actuar en la mitosis (Pérez de Castro et al., 2007).

\subsection{Tipos de ciclos celulares}

Los ciclos celulares somáticos presentan variaciones dependiendo de los requerimientos del desarrollo. Por ejemplo, en el ciclo celular embrionario (clivaje), se saltean las fases $G_{1}$ y $G_{2}$; en los ciclos celulares meióticos se producen gametas con número haploide y por último, existen los ciclos de endoduplicación (o "endoreplicación"), en los cuales la fase S no es seguida por la fase M. Todas estas variantes de ciclos celulares pueden coexistir en algunos animales como en el nematode Caenorhabditis elegans (van den Heuvel, 2005).

Podemos sintetizar que son tres las propiedades fundamentales que caracterizan el ciclo celular mitótico o somático, en el cual la replicación y partición de las moléculas de ADN ocurre en 4 fases. Primero, el proceso de síntesis de ADN y de mitosis debe alternarse en cada línea celular para mantener la ploidía generación tras generación. En una célula eucariota típica, las fases $S$ y M están separadas por dos fases gap: $\mathbf{G}_{\mathbf{1}}$ y $\mathbf{G}_{\mathbf{2}}$. Segundo, los ciclos alternantes de $S$ y $M$ deben ser balanceados con otros procesos biosintéticos para alcanzar el incremento en dos veces de todos los otros componentes celulares. Tercero, la célula debe ser capaz de detener la progresión a través del ciclo celular si surgiera cualquier problema en la síntesis de ADN o mitosis (Barik et al., 2010). 


\section{Ritmos biológicos}

\subsection{Ritmos biológicos}

Es sabido que los distintos procesos de la naturaleza varían en forma rítmica. Pero, durante la evolución, los seres vivos han sabido adaptarse a las condiciones cambiantes de la naturaleza por medio de los ritmos biológicos. (Escobar et al, 2001). Un ritmo biológico se define como la variación cíclica de una función fisiológica presente en cualquier ser vivo (Virag and Lust, 2014). Por medio de la homeostasis el cuerpo responde a los estímulos externos de manera de mantener todas las variables del medio interno en niveles constantes.

La homeostasis puede ser reactiva o predictiva (Golombek, 2007):

Reactiva: el cuerpo responde ante un estímulo del ambiente con mecanismos que permiten restablecer los niveles de ciertas variables fisiológicas para mantenerlos relativamente constantes, ej.: ingesta de glucosa.

Predictiva: el organismo posee mecanismos endógenos de variación que predicen los cambios que ocurrirán más tarde. En cierta forma la respuesta precede al estímulo. Aquí incluimos a los ritmos biológicos que son considerados como una forma de adaptación conductual y fisiológica en respuesta al medio ambiente cambiante y cíclico (Ángeles-Castellanos et al., 2007).

Para comprobar el carácter endógeno de los ritmos deben realizarse los experimentos bajo condiciones de laboratorio constantes. Si los ritmos desaparecen, entonces se trata de ritmos exógenos; por el contrario, si persisten, son endógenos o marcapasos (Golombek, 2007). 


\subsection{Ritmos circadianos}

Dependiendo de la duración temporal de los ritmos, éstos pueden ser circadianos, aquellos con períodos cercanos a las 24 h (ej., actividad/reposo, temperatura corporal), ultradianos aquellos con períodos menores a los circadianos (ej., secreciones pulsátiles hormonales) e infradianos aquellos con períodos mayores a los circadianos, como los ritmos estacionales (ciclo menstrual, hibernación). El ambiente es el que condiciona esta periodicidad. Podemos decir que no existe función que no posea ritmos diarios, tanto sea el comportamiento, la fisiología, la biología celular o incluso los fenómenos moleculares. Como parte de estas fluctuaciones, las distintas variables poseen valores máximos y mínimos: las funciones catabólicas suelen tener sus máximos durante el día mientras que las anabólicas (funciones de reparación, y crecimiento), durante la noche (Golombek, 2007).

El sistema circadiano se encuentra formado por un reloj biológico dominante o central, el NSQ (núcleo supraquiasmático en los mamíferos), un tracto retino-hipotalámico (vía aferente de transmisión de información luminosa al núcleo) y vías eferentes que transmiten las señales a los sistemas efectores que expresan los diferentes ritmos fisiológicos y conductuales (Ángeles-Castellanos, 2007). EI NSQ es capaz de conferirle este orden temporal a los procesos internos y a la conducta. Se ha comprobado que si se extirpa, se pierden los ritmos circadianos. Las vías aferentes, en cambio, transmiten el paso del tiempo hacia los relojes endógenos y ajustan continuamente sus oscilaciones al tiempo geofísico (Golombek, 2007).

Al proceso de ajuste de los ritmos a los ciclos ambientales se lo conoce como sincronización. Para el NSQ, el principal sincronizador ambiental es la alternancia de luz-oscuridad (o Zeitgeber: "dador, indicador de tiempo"), recibiendo esta señal por aferencias desde la retina. El alimento también es un sincronizador relevante para los ritmos biológicos pero solamente en casos de restricción de alimento o de ayuno y no bajo condiciones de ad libitum y de animales obesos. Otros marcapasos son los secundarios o esclavos, como los pulmones y el hígado, los cuales muestran oscilaciones circadianas y actuarían sincronizando además, otros ritmos biológicos del cuerpo (Escobar et al., 2001). 
Los ritmos circadianos de la proliferación celular así como las funciones hepáticas específicas se activan en el hígado de las ratas a partir del día 20 de vida. Esto se corresponde con la activación y evolución circadiana del eje hipotálamo-hipofisario-adrenal (Touitou, 1997). Además, en estudios in vitro se ha demostrado que el hígado funciona como un "marcapasos" local, el cual muestra oscilaciones circadianas debido a que poseería algún mecanismo de estimación del tiempo y se acepta que actúa como sincronizador de otros ritmos biológicos del organismo (Escobar et al., 2001). Probablemente, la importancia de este órgano radique en que señala al sistema nervioso central los cambios en el estado de balance energético ya que posee numerosos genes que están involucrados en el metabolismo de lípidos, proteínas y carbohidratos (Escobar et al., 2001; Gatfield and Schibler, 2008).

La cronobiología es la ciencia que estudia los ritmos biológicos en todos los niveles de organización (Golombek, 2007).

Una de las aplicaciones que tiene el estudio de los ritmos es la cronopatología, que centra su interés en los procesos rítmicos, fisiológicos y fisiopatológicos, asociados a la morbilidad y mortalidad en algunas enfermedades vasculares, respiratorias, etc. (Ángeles-Castellanos et al., 2007).

2.3 Ritmos circadianos en la expresión del VEGF, síntesis de ADN y actividad mitótica.

En los mamíferos los ritmos circadianos influyen en la hora de la división celular in vivo. Las variaciones día-noche en la síntesis de ADN y en el índice de actividad mitótica ocurren en la mayoría de los tejidos. Sin embargo, la manera en que los relojes circadianos controlan el momento de la división celular todavía es incierto (Matsuo et al., 2003).

Como hemos mencionado antes, el ritmo circadiano en la proliferación celular y de las funciones hepáticas aparecen en el hígado de ratas a partir del día 20 de vida y se dan tanto en el crecimiento normal como en la regeneración posthepatectomía (Touitou, 1997). En ratones hepatectomizados, el pico de replicación de ADN ocurre siempre $36 \mathrm{~h}$ posteriores a la operación, independientemente de la hora del día en el cual se haya realizado el 
procedimiento. La entrada en mitosis de aquellas células que ya replicaron su ADN (células G2) siempre ocurre a la misma hora del día (Fausto et al., 2006). Este hecho demuestra que un reloj biológico controla la transición G2/M (Matsuo et al., 2003). Sin embargo, al comparar los picos de síntesis de ADN (ADNs) de ratas y ratones, se observó que los mismos ocurrían a distinta hora posthepatectomía (Weglartz and Sandgren, 2000). Este último hecho demostraría que, en realidad, la hora de replicación de ADN no está bajo el control de los ritmos circadianos, resultando ser una propiedad intrínseca de los hepatocitos y un proceso autónomo (Touitou, 1997).

Se han encontrado variaciones circadianas en el hígado para la síntesis de ADN y la $A M$ de ratones machos de 21 días y para la $A M$ de ratones de 28 días (Echave Llanos et al., 1971a), para la síntesis de ADN y la AM de ratones adultos (Surur et al., 1985), para la AM de los hepatocitos de ratas machos (marcados con timidina tritiada) (Grisham, 1962) y de expresión del VEGF en ratones macho y hembra adultos (Fernández Blanco et al., 2011). Se han demostrado, además, la existencia de ritmos circadianos en la actividad mitótica de otras poblaciones celulares no hepáticas de ratones jóvenes intactos (Barbason et al., 1987; Andrini et al., 1999; García et al., 2001; Furnus et al., 2003).

\section{$3 \quad$ Angiogénesis}

\subsection{Definición}

La angiogénesis es un proceso en el cual nuevos capilares son formados a partir de preexistentes, tanto en un contexto fisiológico (ejercicio, cicatrización de heridas) como patológico (cáncer) (Stefanini et al., 2008). Otros autores lo definen como un proceso hipóxico y dependiente de los factores de crecimiento que consiste en la formación de nuevas estructuras vasculares a partir de preexistentes (Novo et al., 2007). Es un proceso complejo que depende de la interacción coordinada entre las células endoteliales, pericitos, células circundantes y de la asociación con la matriz extracelular y con la membrana basal vascular (Chung and Ferrara, 2010). Los vasos sanguíneos atraviesan 
todos los órganos para aportar oxígeno, nutrientes y moléculas señal a los tejidos en crecimiento, tanto durante la embriogénesis como en la vida adulta (Karamysheva, 2008). Además, es un proceso complejo en el cual participan varios componentes reguladores hormonales y celulares (van der Bilt and Borel Rinkes, 2004).

\subsection{Mecanismos de vascularización (Kempf, 2004):}

a) Vasculogénesis: es responsable de la formación del corazón y de los primeros vasos sanguíneos dentro del embrión y de la circulación en el saco vitelino. Representa la diferenciación y crecimiento de los capilares. Los hemangioblastos mesodermales se diferencian a angioblastos extraembrionarios (situados en el saco vitelino) e intraembrionarios los cuales se conectan estableciendo, de esta manera, el primer plexo vascular (Patan, 2004; Kempf, 2004).

Las primeras investigaciones de Asahara et al. (1997) demostraron que este proceso también ocurría en los adultos mediante las células derivadas de la médula ósea. Las mismas participarían en la reparación vascular, regeneración, metástasis tumoral, neoangiogénesis y la promoción del crecimiento ("vasculogénesis posnatal").

b) Angiogénesis: es la responsable de la formación de nuevos vasos sanguíneos a partir de un plexo vascular primario. Los nuevos capilares son formados mediante 2 mecanismos distintos: uno por la brotación desde capilares preexistentes o a través de la división de lechos preexistentes en lechos más pequeños (Peirce and Skalak, 2003).

La angiogénesis es responsable del modelado y expansión de la vasculatura embrionaria y es estimulada por la carencia de oxígeno y un entorno inflamatorio (Patan, 2004; Carmeliet and Collen, 2000).

c) Arteriogénesis: es el crecimiento de arteriolas colaterales preexistentes a arteriolas colaterales funcionales. A diferencia de la angiogénesis no depende de la hipoxia o isquemia. Es el remodelado de vasos arteriales para mejorar el flujo sanguíneo hacia el lecho vascular (Schaper et al., 2003). 


\subsection{Factores angiogénicos.}

Aunque la mayoría de los vasos sanguíneos en los organismos adultos permanecen quiescentes, las células endoteliales retienen la posibilidad de dividirse rápidamente en respuesta a un estímulo fisiológico, que muchas veces resulta en la activación de la angiogénesis (Karamysheva, 2008).

Existen varias moléculas que pueden servir como reguladores positivos de la angiogénesis, como el FGFa y $\beta$, TGFa y $\beta$, el HGF, el TNF $\alpha$, la angiogenina, la interleuquina-8 y las angiopoyetinas. Sin embargo, no todos son factores específicos de las células endoteliales (Karamysheva, 2008).

Por otro lado, se sabe que el mantenimiento de la homeostasis vascular depende del balance entre factores pro y antiangiogénicos y es estrictamente regulado por interacciones de los factores con los receptores, rutas de señalización intracelular, así como por la interacción entre las células y su matriz extracelular (Carmeliet, 2003).

\subsubsection{Factor de crecimiento del endotelio vascular (VEGF)}

EL VEGF fue descubierto en los años '80 en las células folículoestrelladas de la hipófisis bovina y en una variedad de líneas tumorales. En sus orígenes, se lo denominó "Factor de permeabilidad vascular" (FPV), término acuñado por Senger et al. en 1983, como resultado de analizar la creciente extravasación de tintura de los vasos sanguíneos que producía en experimentos realizados en una línea de células tumorales del cerdo de guinea. Posteriormente, en 1989, los endocrinólogos Ferrara and Henzel y Plouet et al. de manera separada, lo identifican como un factor tumoral angiogénico, y lo denominan "VEGF" y "vasculotropina", respectivamente. Actualmente, el término VEGF se aplica a una molécula que puede ser vascular, endotelial o de crecimiento específica (Bates, 2010).

El VEGF tiene un rol fundamental en la regulación de la angiogénesis normal y anormal y es uno de los factores esenciales en la cascada angiogénica, ya que la estimula (Ferrara and Davis-Smyth, 1997). Su importancia está dada por su habilidad en regular y coordinar las múltiples funciones endoteliales (Zachary, 
2003; Bao et al., 2009), estimulando, por ejemplo, los ARNm de las ciclinas D, las cuales intervienen en la transición del estado quiescente al proliferativo de las células, la progresión durante G1 y la transición G1/S (Jeremy and Dashwood, 2006).

Además, el VEGF incrementa la permeabilidad vascular por lo que también se lo llamó FPV, induce la degradación de la membrana basal endotelial y de la matriz extracelular, facilitando el movimiento endotelial hacia el espacio extravascular, así como también la migración de las células endoteliales durante las cicatrizaciones y la proliferación de las células endoteliales (Bao et al., 2009). También estimula el crecimiento de las células endoteliales de las arterias, venas y vasos linfáticos, siendo un factor de supervivencia de dichas células in vivo e in vitro (Gerber et al., 1998; Benjamin et al., 1999). Sin embargo, el efecto del VEGF in vivo es diferente en organismos en crecimiento y adultos, ya que la inhibición del VEGF en ratones recién nacidos produce apoptosis, mientras que en adultos de más de 4 semanas de edad, no tiene prácticamente efecto (Gerber et al., 1999). Se ha visto, que en la homeostasis de las células endoteliales de ratones adultos, bajo condiciones normales, participaría un control autocrino del VEGF (Lee et al., 2010).

El descubrimiento de una subfamilia de isoformas antiangiogénicas del VEGF agregó al conocimiento previo una mayor complejidad para interpretar la regulación de la angiogénesis, ya que éstos actuarían tanto en tejidos humanos normales como en enfermedades angiogénicas (cáncer, retinopatía) (Woolard et al., 2009).

\subsubsection{Estructura}

El VEGF representa una superfamilia de proteínas homodiméricas que actúan en la angiogénesis y linfangiogénesis y que existen bajo 5 isoformas

diferentes. Éstas resultan del empalme alternativo de sus ARNm, con largos de 121, 145, 165, 189 y 206 aminoácidos y, comúnmente, se refieren como VEGF-A (VEGF ó VEGF 165$)$, VEGF-B, VEGF-C, VEGF-D, y el factor de crecimiento placental (PIGF). Además, existen otros dos miembros que son únicos en cuanto a que poseen funciones diferentes, el VEGF-E, que es un VEGF viral y el VEGF- 
F, proveniente del veneno de serpiente (Yamazaki and Morita, 2006). Por otro lado, si consideramos las isoformas antiangiogénicas, resultan varios subtipos diferentes de VEGF, uno de los cuales es el VEGF VE5 $_{165}$ ("b" por ser la isoforma antiangiogénica del VEGF $F_{165}$ ) (Woolard et al., 2009). El VEGF 165 es la isoforma más estudiada y disponible (Bao et al., 2009).

A medida que aumenta la longitud de la cadena, el VEGF cambia de una forma débilmente ácida a una básica, la cual mejora la habilidad de la molécula a unirse a la heparina por su carboxilo terminal. A la inversa, el amino terminal del VEGF contiene una secuencia señal para la secreción de proteínas (Leung et al., 1989). La biohabilidad del VEGF depende de la isoforma así, el VEGF $F_{121}$, se secreta libremente, y el $V_{E G F}$ y y el $V E_{18 F} F_{206}$ se secretan pero, en gran medida, vinculados a la heparina que reside en la superficie celular. EI VEGF 145 y VEGF ${ }_{165}$ muestran características intermedias, con unión equivalente y formas libres. $E$ balance entre la forma libre y las otras formas del VEGF tiene implicancias importantes para un efecto local vs. un efecto sistémico (Bao et al., 2009).

La gran variedad de efectos que puede tener el VEGF en los distintos tejidos estaría relacionada al potencial que posee para formar isoformas alternativas (Bates, 2010).

Por otro lado, la presencia de moléculas similares al VEGF y a sus receptores en invertebrados que carecen de sistema vascular indica que esta familia de factores de crecimiento surgió en un momento muy temprano de la evolución de los organismos multicelulares para mediar funciones de desarrollo primordiales (Holmes and Zachary, 2005).

\subsubsection{Tipos de VEGF}

\section{VEGF-A}

El VEGF-A (también llamado VEGF), que es el mayor regulador de la angiogénesis y vasculogénesis, puede ser generado por casi todas las células bajo condiciones de hipoxia o estrés y es altamente expresado en tejidos en crecimiento o remodelado tisular (Bates, 2010). Además, promueve la supervivencia de las células endoteliales mediante la inducción de la enzima 
óxido nítrico sintetasa endotelial, incrementando la producción de ácido nítrico y, por otro lado, induciendo la expresión de proteínas antiapoptóticas como la Bcl-2 y la A1 de las células endoteliales (Kroll and Waltenberger, 1999).

EI VEGF estimula la proliferación, migración y la formación de tubos de las células endoteliales (Ferrara et al., 2003). Se une a los receptores VEGFR1 (flt-1) y al VEGFR2 (KDR/flk-1), los cuales desempeñan roles distintos durante la angiogénesis, pero también a los receptores Nrp-1y Nrp-2 (neuropilina-1 y 2, respectivamente) (Shibuya, 2006; Klagsbrun, et al., 2002).

\section{VEGF-B}

La hipoxia no estimula el cambio de sus niveles. Las isoformas 167 y 186 se hallan en humanos en los músculos esqueléticos, miocardio y tejido adiposo marrón. Se une a los receptores VEGFR1 y Nrp-1. De acuerdo a ciertos estudios podría ser el responsable de formar las arterias colaterales coronarias (Yamazaki and Morita, 2006).

\section{VEGF-C}

Es producido como una proteína precursora y activada proteolíticamente en la matriz extracelular, con gran afinidad para los receptores VEGFR2 y VEGFR3.

Induce mitógénesis, migración y supervivencia de las células endoteliales y se expresa en el corazón, intestino delgado, placenta, ovario y la glándula tiroides en el adulto. Varios estudios lo identifican como un factor linfangiogénico que ejerce su rol mediante el VEGFR3 (Karkkainen et al., 2004). Es indispensable para la linfangiogénesis embrionaria y para los tumores e inflamaciones asociadas a la linfangiogénesis (Roy et al., 2006).

\section{VEGF-D}

Es una proteína que se expresa en muchos tejidos adultos incluyendo el endotelio vascular, corazón, musculatura esquelética, pulmones e intestino. En 
humanos se une a los VEGFR2 y 3, mientras que en los ratones, al VEGFR3 (Jeltsch et al., 1997). Estimula la proliferación de las células endoteliales y tiene propiedades angiogénicas in vivo e in vitro. Se cree que tendría rol en la angiogénesis tumoral y linfangiogénesis (Stacker et al., 2001; Achen et al., 2001).

\section{VEGF-E}

Este factor de crecimiento fue descubierto en el genoma del parapoxvirus (Orf virus) que infecta a ovinos, caprinos y ocasionalmente, a los humanos (Lyttle et al., 1994). Sus diferentes tipos se unen a los receptores VEGFR2 y Nrp-1 y son capaces de estimular la mitosis de las células endoteliales y la permeabilidad vascular (Yamazaki and Morita, 2006).

\section{PIGF}

El factor de crecimiento placentario (PIGF) es un miembro de la familia del VEGF que fue identificado en la placenta, aunque también se halla en el corazón y los pulmones. Incluye 4 isoformas que se unen a los receptores VEGFR1. Algunos de los efectos que están comprobados son el crecimiento y viabilidad de las células endoteliales y la angiogénesis asociada al VEGF (Roy et al., 2005).

\section{VEGF-F}

Es el miembro más reciente descubierto de la familia del VEGF y fue hallado en el veneno de serpientes. Se aislaron dos subtipos, los cuales se denominaron vammin y VR-1. A partir de estudios realizados sobre su estructura cristalina se piensa que podrían llegar a interaccionar con la heparina o con moléculas similares, ya que el VEGF-F presenta un dominio de unión para la misma. También se ha visto que estimula la proliferación de las células endoteliales in vitro. Todos los tipos de VEGF-F reconocen al receptor KDR (VEGFR2) pero no a otros receptores del VEGF (Yamazaki et al., 2003; Yamazaki et al., 2009; Suto et al., 2005). 


\subsubsection{Receptores}

La interacción entre el VEGF y sus receptores es esencial para muchos procesos proangiogénicos, tanto en los procesos fisiológicos normales como patológicos.

Los VEGFs actúan mediante la unión a un receptor específico de VEGF (VEGFR). Se conocen el VEGFR1 (o flt-1), el VEGFR2 (o flk-1 en ratón y KDR en humano) y el VEGFR3 (o flt-4). Los tres receptores pueden ser usados por las diferentes isoformas para incrementar la permeabilidad vascular y angiogénesis, entre otras acciones. Todos los receptores funcionan por homo o heterodimerización y por la activación de una tirosina quinasa intracelular (Bates, 2010).

Los receptores KDR y flt-1 se localizan en la superficie del endotelio de los vasos sanguíneos en desarrollo y maduros. El flk-1 es importante para la diferenciación de las células endoteliales, mientras que flt-1 se requiere para la organización de los vasos sanguíneos. Además, los flt-1 podrían mediar la permeabilidad vascular, la respuesta quimiotáctica de los neutrófilos y macrófagos, la expresión de metaloproteinasas de la matriz en células endoteliales del músculo liso y la inducción de proteínas antiapoptóticas (Bao et al., 2009). Para LeCouter et al. (2003) el VEGFR2 es el mediador principal entre el VEGF-A y la mitogénesis, angiogénesis y permeabilidad vascular. EI VEGFR1, en cambio, estaría implicado en la inhibición de la mitosis endotelial VEGFdependiente y en la quimiotaxis de los monocitos o supervivencia de las células hematopoyéticas (LeCouter et al., 2003). El receptor VEGF3 se relacionaría con la regulación del crecimiento vascular linfático mediante su unión a los VEGF-C y -D (Alitalo et al., 2005).

EI VEGF y su sistema de receptores están involucrados en la formación de los vasos sanguíneos y vasos linfáticos en mamíferos desde las fases más tempranas de la embriogénesis (Ferrara and Davis-Smyth, 1997; Alitalo and Carmeliet, 2002). 
Los receptores poseen roles diferentes tanto en la angiogénesis patológica como fisiológica y durante la embriogénesis temprana, para alcanzar un balance apropiado de la vasculatura (Shibuya, 2006).

\section{VEGFR1}

Este receptor posee una característica distintiva. Estudios genéticos muestran que existe una proteína del VEGFR1 soluble que además de la regulación positiva que utiliza la vía tirosina quinasa, también podría funcionar como un inhibidor del VEGF-A, por medio de la regulación negativa. En ratones mutantes que carecen de flt-1 hay una muerte temprana de los embriones, con un sobrecrecimiento y desorganización de sus vasos sanguíneos. Es decir, que el VEGFR1 jugaría un rol negativo al suprimir las señales proangiogénicas en el embrión temprano para establecer un balance esencial para la angiogénesis fisiológica (Shibuya, 2006).

\section{VEGFR2}

Desde la vida posnatal hasta la adulta, el VEGFR2 se encuentra en las células del endotelio vascular y linfático, así como en las células endoteliales de ratones normales, aumentando sus niveles durante la angiogénesis (Shibuya, 2006; Lee et al., 2007). Niveles más bajos también se observan en las células neuronales, osteoblastos, células ductales pancreáticas y megacariocitos (Matsumoto and Claesson-Welsh, 2001). Dentro del tejido tumoral las células tumorales y las células estromales activadas expresan niveles elevados de VEGFA, pero poco VEGFR2, mientras que las células endoteliales del tumor exhiben una sobre-expresión del mismo. Esto sugiere un patrón paracrino entre el VEGFA y el VEGFR2 de las células tumorales y el endotelio vascular en la estimulación de la angiogenesis tumoral (Ferrara and Davis Smith, 1997; Alitalo and Carmeliet, 2002; Shibuya and Claesson-Welsh, 2006). 


\section{VEGFR3}

Se expresa en el endotelio linfático de los embriones y de los organismos adultos por lo que cualquier modificación en la cascada de señalización intracelular altera la linfangiogénesis (Alitalo and Carmeliet, 2002). Sin embargo, en estudios de cultivo, se demostró que la activación de este receptor es suficiente para proteger a las células de la apoptosis e inducir su proliferación y migración. Sus ligandos son el VEGF-C y $D$, pero estos factores también se pueden unir al receptor VEGFR2 (Karamysheva, 2008).

\section{Neuropilinas}

Es una clase diferente de receptor, que no pertenecen al grupo tirosina quinasa y que se pueden unir al VEGF ya que se hallan en la superficie de algunas células tumorales y endoteliales (Soker et al., 1998). El VEGF165 induce la formación de complejos entre la Nrp-1 y el receptor VEGFR2 (KDR) para mejorar la señalización del VEGFR2 durante la migración de las células endoteliales in vitro y la arteriogénesis in vivo (Fantin et al., 2014).

\section{Unidad funcional hepática}

\subsection{Tipos}

La estructura del lóbulo de Kiernan o clásico es hexagonal con los tractos portales en los vértices del mismo y con una vena hepática en el centro (Kiernan, 1833). El lóbulo portal, descripto por Mall (1906), tiene un tracto portal en el centro y vénulas centrales en la periferia. Definiendo la unidad funcional sobre la base del flujo microcirculatorio en el interior del hígado, Rappaport et al. (1954) describieron el acino hepático. Estas unidades permiten explicar algunos procesos fisiológicos y patológicos en el hígado (Cascales Angosto, 2009).

Los hepatocitos se organizan en el lobulillo hepático describiendo anatómicamente tres zonas: periportal (zona upstream), la cual rodea el tracto 
portal donde ingresa la sangre; media; y perivenular o centrolobulillar (zona downstream), que es pobremente oxigenada y se halla alrededor de la vena central. De esta manera, sangre rica en oxigeno, sustratos y hormonas ingresa periportalmente (vía aferente) y sigue la dirección perivenular con sangre que se va empobreciendo de estos elementos, y al mismo tiempo se va enriqueciendo en $\mathrm{CO}_{2}$ y otros productos (vía eferente). Por otro lado, funcionalmente, los hepatocitos residen en acinos, compuestos por tres zonas metabólicas: zona 1, 2 y 3. Debido a esta topografía espacial, los diferentes tipos celulares no tienen la misma exposición a los recursos y componentes que ingresan al órgano (SheikhBahaei et al., 2009).

También, a su vez, se puede subdividir las zonas periportal y perivenular en proximal y distal de acuerdo al patrón de ciertas enzimas y de sus ARNm, que se ubican sólo en una de estas subdivisiones (Jüngermann and Kietzmann, 2000).

\section{$5 \quad$ Zonación metabólica}

El hígado posee un potencial catalítico altamente diversificado. No sólo cataliza todos los procesos sintéticos, degradativos y protectivos necesarios para la formación y mantenimiento de sus estructuras celulares y extracelulares, sino que también es un centro de los diversos metabolismos, de defensa, de control del sistema hormonal y un reservorio sanguíneo. La gran cantidad de funciones que cumple el hígado son llevadas a cabo por las células parenquimáticas así como por muchos otros tipos de células no parenquimáticas (Jüngermann, 1995).

A pesar de que este órgano histológicamente es homogéneo no lo es a nivel morfométrico e histoquímico. Esta heterogeneidad está relacionada con el aporte sanguíneo. Cerca del $80 \%$ del flujo que recibe el órgano lo hace por vía de la vena porta mientras que aproximadamente el $20 \%$ de flujo llega por la arteria hepática. Aquellas células ubicadas en la zona periportal difieren de aquellas de la zona perivenular en las enzimas, translocadores, receptores, y estructuras subcelulares y por ello tienen capacidades funcionales y metabólicas distintas. Esta es la base de la zonación metabólica, concepto propuesto en un principio para el metabolismo de los glúcidos y, posteriormente, ampliado para explicar el metabolismo de los aminoácidos y del amonio, el metabolismo protectivo de los 
xenobióticos, y la formación de las proteínas plasmáticas (Jüngermann and Kietzmann, 1996). Se denomina, entonces, zonación hepática a la distribución heterogénea de productos, sustratos y enzimas en los hepatocitos (Fig. 3) (Jüngermann and Kietzmann, 1997; Braeuning et al., 2007).

La heterogeneidad funcional y morfológica es el resultado de las diferencias zonales en la activación del genoma celular causado por gradientes de oxígeno, sustratos, hormonas, y niveles de mediadores, inervación, así como también en las interacciones célula-célula y célula-biomatriz. (Jüngermann and Kietzman, 1996). Además, se han descripto diferencias entre las zonas periportal (zona 1), media (zona 2) y perivenular (zona 3) en el acino hepático, en cuanto al número y tamaño de las organelas, al patrón de actividad enzimática, a la ploidía, la inervación autónoma y el número de células de Kupffer (McCuskey et al., 2003; Burkhardt et al., 2004). Sin embargo, algunos procesos no están estrictamente zonados, como la síntesis de la transferrina, que es una proteína sérica encargada del transporte del hierro en el plasma (Colnot and Perret, 2011).

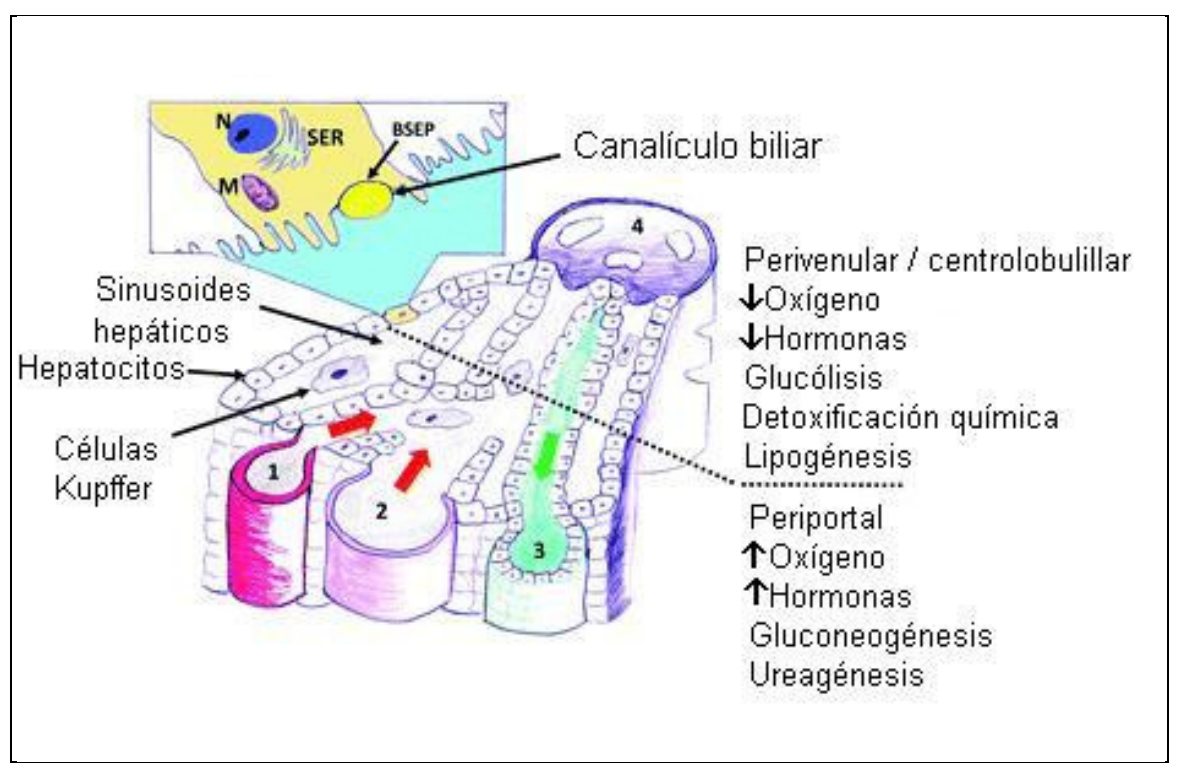

Fig. 3 Diagrama que ilustra la unidad funcional de un acino hepático. Se muestra la tríada portal con la arteriola hepática (1), vena portal (2) y el conducto biliar (3). Además, la vena central (4) y la dirección de la circulación biliar y hepática (flechas verde y roja, respectivamente. Núcleo $(\mathrm{N})$, retículo endoplásmico liso (REL), bomba de exportación de ácido biliar (BSEP), Mitocondria (M) (Williams et al., 2013). 
5.1 Mecanismos posibles de la zonación hepática

Se han propuesto varias hipótesis como mecanismos posibles de zonación (Colnot and Perret, 2011):

1- Hipótesis del desarrollo: los hepatocitos periportales y perivenulares tendrían un origen embriológico y linaje diferentes. Sin embargo, no se puede hacer un reconocimiento de los mismos por su morfología y además, el hígado perinatal de ratones no presenta zonación hasta al menos pasada la primera semana desde el nacimiento (Torre et al., 2010).

2- Teoría de "flujo hepático de la proliferación" (streaming liver): se propuso en base a la observación de que los hepatocitos periportales son más propensos a proliferar. La misma postula que los hepatocitos se originarían en el área periportal, donde residirían las células madre hepáticas. Los hepatocitos luego migrarían a lo largo del eje portocentral para convertirse en perivenosas, adquiriendo durante la maduración un perfil metabólico particular. Esta teoría estaría descartada ya que la renovación de los hepatocitos ocurre en ambas zonas.

3- Hipótesis de la sangre: postula que la sangre que ingresa al lobulillo hepático es rica en oxígeno pero, a medida que va pasando por el eje portovenoso, va produciendo un gradiente de oxígeno en los siusoides, creando distintos microambientes. Según este modelo, la zonación estaría determinada por las concentraciones de $\mathrm{O}_{2}$, hormonas, drogas, 0 metabolitos en la sangre. Es la hipótesis más probable, aunque debe ser más estudiada debido a que algunos procesos que determinan la zonación pueden ser voluntariamente revertidos mientras que otros, como la glucólisis, gluconeogénesis y la detoxificación del amonio no, aun cuando existan cambios en los niveles de oxígeno y de hormonas (Jüngermann and Kietzmann, 1996).

4- Control transcripcional de la zonación: hay una expresión diferencial de genes que codifican para enzimas que intervienen en las distintas 
funciones. El control a lo largo del eje portocentral podría ser tanto transcripcional como postranscricpcional. Dentro del control transcripcional se han caracterizado ARNm propios de los hepatocitos periportales y pericentrales, confirmando que la zonación de la glucosa, del amonio y del metabolismo de las drogas se deben a la presencia de esos ARNm (Braeuning et al., 2006). Se ha encontrado el gen de la glutamina sintetasa en la zona perivenular y la misma es blanco de la $\beta$-catenina, la cual está involucrada en la zonación hepática.

5.2 Zonación hepática del VEGF, de la síntesis de ADN y de la actividad mitótica.

Se ha demostrado una heterogeneidad en la distribución de los valores de la síntesis de ADN (ADNs) dentro del lobulillo hepático con los valores más altos en la zona periportal (Reynaert et al. 2001; Ohtake et al. 2004). De acuerdo a estos autores, la ADNs de los hepatocitos proliferantes comenzaría en esta zona para luego progresar hacia las zonas centrolobulillares. También se demostró que los hepatocitos regenerantes localizados en las áreas periportales eran la mayor fuente de producción de VEGF (Shimizu et al., 2001; Taniguchi et al., 2001). Respecto de la AM, Burkhard et al. (2004), compararon distintas cepas de ratones y no encontraron figuras mitóticas, ni en la zona 1 ni en la 3 (zona periportal y perivenular, respectivamente).

\section{Crecimiento}

A lo largo de los años se ha tratado de decifrar cuáles son las sustancias que influyen o condicionan el crecimiento de los tejidos mediante la utilización de distintos modelos. Hoy se sabe que se trata de un mecanismo muy complejo y que involucra interacciones entre genes, medio ambiente, nutrición y hormonas y que se encuentra relacionado a procesos como el envejecimiento y la apoptosis, ya que cuando prima la proliferación por sobre la muerte celular, se produce crecimiento (Barbeito, 2010). 
El crecimiento puede producirse de diversas maneras: por multiplicación celular, aumento en el tamaño celular y depósito de materiales extracelulares, como hueso y caparazones. Más adelante en el desarrollo, el crecimiento consiste en la proliferación celular, que puede además influir sobre la forma final o en cómo las partes del cuerpo crecen con diferentes ritmos (Wolpert and Tickle, 2011).

El contenido de ADN se usa como un índice para medir las células en división y por ende, el crecimiento de un tejido (Winick and Noble, 1965). La actividad mitótica es un indicador muy valioso del crecimiento hepático de los animales jóvenes o parcialmente hepatectomizados ya que aporta información acerca del número de células que se están dividiendo al momento del sacrificio (Echave Llanos and Sadnik, 1964).

El crecimiento es regulado a través de distintas rutas de señalización, como las hormonas y los factores de crecimiento. Postnatalmente, la hormona reguladora del crecimiento y desarrollo de los animales más importante es la GH (hormona de crecimiento o somatotropina), mientras que de los factores de crecimiento, los IGFs (factores de crecimiento insulínicos) serían los miembros más importantes entre los sistemas de señales promotoras del crecimiento (Lupu et al., 2001). La GH regula el crecimiento del animal uniéndose a su receptor (GHR) situado en el órgano blanco o en el hígado, produciendo la liberación de IGF-1. Una vez que el mismo ha alcanzado el órgano blanco se une a su receptor para regular el crecimiento y desarrollo del animal de una manera autocrina/paracrina (Sun et al., 2012).

En general, a medida que avanza la edad en los ratones, disminuyen el crecimiento/proliferación y el metabolismo que aumenta el estrés oxidativo en el hígado; aumentan los genes asociados con la inflamación, se pierde el control normal del ciclo celular y de la replicación del ADN. Además, el avance de la edad está acompañado por la supresión de genes involucrados en la vía del GH/lHF-1 (hormona de crecimiento/factor de crecimiento insulino dependiente-1), del metabolismo de los carbohidratos, etc (Lebel et al., 2011). 


\section{$7 \quad$ Regeneración hepática}

\subsection{Capacidad regenerante del hígado}

Debido a la enorme variedad de funciones que realiza el hígado (detoxificación, síntesis de proteínas séricas, formación de lipoproteínas, almacenamiento de glucógeno, etc.) y que son demandadas por el resto del organismo, las mismas han tenido que ser aseguradas por eventos evolutivos, los cuales han otorgado a este órgano una capacidad extraordinaria de regeneración (Cascales Angosto, 2009). Esta capacidad proliferativa, observada después de una hepatectomía parcial (HP), logra regular con precisión su crecimiento, ajustándolo a su tamaño original, lo que se debe a la enorme capacidad replicativa de los hepatocitos. La proliferación de los mismos requiere del estímulo directo de factores de crecimiento como el EGF, HGF y TGF $\alpha$ en una fase temprana de la regeneración hepática y de factores de crecimiento como el VEGF que, indirectamente, los estimulen en una fase posterior (Fausto, 2000; Taniguchi et al., 2001). También han sido demostrados altos niveles séricos de TGF $\alpha$ y HGF luego de la HP (Tomiya et al. (1997). Al mismo tiempo, inmediatamente después de la HP, se produce un extenso remodelado de la matriz extracelular hepática (Fausto, 2000).

Uno de los acontecimientos que se manifiestan inmediatamente después de la hepatectomía es la aparición del receptor de la uroquinasa en la membrana plasmática del hepatocito y el aumento de la actividad de la enzima (Mars et al., 1996). La membrana plasmática se hiperpolariza a los 30 minutos de la hepatectomía y a las 5 horas se observan grandes cambios morfológicos en el canalículo biliar. Dentro de los 30 minutos se desencadena la inducción de varios genes nuevos que se denominan tempranos inmediatos. Esta inducción es independiente de la síntesis de nuevas proteínas. Algunos marcadores fetales aparecen en el hígado en regeneración, idénticos a los expresados en hígado fetal (como la hexoquinasa) (Michalopoulos and DeFrances, 1997). Además, aparece una acumulación de triglicéridos (esteatosis) en los hepatocitos desde las 20- 72 horas de la hepatectomía, asociada con una marcada inducción de enzimas lipogénicas y que podría tener como función abastecer de energía a los hepatocitos en las sucesivas rondas de proliferación y de reponer los fosfolípidos de membrana 
de los hepatocitos que se están replicando (Delahunty y Rubinstein, 1970; Zou et al., 2012).

El hepatocito adulto de los mamíferos posee una larga vida (300- 400 días), es muy activo desde el punto de vista transcripcional y en condiciones normales, la capacidad de replicación de su ADN es muy baja. Sin embargo, bajo cualquier tipo de lesión esta situación se revierte y comienza a replicar (Cascales Angosto, 2009).

El hígado es capaz de modular su masa de acuerdo a sus requerimientos funcionales, ya sea proliferando en condiciones de deficiencia funcional, o bien sufriendo apoptosis, en casos de exceso. En ambos casos, el hígado se remodela para preservar su arquitectura y organización histológica. Aunque los hepatocitos son los primeros en responder a la agresión, otros tipos celulares también intervienen, en un orden cronológico y secuencial; primero se dividen los hepatocitos y posteriormente las células de Kupffer y endoteliales, seguido de la neoformación de vasos y de los canalículos biliares, hasta reproducir la estructura hepática (Cascales Angosto, 2009; Cienfuegos et al., 2014).

La masa hepática se halla estrictamente controlada por mecanismos promitóticos y apoptóticos. En humanos, cuando se realiza un trasplante con un hígado de menor tamaño, éste crece rápidamente para acomodarse a las necesidades del receptor (Van Thiel et al., 1987; Francavilla et al., 1994). Hígados de gran tamaño trasplantados a receptores pequeños sufren apoptosis hasta alcanzar la relación normal de masa hepática/masa corporal que en los humanos es de aproximadamente 2,5\% (Van Thiel et al., 1987). Aparentemente, la capacidad replicativa de los hepatocitos está regulada, en parte, por la capacidad de sus telómeros cromosómicos para permanecer en un estado competente de replicación (Cascales Angosto, 2009).

7.2 Fases de la regeneración hepática

La regeneración hepática es un evento que involucra múltiples procesos celulares y una compleja interacción entre citoquinas y factores de crecimiento. Podemos ordenar y dividir al proceso regenerativo hepático en tres fases o rutas: iniciación, proliferación e inhibición (Tarla et al., 2006; Fausto et al. 2006). Las 
señales estimuladoras son liberadas en el hígado o a la circulación después de la pérdida de la masa hepática debido a la HP (Michalopoulos and Khan, 2005).

Fase de iniciación (o de priming).

En esta etapa del proceso participan las células no parenquimáticas y los hepatocitos remanentes. Debido a la expresión temprana (primeras horas $\mathrm{PH}$ ) de determinados genes (Fausto et al., 2006), las células producen una serie de factores de crecimiento, como el factor de necrosis tumorala (TNF $\alpha$ ), linfotoxina $\beta$ (LT $\beta$ ) e interleuquinas-1 y 6 (IL-1, IL-6). El TNFa se une al receptor soluble TNFR1, resultante en la translocación del factor nuclear Kappa-B (NF-kB). Este factor transcripcional NF-kB controla la expresión de los genes que codifican para las citoquinas (Tarla et al., 2006). Las citoquinas actúan durante esta fase inicial de la regeneración hepática, que corresponde al ingreso de los hepatocitos quiescentes dentro ciclo celular $\left(\mathrm{G}_{0}-\mathrm{G}_{1}\right)$ (Fausto et al., 2006). Además, el NF-kB regula el ciclo celular y es antagonista de la apoptosis en el proceso regenerativo hepático. Uno de los tipos biológicos de este factor transcripcional se halla dentro del citoplasma y su activación ocurre unos pocos minutos después de la HP y dura entre 1-2 h (Kountouas et al., 2001). Además, el TNFa induce la expresión de la IL-6, la cual es una señal para la transducción y activación de la transcripción de STAT (proteína de señal de transducción y activadora de proteínas de transcripción). STAT es importante en la inhibición de la apoptosis de los hepatocitos. Por lo tanto, la deficiencia del TNFa como de la IL-6 disminuyen la regeneración hepática en ratones (Tarla et al., 2006).

Como resultado de la activación de los factores de transcripción NF-kB y STAT los hepatocitos programan la respuesta de crecimiento mediante la activación de pro-oncogenes (c-myc, c-fos, etc.). El óxido nítrico (NO) también participa en el proceso generando óxido nítrico sintetasa (NOS-2), que previene la activación pro-apoptótica mediada por TNFa y protege a los hepatocitos contra la muerte celular.

En la hepatectomía parcial no sólo se induce la transición G0-G1 de los hepatocitos, sino también el aumento de la expresión de los factores de 
crecimiento, sin los cuales los hepatocitos no podrían sintetizar su ADN (Loyer et al., 1996).

Fase de proliferación (o de factores de crecimiento).

En esta segunda fase el factor de crecimiento hepatocítico (HGF), que es un péptido mitógeno secretado por las células no parenquimáticas después de la HP, actúa de manera endocrina o paracrina en los hepatocitos e induce la expresión temprana de genes de la regeneración (Kountouas et al., 2001). El HGF y sus receptores MET se consideran los principales estimuladores de la progresión $\mathrm{G}_{1}-\mathrm{S}$ en los hepatocitos remanentes. Los hepatocitos son sensibilizados por el TNFa, la IL-6 y el NO para responder a los factores de crecimiento. Otros mitógenos involucrados en la fase regenerativa son el TGFa y el EGF (factor de crecimiento epidermal). Ambos factores comparten el mismo receptor, el EGFR. La expresión del TGFa es inducida en los hepatocitos aproximadamente entre las 2-3 h después de la HP y podría estimular la proliferación de los hepatocitos y de las células endoteliales (Webber et al., 1994). La sustancia de estimulación hepática (HSS), que es un factor de crecimiento péptídico específico del hígado, se encarga de la protección y proliferación de los hepatocitos mediante la reparación de la síntesis de ADN y de la autofosforilación de los residuos tiroxina de los EGFR (An et al., 1999).

\section{Fase de inhibición.}

Durante esta fase las señales de terminación del crecimiento o señales stop provocan una disminución de la síntesis de ADN, como el factor TGF $\beta$, secretado tanto por los hepatocitos como por las plaquetas (Nihikawa et al., 1998). En ratones, su aumento produce la ausencia de regeneración y la aparición de hepatocarcinomas (Bottinger et al., 1996). Otro inhibidor mitótico es la IL-1 que se expresa en las dos fases de la regeneración, primero como un estimulador de la proliferación y al final del proceso (Tarla et al., 2006). 
Además de considerar en el proceso regenerativo a las sustancias estimuladoras e inhibidoras, no debe excluirse del mismo a la matriz extracelular hepática (MEC), ya que forma una red alrededor de las células y hace posible el almacenaje y la transmisión de señales mediante la unión y liberación de los factores de crecimiento, hormonas, enzimas y citoquinas. Es justamente en ella, donde se producen una serie de mecanismos proteolíticos que forman parte del proceso de restauración del tejido hepático. El pro-HGF, por ejemplo, es metabolizado en esta matriz (Tarla et al., 2006).

\subsection{Regeneración hepática y angiogénesis}

Existe una relación estrecha entre la regeneración hepática y la angiogénesis. Luego de la HP los hepatocitos primero proliferan y después se produce la angiogénesis para que el hígado alcance su volumen funcional óptimo a los 7-10 días posteriores a la operación (Michalopoulos and DeFrances, 1997; Lieckens et al., 2001; Ross et al., 2001). Mientras que los agentes angiogénicos se incrementan en el hígado en regeneración en los primeros días siguientes a la operación (un 42\% el segundo día, $16 \%$ el octavo día), los agentes antiangiogénicos más importantes se elevan en los últimos días (días 2 y 8 un 46\% y 64\%, respectivamente) (Greene et al., 2003; Drixler et al., 2002). Tal vez, este efecto negativo de los agentes antiangiogénicos en la regeneración explique la aparición más tardía de la angiogénesis respecto de la proliferación hepatocítica. Por otro lado, Greene et al. (2003) hipotetizaron que las células endoteliales sean el punto de quiebre fisiológico que frene la regeneración hepática ya que se vio que la apoptosis de las mismas se incrementa el mismo día que el hígado alcanza su volumen previo a la operación. En ratas el pico de la proliferación y de la angiogénesis ocurren los días 1 y 3, respectivamente (Dogrul et al., 2010).

En esta secuencia de eventos durante el proceso regenerativo del hígado, tiene un rol central el VEGF ya que es requerido no sólo para la proliferación sino también para la supervivencia e integridad de las células endoteliales neoformadas (Gerber et al., 1999; Hicklin and Lee 2005; Ribatti, 2004). 
En esa interacción entre los hepatocitos y las células endoteliales el pico de VEGF de los hepatocitos se corresponde con el de sus receptores situados en las células endoteliales, y con el posterior pico de proliferación de las células endoteliales (Sato et al., 2001). Éstas conectan el aporte de oxígeno a la demanda metabólica. Las células, normalmente, se oxigenan por el oxígeno difusible pero cuando los tejidos crecen más allá del límite de difusión de este gas, la hipoxia desencadena el crecimiento vascular. Esto sucede por medio de una señalización a través de factores de transcripción inducibles por hipoxia, los cuales sobre o hipo regulan la expresión de factores pro y anti angiogénicos, respectivamente.

\subsection{Regeneración hepática en humanos}

El proceso de regeneración hepática en ratones y humanos es similar, por ello, los resultados obtenidos en ratones pueden aplicarse al hígado humano (Fausto, 2001). Salvo por restablecimiento hepático tras la resección por carcinoma o bien a continuación de un traumatismo grave, la regeneración en el hígado de humano se inicia, generalmente, por una lesión de origen viral, por desequilibrio dietético, intoxicación por alcohol u otras toxinas hepáticas (Post and Hoffman, 1967).

7.5 La expresión del VEGF, la síntesis de ADN y la actividad mitótica durante la regeneración hepática

El hígado puede restaurar la pérdida de sus propias células mediante el mecanismo de regeneración hepatocelular, capacidad considerada de relevancia fisiológica en numerosas enfermedades hepáticas, tales como la hepatitis aguda, viral y alcohólica, alteraciones metabólicas o después de cirugía hepática. En el modelo de regeneración por hepatectomía parcial $(70 \%)$ de ratas, los hepatocitos remanentes experimentan una transición desde el estado quiescente al proliferativo y entran en el ciclo celular de una manera sincrónica. La síntesis de ADN comienza 12-16 horas después de la hepatectomía y alcanza su máximo a las 24- 48 horas, involucrando al $90 \%$ de los hepatocitos (Mehendale, 1991). El inicio de la mitosis se 
registra 6-8 horas más tarde que la síntesis de ADN. Tres días después de la hepatectomía, la masa celular original del órgano se encuentra casi restaurada. La regeneración in vivo parece presentar una respuesta bifásica. Durante la primera ronda de división, los hepatocitos son las únicas células hepáticas que se encuentran involucradas en la replicación de ADN (fase $S$ con máximo a las 24 horas) y en la actividad mitótica (fase $M$ con máximo a las 30 horas). La segunda ronda mitótica, que es menos sincrónica, ocurre más tarde y en ella participan todas las células hepáticas, parenquimáticas y no parenquimáticas. De esta manera las células no parenquimáticas se replican después que los hepatocitos. Las células de Kupffer, estrelladas (de Ito) y las células de los conductos biliares, replican su ADN a las 48 horas, y las endoteliales, más tarde (Cascales Angosto, 2009).

Por otro lado, se ha visto que en ratones el VEGF está temporalmente relacionado con la proliferación de los hepatocitos durante la regeneración hepática, al igual que ante la presencia de regeneración hepática acompañada por la portación de un tumor (Furnus et al., 2003; García et al., 2010). Bajo estas condiciones experimentales, en el ciclo celular de los ratones adultos $\mathrm{C} 3 \mathrm{H} / \mathrm{S}$, el pico de VEGF se presenta antes del pico de la ADNs y de la AM por lo que dicho pico podría ubicarse en la fase G1/S (Andrini et al., 2011; Furnus et al., 2003). Por otro lado, también se ha visto, que el ARNm del VEGF se incrementa de manera gradual en los hepatocitos, probablemente entrando en la fase G1 del ciclo celular, y que es mayor en las células después de la fase S o de M (Tanikawa and Ueno, 1999).

\section{Modelos experimentales de la regeneración hepática. La hepatectomía parcial.}

La regeneración hepática es el modelo más estudiado para evaluar la respuesta a la pérdida de tejido hepático. Ésta puede ocurrir como resultado de un daño tóxico (como con tetracloruro de carbono), exposición a un virus, trauma o por la remoción quirúrgica (Cascales Angosto, 2009).

Debido a que cada lóbulo hepático posee su propio pedículo conteniendo la tríada portal, su remoción es sencilla y reproducible. El hígado de rata se divide en 4 lóbulos: caudado (LC), derecho (LD), medio (LM), e izquierdo (LI). A su vez, 
el LC se divide en los procesos anterior y posterior. EL LD en los lóbulos superior e inferior. EI LM en lóbulo medio derecho e izquierdo.

La anatomía lobular hepática en ratones es muy similar a la de la rata aunque existe diferencia entre las mismas respecto del volumen de los lóbulos (Hummel et al., 1966; Cook, 1965). Sin embargo, lo más destacable es que estos roedores difieren entre sí en la respuesta temporal del proceso regenerativo ya que es especie-dependiente (Mangnall et al., 2003).

La remoción de los lóbulos medio e izquierdo es sencilla y permite crear una alta estandarización de la reducción de la masa hepática, creando el modelo de hepatectomía parcial al 70\%. Los otros modelos de hepatectomías al 90, 95 y 97\% se utilizan para el estudio de la regeneración hepática aunque también para los estudios de falla renal aguda (Madrahimov et al., 2006). Para la HP al $90 \%$ se extirpan los lóbulos LD, LM y LI; para el 95\% además, se remueve el proceso anterior del LC y para el 97\%, además del proceso anterior, el posterior (Martins et al., 2008).

Los estudios sobre la regeneración hepática han utilizado mayoritariamente modelos animales para ese propósito y el modelo más popular es el que emplea roedores para realizar la hepatectomía parcial al 70\% (Michalopoulos, 2011). Luego de extirpar los lóbulos hepáticos, los lóbulos remanentes que permanecen en el organismo se encuentran sometidos a un incremento en el flujo y presión de sangre portal.

La hepatectomía parcial es hasta la fecha el modelo experimental más cercano de regeneración hepática, que no va acompañado por lesión hepatocelular y es por tanto el modelo preferido para estudiar in vivo la respuesta regenerativa (Cascales Angosto, 2009).

Estrictamente, el término "regeneración hepática" debe ser aplicado a la neoformación por pérdida de tejidos u órganos en el adulto, es decir, a la regeneración epigenética. El fenómeno es prominente en anfibios, que pueden regenerar la cola, miembros e incluso lentes oculares. En los roedores, cuando se eliminan los lóbulos hepáticos, los lóbulos remanentes sufren una hiperplasia compensatoria que da lugar a que aumente su masa, hasta que ésta llega a alcanzar su masa original. Lo mismo ocurre en humanos después de la 
hepatectomía parcial o después de recibir un injerto pequeño (Cascales Angosto, 2009).

\section{Efecto de la portación de un tumor y de la hepatectomía parcial en la proliferación celular hepatocítica y en la expresión del VEGF.}

Muchos años atrás se observó que la presencia de un tumor en cualquier parte del cuerpo podía alterar los patrones metabólicos del hígado del huésped, induciendo cambios medibles de varios componentes del metabolismo y de la tasa mitótica de las células hepáticas. Además, se observó que en los ratones y ratas que presentaban tumores espontáneos o malignos trasplantados, el peso del hígado era mayor que en aquellos que carecían de tumor (Annau et al., 1951; Medigreceanu, 1910; Yeakel, 1948; Yeakel and Farris, 1947). Debido a ello, y con el objeto de cuantificar el posible impacto que tendría la portación de un tumor sobre el crecimiento del hígado, dos de los modelos experimentales más utilizados han sido el injerto de un tumor y la inyección de un extracto tumoral en el animal. Dentro del primer grupo, incluimos a varios trabajos, algunos de los cuales han sido realizados empleando la cepa $\mathrm{CH} 3 / \mathrm{S}$ de ratones del Bioterio de la Cátedra "A" de Citología, Histología y Embriología. Se observó que el injerto de los hepatomas SS1K y ES12a en ratones hepatectomizados machos adultos estimulaba la AM de los hepatocitos y adelantaba su pico, respecto de los solamente hepatectomizados (Badrán et al., 1984; Barbeito et al., 2002). Con ratones más jóvenes, en cambio, se estimulaba la $\mathrm{AM}$ de los animales hepatectomizados y portadores-hepatectomizados, ocurriendo para ambos grupos el pico a las $48 \mathrm{~h} \mathrm{PH}$ (Theologides and Zaki, 1969). Paschkis et al. (1955) observaron que ciertos hepatomas crecían mejor cuando los ratones habían sido hepatectomizados. Otros grupos de trabajo que analizaron la proliferación, pero del hígado normal, fueron Annau et al. (1951), quienes observaron que la AM de ratones y de ratas aumentaba cuando portaban distintos tipos de tumores. Resultados similares fueron hallados por Morgan and Cameron (1973) para la ADNs. 
Dentro de los trabajos que utilizaron extractos de tumor, se observó un efecto inhibidor sobre la AM de los hepatocitos regenerantes, cuando se utilizaron los hepatocarcinomas ES2, SS1H y SS1K (Echave Llanos et al., 1986; Badrán et al., 1985a). Sin embargo, también fue demostrado que un mismo tumor podía tener distintos efectos sobre la proliferación hepatocítica si era injertado o inyectado. Este es el caso del trabajo que realizaron Moreno (1984), en el cual se empleó el tumor SS1K, que no sólo ejercía un efecto inhibidor como mencionamos antes, sino que podía estimular la respuesta regenerativa del hígado cuando el mismo había sido injertado, con un pico de AM más elevado y anticipado con respecto a los ratones no portadores (Badrán et al., 1984).

Debido al conocimiento de que los tumores de cierto tamaño son angiodependientes y de que la cascada angiogénica es promovida por el VEGF, es que algunos autores se han dedicado al estudio de este factor de crecimiento en animales portadores de un injerto de tumor. Tal es el caso de Andrini et al. (2013), quienes encontraron que la portación del tumor ES2 podía estimular, directa o indirectamente, la expresión del VEGF, provocando valores más altos y el adelanto del pico, respecto de los ratones no portadores hepatectomizados y de los animales intactos.

Así como algunos estudios se centraron en la influencia que podría tener en la proliferación hepatocítica la portación de un tumor, otros estudiaron el efecto de la hepatectomía parcial en el crecimiento del tumor. Ello se debe a que la hepatectomía es un tratamiento quirúrgico comúnmente utilizado para los tumores hepáticos primarios o en metástasis hepáticas de tumores primarios localizados en otros órganos. De esta manera, la hepatectomía podría alterar el crecimiento de tumores extrahepáticos o hepáticos no ubicados en el área extirpada. En un estudio de Lee (1971), se observó que unos hepatomas trasplantables crecían más rápido cuando el huésped había sido hepatectomizado o cuando el injerto de tumor se producía el mismo día de la HP (Asaga et al., 1991; Sun et al., 1996). Sin embargo, la hepatectomía parcial puede tener distintos efectos sobre la ADNs y la $A M$ de las células tumorales, debido a que en los experimentos se trabaja en diferentes momentos y sitios de injerto, y con neoplasias de distinto origen (García et al., 2010). 


\section{HIPÓTESIS}

1- La expresión del VEGF, la ADNs y la AM presentan variaciones circadianas en los ratones jóvenes.

2- El valor máximo de expresión del VEGF se presenta antes del pico de síntesis de ADN.

3- El injerto del tumor modifica la temporalidad y magnitud de los valores de expresión del VEGF, de la ADNs y de la AM.

4- La expresión del VEGF, la ADNs y la AM se encuentran distribuidos de una manera homogénea dentro del lobulillo hepático. 


\section{OBJETIVO GENERAL}

Estudiar la expresión de factores relacionados con la angiogénesis durante la regeneración hepática en ratones jóvenes intactos y portadores de un tumor.

\section{OBJETIVOS ESPECÍFICOS}

1. Estudiar la expresión del VEGF y de la ADNs en el hígado de ratones jóvenes intactos a lo largo de un período circadiano.

2. Estudiar la expresión del VEGF, de la ADNs y de la AM en el hígado en regeneración de ratones jóvenes.

3. Estudiar la expresión del VEGF, de la ADNs y de la AM en el hígado en regeneración de ratones jóvenes portadores de un tumor maligno.

4. Establecer la posible relación temporal entre la expresión del VEGF, la síntesis de ADN y la actividad mitótica durante la regeneración hepática en ratones jóvenes portadores y no portadores de un tumor maligno. 


\section{MATERIALES Y MÉTODOS}

\section{Animales}

Se utilizaron 169 ratones de la cepa $\mathrm{C} 3 \mathrm{H} / \mathrm{S}$ provenientes del bioterio de la Cátedra de Citología, Histología y Embriología "A" de la Facultad de Ciencias Médicas de la Universidad Nacional de La Plata. Los animales estuvieron bajo las condiciones y cuidados que rigen en la Guía para el Cuidado y Uso de Animales de Laboratorio de Investigación del Consejo Nacional de Investigaciones (Guide for the Care and Use of Laboratory Animal Research of the National Research Council).

La cepa se mantiene por endocría, en el citado bioterio, desde 1966, año en que ingresaron los reproductores, remitidos por el Profesor J. W. Wilson (Department of Biology, Brown University, Providence, Rhode Island, USA).

Los ratones empleados para los diferentes experimentos fueron machos jóvenes de $28 \pm 1$ días de edad (Fig. 4). Desde el nacimiento, los animales fueron mantenidos en un cuarto con temperatura de $22 \pm 2^{\circ} \mathrm{C}$, bajo un régimen de luz artificial (luz fluorescente de 40 vatios, ubicada sobre las cajas), desde las 06:00 h hasta las 18:00 h, alternando con 12 horas de oscuridad (desde las 18:00 h hasta las 06:00 h). Al cumplir los 21 días fueron destetados, separados según el sexo y colocados en cajas, de a siete animales, en una sala de reserva bajo las condiciones de iluminación y temperatura descriptas (Fig. 5).

El agua y el alimento fueron administrados ad libitum. Se utilizó agua clorinada y pellets de alimento balanceado rata/ratón (alimento balanceado № 3 Ganave).

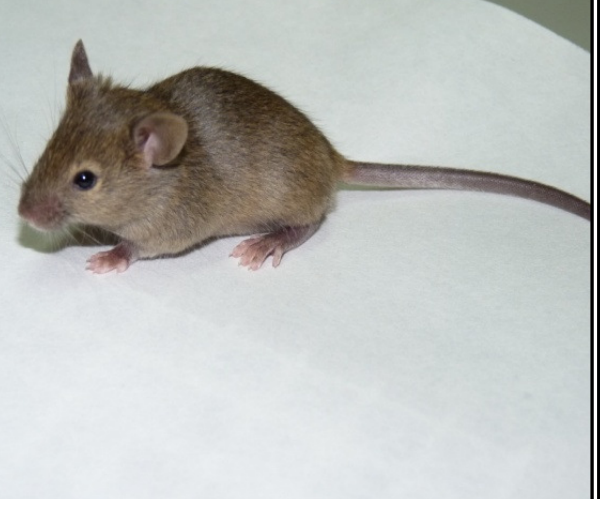

Fig. 4 Se observa un ratón de 28 días de la cepa $\mathrm{C} 3 \mathrm{H} / \mathrm{S}$ del Bioterio de la Cátedra A de Citología, Histología y Embriología. 


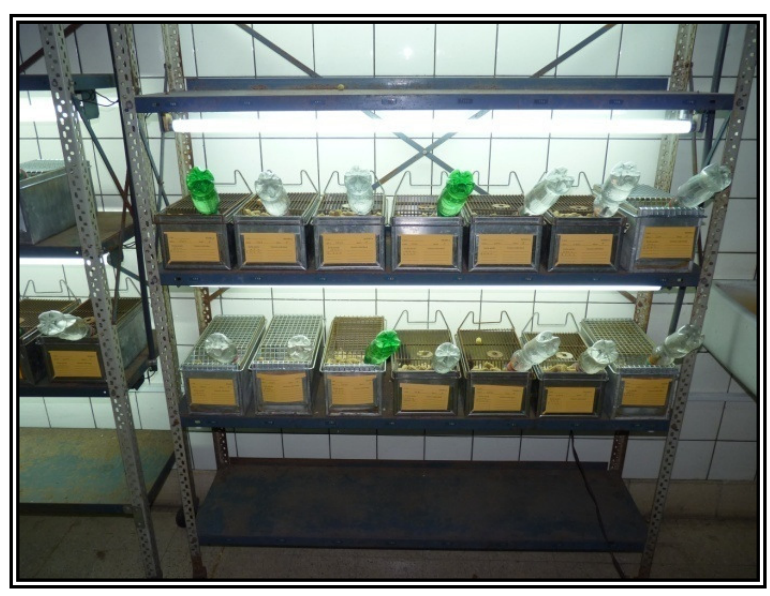

Fig. 5 Foto que muestra la sala de Ritmos del Bioterio de la Cátedra A de Citología, Histología y Embriología.

\subsection{Estandarización para análisis de periodicidad}

Las condiciones requeridas para análisis de periodicidad, establecidas por Halberg et al. (Halberg et al., 1958) son:

- Aislamiento en cajas metálicas individuales en un cuarto ad hoc denominado de ritmos.

- Régimen de alimentación y suministro de agua ad libitum.

- Iluminación con luz artificial fluorescente de 06:00 h a 18:00 h, alternada con $12 \mathrm{~h}$ de oscuridad. Tanto el diseño de la caja como la ubicación de la fuente de luz deben asegurar una iluminación directa y uniforme en todo el interior de la caja.

- Reposición de agua y comida a cargo de una sola persona, quien ingresa al cuarto una vez por día a las 06:00 h o a las 17:50 h.

- Temperatura estable entre los 23 y $25 \stackrel{\circ}{\circ}$.

El aislamiento de los animales permite eliminar los efectos del estrés generados por la competencia alimenticia. Mientras que la iluminación homogénea, en toda la caja, impide que aparezcan sectores sombreados en los que los animales inhiban su actividad alimentaria (Echave Llanos et al., 1963). 


\subsection{Tumor ES2}

\section{Características}

Es el segundo (2) tumor espontáneo (E) de la cepa C3H/S (S) obtenido en nuestro Laboratorio. Fue hallado en el año 1970 en un ratón hembra de 625 días de edad, portadora de un hepatocarcinoma trasplantado. Fue injertado en hembras de la cepa original y cuatro meses después del trasplante inicial se hizo el primer repique de mantenimiento en hembras adultas de la cepa $\mathrm{C} 3 \mathrm{H} / \mathrm{S}$, en la que continúa hasta hoy. Esta neoplasia es un carcinoma hepatocelular indiferenciado de crecimiento rápido.

El tumor trasplantado aparece luego de 5 días y alcanza un diámetro promedio de $2 \mathrm{~cm}$ a los 15 días después de haber sido injertado. Mata el $50 \%$ de los huéspedes dentro de los 30 días (Badrán et al., 1985c).

Este tumor ha sido caracterizado en nuestro Laboratorio desde el punto de vista morfológico (Reuber, 1966) y biológico (Moreno, 1984).

Es un tumor encapsulado, de firme consistencia. Al corte se muestra como un tumor sólido, con extensas áreas de necrosis y hemorragias. Microscópicamente presenta células pequeñas, indiferenciadas, con núcleos de tamaño variable, muchos picnóticos, algunos vesiculosos (Fig. 6). Se observan, además, numerosas figuras mitóticas y focos incipientes de necrosis. Esta neoplasia se mantiene por trasplantes seriados.

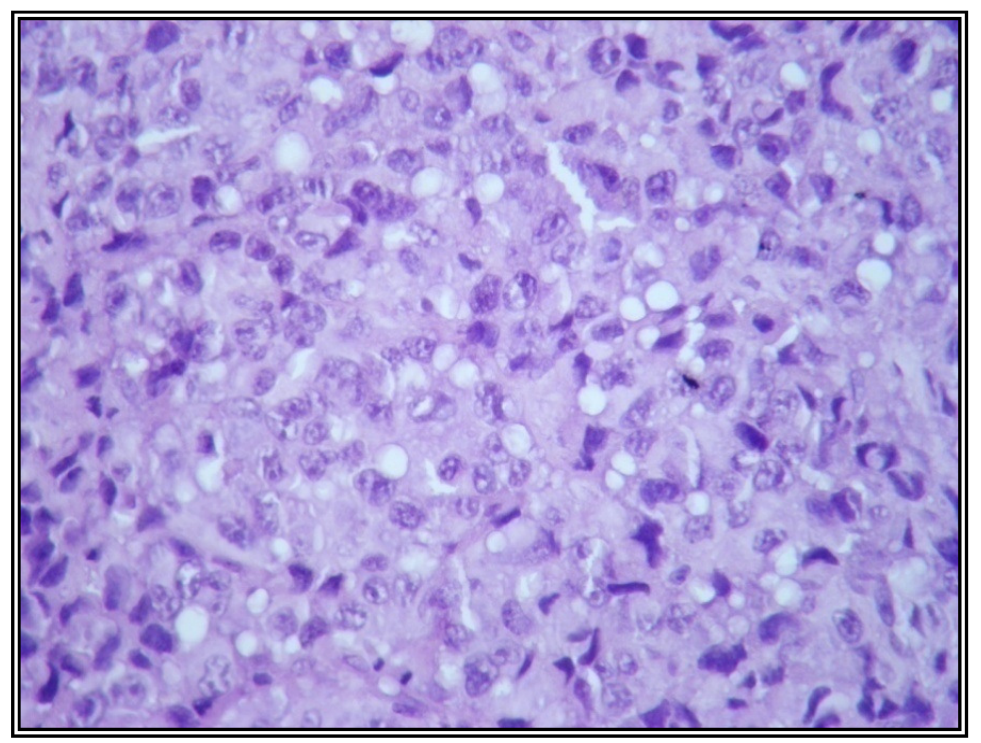

Fig. 6 Foto que muestra un corte histológico del tumor ES2 coloreado con Hematoxilina-Eosina a 40X (cortesía del Dr. Carlos Martín). 
1.3 Injerto del tumor

El tumor ES2 se mantiene en el bioterio por injerto seriado subcutáneo, siguiendo la técnica descripta por R. Iglesias y adaptada por Moreno (1984). Para cada pasaje del carcinoma se utilizaron dos dadores con tumores sin úlceras. En los trasplantes para mantenimiento de la línea tumoral se utilizaron por lo menos siete receptores.

Los animales dadores del tumor fueron sacrificados por decapitación y sangría. Los segmentos de la neoplasia se extrajeron con instrumental estéril. Con una tijera curva se disgregaron los trozos de tumor en una cápsula de Petri con solución fisiológica, hasta lograr fragmentos de tejido no detectables macroscópicamente. Posteriormente se agregó solución fisiológica hasta alcanzar una relación de 1: 3 (1 volumen de tumor por cada 3 de solución fisiológica). Se consigue así una suspensión de aproximadamente $2.10^{6}$ células por $\mathrm{ml}$. A cada animal receptor se le inyectaron, en el tejido celular subcutáneo de la región del lumbar, $0.2 \mathrm{ml}$ de esta suspensión.

Esta técnica se realizó tanto para los trasplantes de mantenimiento del tumor como para aquellos animales utilizados en el Experimento III (ratones portadores-hepatectomizados) que componen el presente trabajo.

En cada repique de mantenimiento se toman muestras de tumor para su control histológico.

\subsection{Receptores de tumor (Experimento III)}

Ratones machos de $21 \pm 1$ días de edad, los cuales fueron injertados con el tumor ES2 para luego ser hepatectomizados a los $28 \pm 1$ días. Posteriormente, los animales fueron sacrificados en grupos de aproximadamente $n=6$ a las 12/26, 16/30, 20/34, 00/38, 04/42 y 08/46 hora del día/hora posthepatectomía (HD/HPH). En todo momento se mantuvieron las condiciones de estandarización para el análisis de periodicidad antes descripto. 
1.5 Técnica quirúrgica.Técnica de Hepatectomía parcial.

Se utilizó la técnica de la subhepatectomía (extirpación de alrededor del $70 \%$ de la masa hepática total) descripta por Brues et al. (1936) y modificada por Echave Llanos (1967).

Este procedimiento se realizó bajo anestesia con éter. Cuando el animal está anestesiado se coloca en posición decúbito dorsal, se lo rasura y se le realiza una incisión en la pared abdominal, sobre la línea blanca, de aproximadamente 1,5 - $2 \mathrm{~cm}$ de largo. Se retira el lóbulo mediano con una pinza de aro y se vuelca sobre una gasa, luego se saca el lóbulo izquierdo y se apoya sobre el mediano. Se corta entonces con una tijera de punta roma el ligamento gastrohepático con el objetivo de liberar el pedículo y facilitar su ligadura. Ambos lóbulos se envuelven con la gasa cruzando los extremos y dejando libre el lugar del pedículo que contiene la arteria hepática, el conducto biliar y la vena porta de estos lóbulos. Se pasa una aguja curva y de punta roma con hilo de lino y se ata el pedículo en su posición más distal, con el objetivo de evitar la necrosis del lóbulo para-gástrico (Fig. 7). Con una tijera de punta roma se corta el pedículo por encima de la ligadura. Luego de esperar unos segundos, para permitir el pasaje de la sangre contenida en los lóbulos a través de la rama de la vena hepática, se realiza una ligadura de lino cerca de la base de implantación de los lóbulos y se corta por encima. Finalmente se sutura con hilo de algodón.

Aquellos animales que presentaron anomalías en el crecimiento fueron eliminados.

Esta técnica fue utilizada en los animales de los Experimentos II y III. 


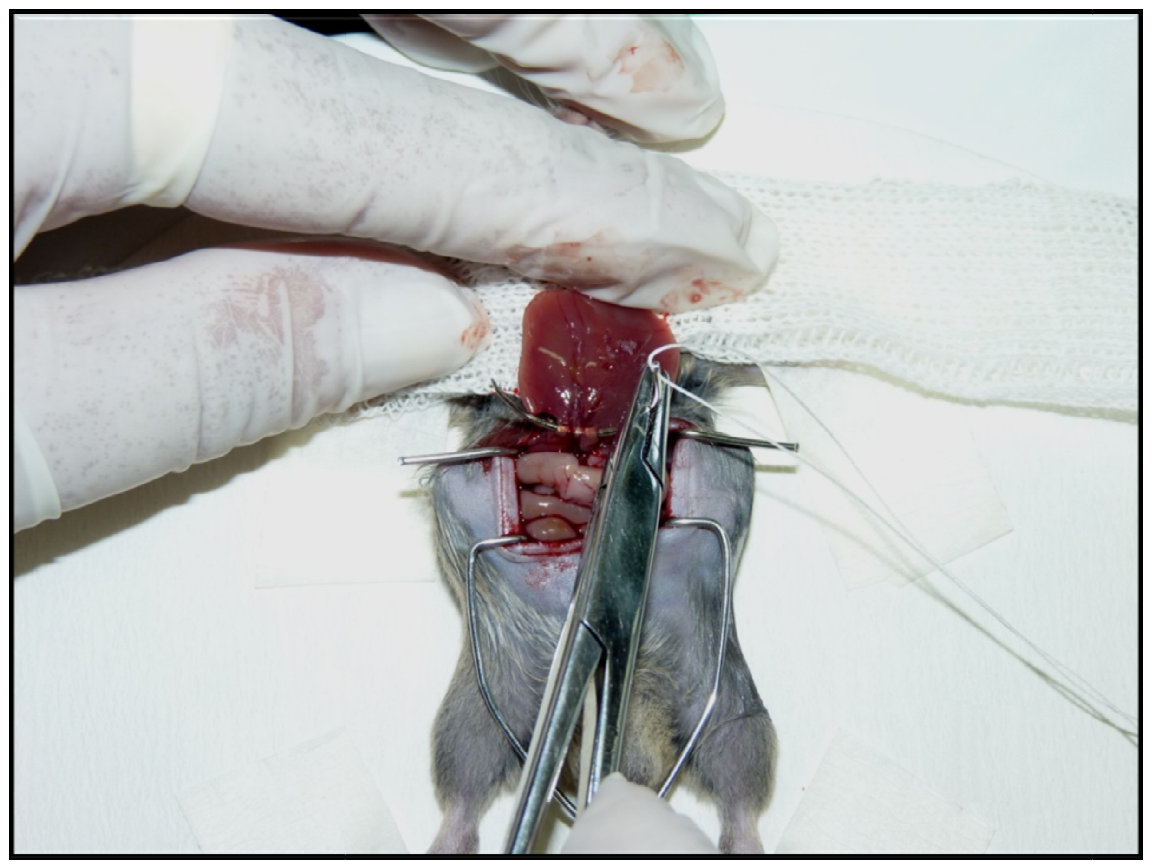

Fig. 7 Foto que muestra la aguja roma por detrás del pedículo gastro-hepático para proceder a su ligadura y al corte de los lóbulos hepáticos.

\subsection{Administración de colchicina.}

Esta técnica se emplea para la detección de las células que están detenidas en mitosis. La colchicina es un inhibidor de la polimerización de la tubulina de los microtúbulos, por lo que la aplicación de esta droga impide la formación del huso mitótico y determina que la mitosis se detenga en la etapa de metafase (Brüel et al., 2014).

A cada animal se le inyectó intraperitonealmente en la fosa ilíaca izquierda una solución de colchicina ( $2 \mu \mathrm{g} / \mathrm{g}$ de peso corporal en $0,01 \mathrm{ml}$ de agua destilada), 4 horas previas a su sacrificio. Durante la necropsia se extrajeron los lóbulos del hígado que se procesaron de acuerdo a la técnica histológica de rutina. Se les realizó el desparafinado con xilol y luego se hidrataron utilizando nuevamente un tren de alcoholes, pero esta vez de concentración decreciente. Por último, se les realizó una coloración con Hematoxilina de Meyer para facilitar la observación de los núcleos y se los montó con un cubreobjeto. 
Con el método statmoquinético se puede determinar el número de células que han entrado en la fase mitótica del ciclo celular desde el momento de la inyección de colchicina $4 \mathrm{~h}$ antes, ya que la misma actúa provocando la disrupción del huso mitótico, y la consecuente falta de la placa ecuatorial. Estas células detenidas en metafase (metafases colchicínica) poseen un aspecto característico y de fácil reconocimiento al microscopio óptico (Fig. 8) (Wright and Appleton, 1980).
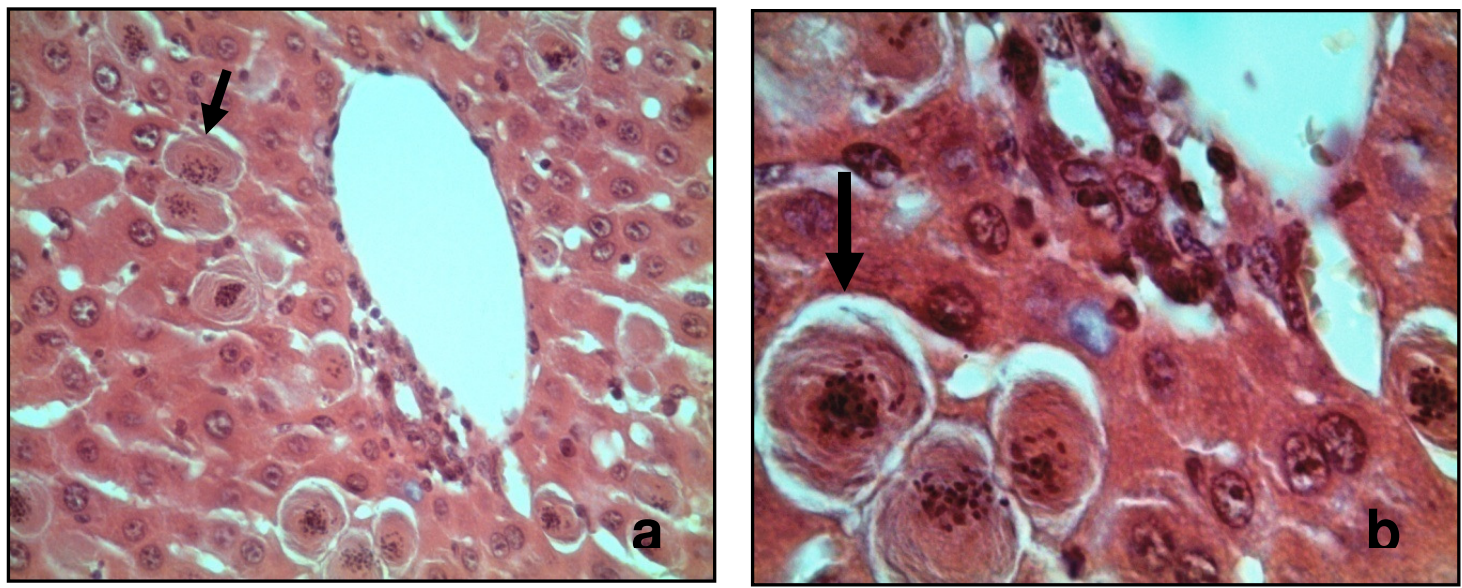

Fig. 8 Fotos que muestran las metafases colchicínicas de los hepatocitos periportales (flechas negras), a 40X (a) y a 100X (b).

1.7 Sacrificio de los animales y recolección de las muestras

Los animales fueron sacrificados por decapitación y sangría. Una vez sacrificados, se realizaron las necropsias. Durante las mismas se extrajeron las porciones triangulares del lóbulo derecho de los hígados las que se ubicaron en canastitas para ser fijados y procesados histológicamente (Fig. 9).

Se registró cada animal en una planilla individual, anotándose cualquier posible alteración macroscópica hallada durante la necropsia. 


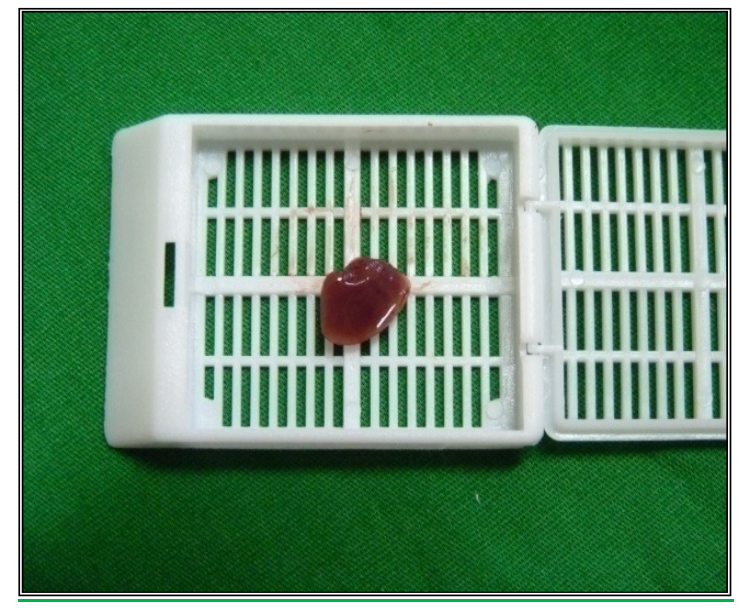

Fig. 9 Foto que muestra el lóbulo triangular del ratón extraído durante la necropsia y colocado en una canastita para su procesamiento según la técnica histológica de rutina.

\section{Técnica histológica}

Coloración con Hematoxilina de Meyer-Eosina.

Los lóbulos extraídos de las necropsias fueron procesados para la observación al microscopio óptico, de la siguiente manera:

Fijación: tiene por finalidad detener los procesos de autólisis del tejido por lo que, inmediatamente después de su extracción, los lóbulos se introducen en cassettes, que se sumergen en frascos con formol al $10 \%$, rotulados con el $\mathrm{N}^{\circ}$ de protocolo de cada animal.

Deshidratación: se deshidrataron mediante pasaje en alcoholes de gradación creciente: $70 \%, 96 \%$ (dos pasajes) y $100 \%$ (dos pasajes).

Aclaramiento: se sumergieron en xilol (dos pasajes) para obtener no sólo el aclaramiento del tejido, sino también para actuar como intermediario entre el medio acuoso de los alcoholes y el graso de la parafina.

Inclusión: se realizaron 3 baños de parafina fundida a una temperatura de aproximadamente $60^{\circ} \mathrm{C}$ y s mantenidos en estufa, a temperatura constante, durante $24 \mathrm{hs}$. Se los retiró de la misma y se dejaron enfriar a temperatura ambiente para obtener el taco. 
Corte: a partir de cada taco se realizaron cortes histológicos de $5 \mu$ de espesor con un micrótomo de Minott, los cuales se colocaron sobre portaobjetos silanizados (Silane, Sigma).

Aclaramiento: los cortes histológicos se sumergieron nuevamente en xilol para su desparafinado (dos pasajes).

Hidratación: los cortes se rehidrataron mediante pasaje de alcoholes de concentración decreciente y se lavaron con agua destilada.

Coloración: se utilizó la técnica de hematoxilina de Meyer y Eosina en solución acuosa. La solución madre de hematoxilina se diluyó en agua destilada (1:4), mientras que la eosina se utilizó al 1\% en agua destilada. La coloración se realizó siguiendo la siguiente secuencia: los cortes desparafinados e hidratados fueron colocados en la solución de hematoxilina de Harris durante 3 a 5 minutos. Pasado ese tiempo se sumergieron en agua corriente para producir el virado del colorante. Luego, los cortes fueron colocados en la solución de eosina por 1 minuto. Posteriormente, se procedió a la deshidratación, aclarado.

Montaje: el corte se montó con bálsamo de Canadá y fue cubierto por un cubreobjeto.

\section{Técnicas inmunohistoquímicas}

3.1 Técnica inmunohistoquímica para Bromodeoxiuridina

En la etapa $S$ se duplican (sintetizan) las moléculas de ADN. Este periodo puede demostrarse experimentalmente mediante la incorporación de BrdU (bromodeoxiuridina), que es un nucleótido modificado (Eynard et al., 2008).

A cada animal se le inyectó intraperitonealmente en la fosa ilíaca izquierda una solución de 5- bromodeoxiuridina (Sigma) (50 mg/kg de peso corporal en 0,01 $\mathrm{ml}$ de agua destilada/g de peso corporal), 1 hora previa a su sacrificio. Durante la necropsia se extrajeron los hígados que se fijaron en formol tamponado durante 24 horas, luego se deshidrataron mediante un tren de alcoholes de concentración creciente, se aclararon en xilol y se incluyeron en parafina. Se cortaron con micrótomo de deslizamiento, obteniéndose cortes de un espesor aproximado de 5 $\mu \mathrm{m}$, y se montaron sobre portaobjetos silanizados (Silane, Sigma). Se les realizó 
el desparafinado con xilol y luego se hidrataron utilizando nuevamente un tren de alcoholes, pero esta vez de concentración decreciente. Los cortes hidratados se sometieron al tratamiento en microondas ( $2 \times 5$ minutos, $750 \mathrm{~W})$ en buffer citrato, pH 6 para la recuperación antigénica. Una vez enfriados, se lavaron en Tris y se sumergieron en una solución de agua oxigenada (20 vol.) al $3 \%$ para bloquear la peroxidasa endógena y así evitar la marcación inespecífica. Se incubaron con el anticuerpo primario (BrdU20a, 1/100, Dako) durante $1 \mathrm{~h}$ en cámara húmeda a temperatura ambiente. Terminada la incubación se volvieron a lavar en Tris y se utilizó el Sistema Envision (Dako) como sistema de detección, durante 30 minutos a temperatura ambiente y en cámara húmeda. Se volvieron a lavar en Tris y se realizó el revelado con 3'3-diaminobencidina (DAB) (Sigma), para la observación de los núcleos en síntesis (de color marrón) (Fig. 10). Por último, se les realizó una coloración suave de contraste con Hematoxilina de Meyer para facilitar la observación de los núcleos no marcados y se los montó con un cubreobjeto.
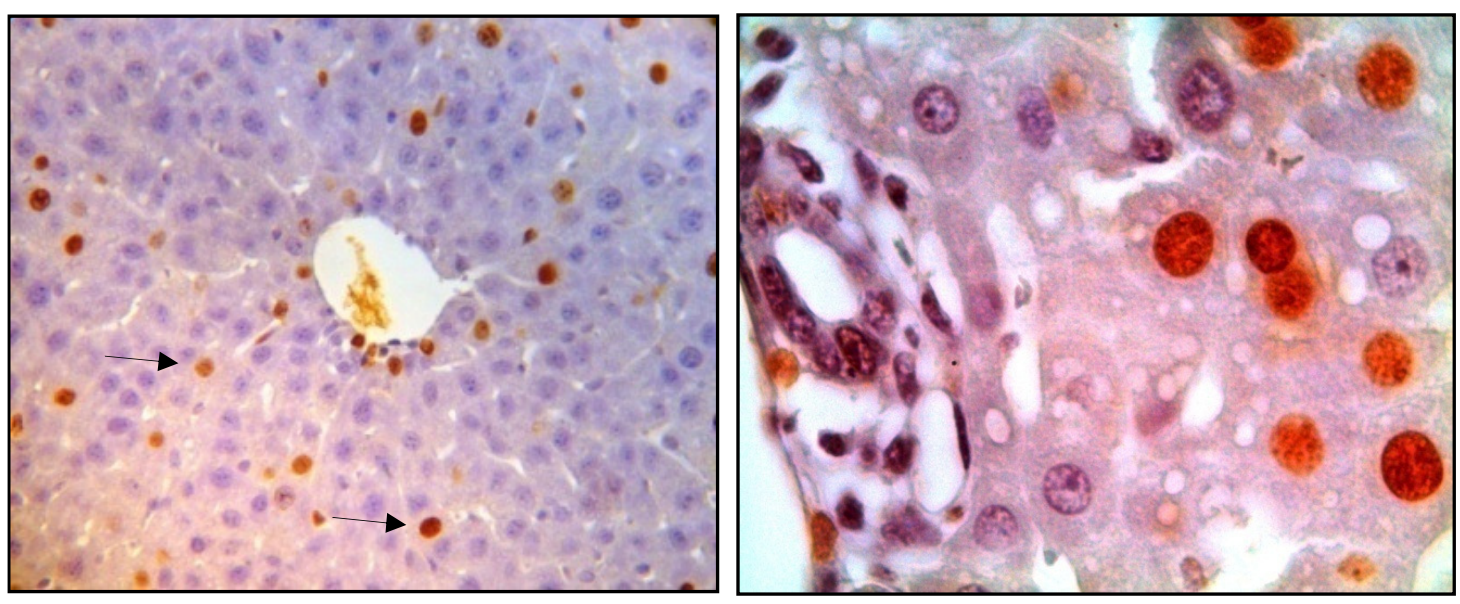

Fig. 10 Fotos que muestran núcleos de los hepatocitos periportales en síntesis marcados con BrdU (flechas), a 40X (a) y a 100X (b).

\subsection{Técnica inmunohistoquímica para VEGF}

Los cortes histológicos se sumergieron en xilol para su desparafinado, se rehidrataron con alcoholes de concentración decreciente y se lavaron con Tris buffer (TBS), pH 7.4. Luego del bloqueo de la peroxidasa endógena con $\mathrm{H}_{2} \mathrm{O}_{2} 3 \%$ durante 15 minutos, se recuperó el epitope mediante calor. Los cortes se lavaron 
nuevamente con TBS y se colocaron en cajas plásticas conteniendo $250 \mathrm{ml}$ de buffer citrato de $0.01 \mathrm{M}, \mathrm{pH} 6$ dentro de un horno a microondas, con plato giratorio, a $750 \mathrm{~W}$ durante 10 minutos $(2 \times 5$ minutos). Las cajas se llenaron con agua destilada luego de cada ciclo para mantener la concentración del buffer. Luego de la exposición al microondas, los preparados se enfriaron en la misma solución durante 20 minutos, se lavaron en TBS y se incubaron con el anticuerpo primario VEGF Clone VG1, monoclonal de ratón y anti-humano, isotopo $\lg _{1}$ (DakoCytomayion, Denmark A/S), a una dilución de 1/80 en una cámara húmeda durante 1 hora, a temperatura ambiente. Se utilizó el Sistema Envision (DAKO, Carpinteria, California, USA) como sistema de detección. La reacción se reveló con DAB (Sigma) en TBS con $0.03 \% \mathrm{H}_{2} \mathrm{O}_{2}$. Finalmente, los cortes fueron contrastados con Hematoxilina de Meyer y montados.

En las células DAB-VEGF positivas se observa una marcación citoplasmática de tipo granular (Fig. 11).

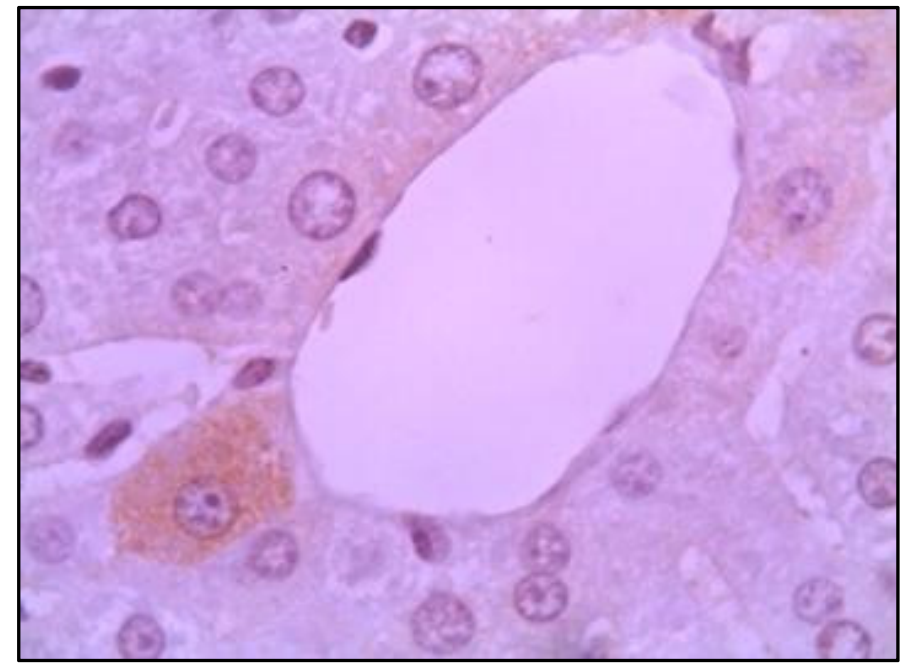

Fig. 11 Foto que muestra la marcación citoplasmática de un hepatocito perivenular VEGF positiva, a 100X. 


\section{Cuantificación y clasificación de los datos}

4.1 Método de recuento y determinación de la población de hepatocitos.

El conteo histológico de los preparados se realizó con un microscopio binocular a 1000 aumentos, con un objetivo de inmersión. El camino que se recorre en dicho examen corresponde al de una guarda griega, en la cual se barre todo el preparado sin repetir campos.

En cada preparado se contaron 3000 núcleos, repartidos en 30 campos microscópicos por zona, con un subtotal de 1500 células para la zona perivenular y 1500 para la zona periportal.

Se consideró un hepatocito como perivenular (HPV) o periportal (HPP) de acuerdo a que se encontrara dentro de las 5 hileras alrededor de la vena central o portal (Fig. 12) (Nagy et al., 2001).

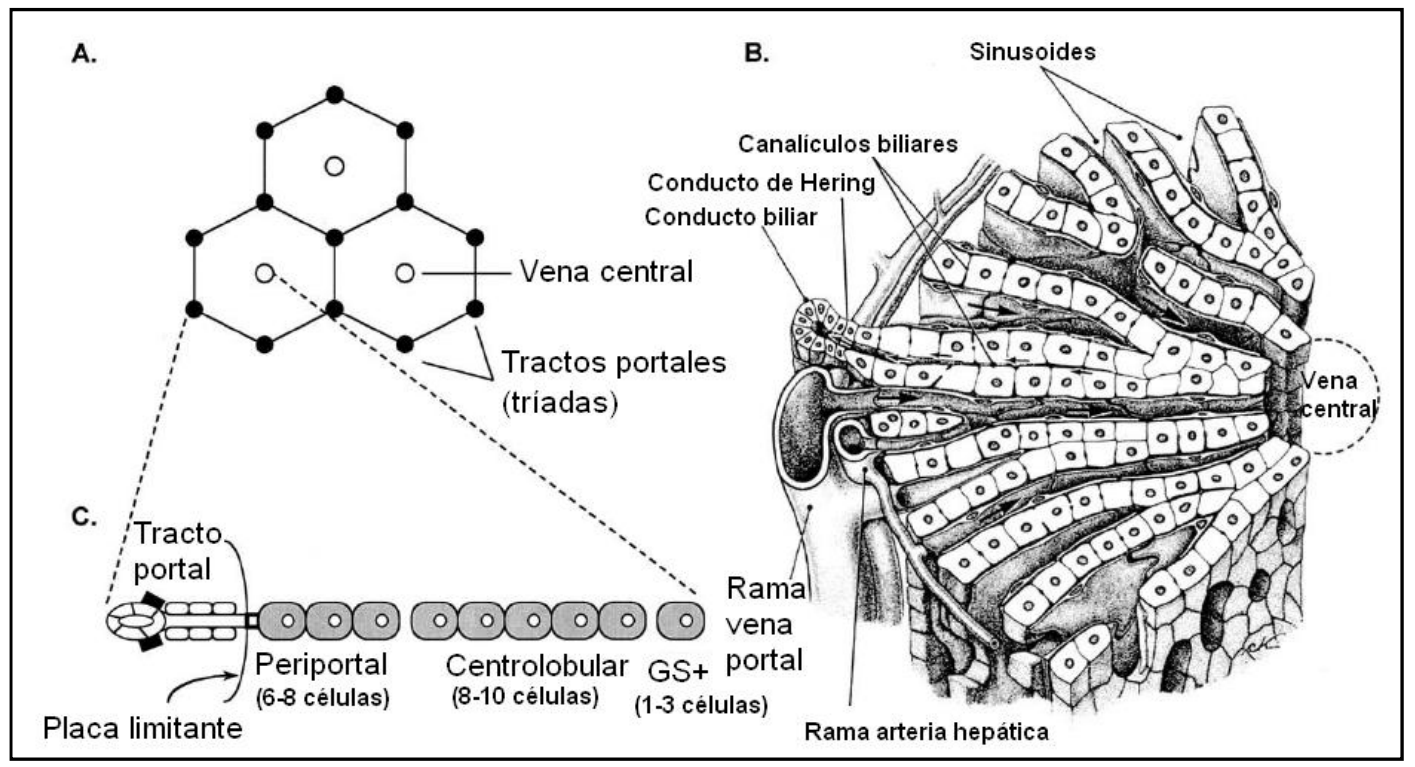

Fig. 12 Representación de los lobulillos hepáticos mostrando las tríadas portales y las venas centrales (A). Mayor aumento de un lobulillo hepático (B). Dibujo que esquematiza la ubicación de los distintos hepatocitos en una trabécula de Remak (C) (El esquema $C$ fue levemente modificado de Fausto y Campbell, 2003). 
Se considerará que hay zonación de la expresión de VEGF, ADNs o AM cuando existan diferencias estadísticamente significativas entre las medias de las zonas periportal y perivenular para cada grupo. Además, la distribución de las distintas variables dentro del lobulillo hepático se considerará como homogénea cuando dentro de un periodo circadiano no existan diferencias entre las zonas. De modo contrario, se considerará como una distribución heterogénea.

\subsection{Método de registro}

Los datos fueron volcados en planillas donde constan: el $n^{\circ}$ de protocolo del animal ("identificación individual”), el $n^{\circ}$ de lote del mismo (hora de sacrificio), para cada zona 3 columnas de 10 filas cada una, en las cuales se registraron las células (citoplasmas) o núcleos marcados (filas 1-9) y el total de hepatocitos cada 10 campos. Se dejó constancia del índice de marcación de cada zona en la planilla de cada animal.

\subsection{Determinación de los índices de marcación}

\section{Índice de expresión del VEGF}

Para establecer el índice de expresión del VEGF de cada zona se contaron las células VEGF positivas y totales de cada preparado histológico. Mediante la fórmula células marcadas x 100 / totales se calculó el porcentaje de células que expresan VEGF.

Los resultados se expresan como células VEGF positivas por 100 núcleos.

\section{Índice de síntesis de ADN}

Para establecer el índice de síntesis de ADN de cada zona se contaron las células BrdU positivas y totales de cada preparado histológico. Mediante la fórmula células marcadas x 100 / totales se calculó el porcentaje de células en síntesis.

Los resultados se expresan como núcleos positivos por 100 núcleos. 


\section{Tasa mitótica}

Para establecer la tasa mitótica de cada zona se contaron las metafases colchicínicas y totales de cada preparado histológico. Mediante la fórmula células con metafases colchicínicas x 100 / totales se calculó el porcentaje de células en mitosis.

Al estar trabajando con el método statmoquinético, los resultados corresponden no a un "índice mitótico", sino a la "tasa mitótica", o sea al número de metafases colchicínicas que se han producido durante las 4 horas (Errecalde, 1994).

Los resultados se expresan como metafases colchicínicas por 100 núcleos.

\section{$5 \quad$ Análisis estadístico de los datos}

A partir de los índices se calculó la media \pm ESM para cada punto horario (n aproximadamente 6). Las medias fueron comparadas empleando los siguientes test estadísticos:

- Test de Student, para comparar las 2 medias entre las zonas perivenular y periportal, para cada punto horario, tanto para los animales Intactos (Int), Hepatectomizados (Hep) y Portadores-Hepatectomizados de tumor (PortHep).

- Test del análisis de la varianza (ANOVA), para analizar las diferencias entre las medias de las 12:00, 16:00, 20:00, 00:00, 04:00 y 08:00 h, dentro de cada zona, tanto en los animales Int, como Hep y como PortHep.

- Postest de Comparaciones Múltiples de Tukey-Kramer, empleado con posterioridad a ANOVA, con el fin de analizar la diferencia estadísticamente significativa obtenida de comparar los 6 puntos horarios dentro de cada grupo. Este postest permitió detectar aquellos puntos horarios responsables de dichas diferencias. 
En todos los casos se consideraron como estadísticamente significativas aquellas diferencias entre las medias cuyo valor de $p$ fuera $<0,05$.

Programa utilizado para el análisis estadístico de los datos:

- INSTAT, para obtención de los estadísticos descriptivos (media, ESM) y de los estadísticos inferenciales "t" test de Student, ANOVA y el postest de Comparaciones Múltiples de Tukey-Kramer. 


\section{DISEÑO EXPERIMENTAL}

EXPERIMENTO I. ESTUDIO DE LA EXPRESIÓN DEL VEGF Y DE LA SÍNTESIS DE ADN EN EL HÍGADO DE RATONES JÓVENES INTACTOS A LO LARGO DE UN PERÍODO CIRCADIANO.

Se utilizaron 37 ratones $\mathrm{C} 3 \mathrm{H} / \mathrm{S}$ machos jóvenes, de 28 días de edad, para el estudio de la periodicidad en el hígado de las distintas variables bajo condiciones normales (animales Intactos).

A los 28 días de edad, los animales se dividieron en dos grupos: uno se utilizó para el estudio de la expresión del VEGF y el otro para la ADNs. Todos se sacrificaron a los 28 días de edad, en lotes de aproximadamente 6 animales, a las $12,16,20,00,04$ y $08 \mathrm{HD}$. Los ratones que se utilizaron para el estudio de la ADNs, una hora antes del sacrificio, se les inyectó intraperitonealmente una solución de 5- bromodeoxiuridina (Sigma) en dosis equivalente a $50 \mathrm{mg} / \mathrm{kg}$ de peso corporal.

Durante las necropsias se extrajo el lóbulo triangular del hígado el cual se procesó para las técnicas de inmunohistoquímica para la detección del VEGF o de los núcleos en síntesis (técnica de bromodeoxiuridina).

En todos los casos se contaron los hepatocitos marcados positivamente con VEGF y las células en síntesis. 
EXPERIMENTO II. ESTUDIO DE LA EXPRESIÓN DEL VEGF, DE LA SÍNTESIS DE ADN Y DE LA ACTIVIDAD MITÓTICA EN EL HÍGADO DE RATONES JÓVENES HEPATECTOMIZADOS A LO LARGO DE UN PERÍODO CIRCADIANO.

Se utilizaron 69 ratones $\mathrm{C} 3 \mathrm{H} / \mathrm{S}$ machos jóvenes, de 28 días para el estudio de la periodicidad de las distintas variables en el hígado bajo condiciones de regeneración posthepatectomía.

A los 28 días de edad, los animales fueron sometidos a una HP (70\%) a las 10:00 h y se dividieron en tres grupos: uno se utilizó para el estudio de la expresión del VEGF, otro para la ADNs y tercer grupo para el estudio de la AM. Todos se sacrificaron a los 28 días de edad, en lotes de aproximadamente 6 animales, a las 12/26, 16/30, 20/34, 00/38, 04/42 y 08/48 HD/HPH. Los ratones para el estudio de la AM se inyectaron intraperitonealmente con colchicina (2 $\mu \mathrm{g} / \mathrm{g}) 4 \mathrm{~h}$ previas al sacrificio. Los ratones que se utilizaron para el estudio de la ADNs, una hora antes del sacrificio, se les inyectó intraperitonealmente una solución de 5- bromodeoxiuridina (Sigma) en dosis equivalente a $50 \mathrm{mg} / \mathrm{kg}$ de peso corporal.

Durante las necropsias se extrajo el lóbulo triangular del hígado el cual se procesó para las técnicas de rutina de Hematoxilina y Eosina y de inmunohistoquímica para la detección para la detección del VEGF o de los núcleos en síntesis (técnica de bromodeoxiuridina).

En todos los casos se contaron los hepatocitos marcados positivamente con VEGF, los núcleos positivos y las metafases colchicínicas. 
EXPERIMENTO III. ESTUDIO DE LA EXPRESIÓN DEL VEGF, DE LA SÍNTESIS DE ADN Y DE LA ACTIVIDAD MITÓTICA EN EL HÍGADO DE RATONES JÓVENES HEPATECTOMIZADOS-PORTADORES DE TUMOR A LO LARGO DE UN PERÍODO CIRCADIANO.

Se utilizaron 63 ratones $\mathrm{C} 3 \mathrm{H} / \mathrm{S}$ machos jóvenes, de 28 días para el estudio de la periodicidad de las distintas variables en el hígado bajo condiciones de portación de tumor y de regeneración posthepatectomía.

Al cumplir los $21 \pm 1$ días de edad, los animales fueron injertados con el tumor y una semana después se sometieron a una HP (70\%), a las 10:00 h. Se dividieron en tres grupos: uno se utilizó para el estudio de la expresión del VEGF, otro para el estudio de la ADNs y un tercer grupo para el estudio de la AM. Todos se sacrificaron, en lotes de aproximadamente 6 animales, a las 12/26, 16/30, 20/34, 00/38, 04/42 y 08/48 HD/HPH. Los ratones para el estudio de la actividad mitótica se inyectaron intraperitonealmente con colchicina $(2 \mu \mathrm{g} / \mathrm{g}) 4 \mathrm{~h}$ previas al sacrificio. Los ratones que se utilizaron para el estudio de la síntesis de ADN, una hora antes del sacrificio, se les inyectó intraperitonealmente una solución de 5bromodeoxiuridina (Sigma) en dosis equivalente a $50 \mathrm{mg} / \mathrm{kg}$ de peso corporal.

Durante las necropsias se extrajo el lóbulo triangular del hígado el cual se procesó para las técnicas de rutina de Hematoxilina y Eosina y de inmunohistoquímica para la detección del VEGF o de los núcleos marcados (técnica de bromodeoxiuridina).

En todos los casos se contaron los hepatocitos marcados positivamente con VEGF, los núcleos positivos y las metafases colchicínicas.

\footnotetext{
- En cada experimento se analizaron, simultáneamente, las zonas periportal y perivenular del hígado.
} 


\section{RESULTADOS}

\section{Zona perivenular}

EXPERIMENTO I. ESTUDIO DE LA EXPRESIÓN DEL VEGF Y DE LA SÍNTESIS DE ADN EN EL HÍGADO DE RATONES JÓVENES INTACTOS A LO LARGO DE UN PERÍODO CIRCADIANO.

Los valores de la expresión del VEGF muestran diferencias significativas a lo largo del período circadiano en los animales Int $(p<0,05)$, observándose el valor más alto a las $00 \mathrm{~h}$ (Tabla 1).

Los valores de síntesis de ADN presentan diferencias altamente significativas $(p<0,0001)$ a lo largo del periodo circadiano en los animales Int, observándose un valor máximo a las $12 \mathrm{~h}$, con una diferencia significativa $(\mathrm{p}<$ $0,001)$ con respecto de los valores de las 00 y $16 \mathrm{~h}$. Además, se encontraron diferencias significativas $(p<0,01)$ entre los valores de las 08 y 16 h (Tabla 1$)$.

EXPERIMENTO II. ESTUDIO DE LA EXPRESIÓN DEL VEGF, DE LA ACTIVIDAD MITÓTICA Y DE LA SÍNTESIS DE ADN Y EN EL HÍGADO DE RATONES JÓVENES HEPATECTOMIZADOS.

Los valores de la expresión del VEGF no muestran diferencias estadísticamente significativas a lo largo del periodo circadiano en los animales Hep. El valor más alto se observa a las 20/34 HD/HPH (Tabla 2).

Los valores de síntesis de ADN presentan diferencias muy significativas a lo largo del segundo día $(p<0,01)$, observándose el valor máximo a las 00/38 $\mathrm{HD} / \mathrm{HPH}$. El mismo presenta diferencias significativas $(\mathrm{p}<0,05)$ con los valores de las 12/26 y de las 16/30 HD/HPH (Tabla 2).

Los valores de la AM presentan diferencias altamente significativas $(p<0,0001)$ a lo largo del segundo día, observándose el valor máximo a las 08/46 
$\mathrm{HD} / \mathrm{HPH}$, con una diferencia significativa $(\mathrm{p}<0,001)$ con el resto de los valores (Tabla 2).

EXPERIMENTO III. ESTUDIO DE LA EXPRESIÓN DEL VEGF, DE LA ACTIVIDAD MITÓTICA Y DE LA SÍNTESIS DE ADN Y EN EL HÍGADO DE RATONES JÓVENES HEPATECTOMIZADOS-PORTADORES DE TUMOR.

Los valores de expresión de VEGF presentan diferencias significativas $(\mathrm{p}<0,02)$ a lo largo del segundo día, observándose el valor más alto a las $08 / 46$ $\mathrm{HD} / \mathrm{HPH}$ (Tabla 3).

Los valores de síntesis de ADN no presentan diferencias significativas a lo largo del segundo día, observándose el valor más alto a las 12/26 HD/HPH (Tabla $3)$.

Los valores de la AM presentan diferencias altamente significativas $(p<$ 0,0001) a lo largo del segundo día, observándose el valor máximo a las 08/46 $\mathrm{HD} / \mathrm{HPH}$ con una diferencia significativa $(p<0,001)$ con el resto de los valores (Tabla 3).

\section{Zona periportal}

EXPERIMENTO I. ESTUDIO DE LA EXPRESIÓN DEL VEGF Y DE LA SÍNTESIS DE ADN EN EL HÍGADO DE RATONES JÓVENES INTACTOS A LO LARGO DE UN PERÍODO CIRCADIANO.

La expresión del VEGF muestra diferencias significativas a lo largo del período circadiano $(p<0,05)$, observándose el valor más alto a las $12 \mathrm{~h}$ (Tabla 4).

Los valores de síntesis de ADN presentan diferencias significativas $(p<0,05)$ a lo largo del primer día, observándose el valor máximo a las $08 \mathrm{~h}$, el cual presenta diferencias significativas $(p<0,05)$ con el valor de las $00 \mathrm{~h}$ (Tabla 4). 
EXPERIMENTO II. ESTUDIO DE LA EXPRESIÓN DEL VEGF, DE LA ACTIVIDAD MITÓTICA Y DE LA SÍNTESIS DE ADN Y EN EL HÍGADO DE RATONES JÓVENES HEPATECTOMIZADOS.

Los valores de la expresión del VEGF muestran diferencias significativas ( $p>0,01)$ durante el período circadiano, observándose el valor máximo a las 20/34 $\mathrm{HD} / \mathrm{HPH}$, el cual presenta diferencias significativas $(p<0,05)$ con los valores de las 12/26, 00/38 y 08/46 HD/HPH (Tabla 5).

Los valores de síntesis de ADN presentan diferencias altamente significativas a lo largo del segundo día $(p<0,01)$, observándose el valor máximo a las $20 / 34 \mathrm{HD} / \mathrm{HPH}$, el cual presenta diferencias significativas con los valores de las $12 / 26(p<0,05), 16 / 30(p<0,01)$ y 08/46 HDHPH $(p<0,05)$ (Tabla 5).

Los valores de la $A M$ presentan diferencias altamente significativas a lo largo del segundo día $(p<0,0001)$ en los animales Hep, observándose el valor máximo a las $08 / 46 \mathrm{HD} / \mathrm{HPH}$, con una diferencia significativa $(p<0,001)$ con el resto de los valores (Tabla 5 ).

EXPERIMENTO III. ESTUDIO DE LA EXPRESIÓN DEL VEGF, DE LA ACTIVIDAD MITÓTICA Y DE LA SÍNTESIS DE ADN Y EN EL HÍGADO DE RATONES JÓVENES HEPATECTOMIZADOS-PORTADORES DE TUMOR.

Los valores de expresión de VEGF presentan diferencias significativas a lo largo del segundo día $(p<0,02)$, observándose el valor más alto a las 08/46 HD/HPH (Tabla 6).

Los valores de síntesis de ADN no presentan diferencias significativas a lo largo del segundo día en los animales PorHep, observándose el valor más alto a las 12/26 HD/HPH (Tabla 6).

Los valores de la AM presentan diferencias altamente significativas $(p<$ 0,0001) a lo largo del segundo día, observándose el valor máximo a las 08/46 $\mathrm{HD} / \mathrm{HPH}$ con una diferencia significativa $(p<0,001)$ con el resto de los valores (Tabla 6). 


\section{Comparación entre las medias de las zonas periportal y perivenular, para} cada punto horario

En los animales Int los valores correspondientes a la expresión de VEGF y la ADNs no presentan diferencias estadísticamente significativas entre las zonas periportal y perivenular (Tablas 7 y 8 , respectivamente).

En los ratones Hep la expresión del VEGF no posee diferencias entre las zonas, a diferencia de la ADNs que presenta diferencias entre la zona periportal y perivenular, a las $04 / 42$ y a las $08 / 46 \mathrm{HD} / \mathrm{HPH} \quad(\mathrm{p}<0,05$ y $p<0,0001$, respectivamente) y de la actividad mitótica, que las posee a las 20/34 HD/HPH ( $p$ $<0.05$ ) (Tablas 9,10 y 11 ).

En los ratones PortHep no existen diferencias significativas entre las zonas periportal y perivenular en la expresión de VEGF y de la ADNs (Tablas 12 y 13). Para la $A M$, se observaron diferencias altamente significativas a las 08/46 HD/HPH $(p<0,0001)$ (Tabla 14).

\section{Comparación de las medias diarias entre los distintos experimentos para} cada variable.

Cuando comparamos el promedio diario $(X d)$ de la síntesis de ADN entre todos los grupos experimentales (Int vs Hep vs PortHep, columnas), observamos una diferencia significativa entre los animales Int y los PortHep $(p<0,001)$ y entre los Int y los Hep $(p<0,01)$, para ambas zonas. Los animales Int presentan los valores más bajos y los Hep y los PortHep, los más altos (Tabla 15).

Por otro lado, cuando comparamos el Xd de la expresión del VEGF entre los distintos grupos experimentales, observamos una diferencia significativa entre los animales PortHep y los Hep $(p<0,01)$ y entre los PortHep y los Int $(p<0,001)$, para ambas zonas. Los animales Hep presentan el valor más bajo respecto de los PortHep, al igual que los Int respecto de los PortHep (Tabla 16).

No existen diferencias significativas entre las $\mathrm{Xd}$ de la $\mathrm{AM}$ entre los animales Hep y PortHep, de ambas zonas (Tabla 17). 


\section{DISCUSIÓN}

En el estado quiescente los hepatocitos no responden completamente a los factores de crecimiento como el HGF, TGFa y al EGF, que en cultivo, son poderosos estimuladores de la síntesis de ADN (ADNs). Para que puedan ejercer su efecto, las células hepáticas deben ser "iniciadas" para dejar el estado quiescente y entrar en el ciclo celular, proceso que en inglés se conoce como priming y que fuera propuesto inicialmente por Molten et al. en 1970.

Existe la idea altamente aceptada de que el hígado tiene una capacidad de replicación limitada (Fausto and Campbell, 2003). Sin embargo, distintos estudios demostraron que los hepatocitos de los ratones en crecimiento y adultos intactos poseen variaciones circadianas en su ADNs (Echave Llanos et al., 1971a; Surur et al., 1985). En coincidencia con estos autores, en nuestro trabajo, los ratones jóvenes intactos también presentan variaciones circadianas en la ADNs. Ello se debe a que los ritmos circadianos influyen en la hora de la división celular in vivo, provocando variaciones diarias en la mayoría de los tejidos, no sólo en la síntesis de ADN sino también en el índice de AM (Matsuo et al., 2003). A su vez, estas variaciones se manifiestan debido a que en los ratones, a partir del día 20 de vida, se produce la maduración del eje hipotálamo-hipofisario-adrenal y con él la sincronización de las funciones hepáticas y la aparición del ritmo circadiano en la proliferación de los hepatocitos, tanto en el hígado regenerante como en el crecimiento posnatal normal del órgano (Van Cantfort and Barbason, 1972; Barbason et al., 1974; Herens et al., 1998). Al analizar la estructura temporal de la ADNs es posible ver que el pico de actividad ocurre entre las 08 y $12 \mathrm{~h}$ del día.

Del mismo modo que para la ADNs, en 1971 Echave Llanos et al. (1971a) describieron variaciones circadianas para la AM de los ratones machos normales de 21 días. Años más tarde, Errecalde (1994) confirma dichos resultados para los animales de 28 días y establece que el pico de AM ocurre a las $12 \mathrm{~h}$. Ello se debe a que la presencia de los ritmos circadianos y los niveles de AM están condicionados por el efecto que ejercen la luz y la comida sobre el SNC, donde el hipotálamo estimula la secreción de la ACTH por la adenohipófisis y secundariamente, la secreción de glucorticoides antimitóticos durante el período 
de actividad y de STH mitogénica durante el reposo. Estos factores hormonales sólo influirían sobre la AM (Echave Llanos, 1963).

Al analizar la expresión del VEGF, también se observaron variaciones diarias, circunstancia que ya había sido señalada en la misma cepa de ratones machos intactos adultos (Fernández Blanco et al., 2011). A diferencia de éstos, que presentaron su valor máximo a las 20 h, en los jóvenes el mismo se encontró a las 00 para la zona perivenular y a las $12 \mathrm{~h}$ para la periportal, con lo cual podría existir un adelantamiento del valor máximo en los hepatocitos perivenulares de los ratones jóvenes en la expresión del VEGF.

Es sabido que la angiogénesis se retrasa con la edad. El correcto funcionamiento de todos los pasos en dicho proceso, depende de la regulación e interacción entre células, factores de crecimiento y proteínas plasmáticas. Dentro de los factores de crecimiento se mencionan el FGF-b, el VEGF, el IGF-1. Por otro lado, existen sustancias como las proteínas ácidas ricas en cisteína secretadas (SPARC) y otras, que compiten con los factores antes mencionados determinando así, si los vasos sanguíneos dentro de un tejido se desarrollarán (Sadoun and Reed, 2003). Estudios in vitro confirmaron que un retraso en la angiogénesis dependiente de la edad estaría asociado con una falla de las funciones celulares, tal como una migración más lenta de las células endoteliales envejecidas y de los fibroblastos (Reed et al., 2000; Reed et al., 2001; Mogford et al., 2002). Las células endoteliales envejecidas producen menos óxido nítrico y tienen una mayor sensibilidad a los estímulos apoptóticos así como también una respuesta defectuosa a los efectos mitogénicos del VEGF y a los antiproliferativos del TGF- $\beta 1$ (Vasa et al., 2000; Rivard et al., 1999; McCaffrey and Falcone, 1993). Considerando lo expuesto anteriormente y teniendo en cuenta la dependencia que posee el proceso de angiogénesis respecto del VEGF, no sólo el máximo de expresión del VEGF se presentaría antes en los ratones jóvenes sino que también el proceso angiogénico, en virtud del crecimiento global de los órganos del animal joven (Clapp et al., 2009).

La presencia de la expresión del VEGF en los hepatocitos jóvenes, puede ser considerada como una posible evidencia indirecta de la estimulación de la angiogénesis hepática bajo condiciones fisiológicas de crecimiento posnatal normal. Asimismo, se sabe que en las ratas las células endoteliales normales 
expresan ARNm de los receptores para VEGF, los cuales pueden intervenir tanto en la angiogénesis patológica como la fisiológica (Mochida et al., 1996). desarrollo vascular hepático comenzaría con la expresión del VEGF, actuando sobre el crecimiento y la morfogénesis de las células endoteliales vasculares y participado de una manera indirecta, en la regulación del tamaño de los órganos y del cuerpo y en la supervivencia en la vida posnatal temprana (Sugiyama et al., 2010; Gerber et al., 1999; Sadoun and Reed, 2003). Dicho de otro modo, el control de la masa de un órgano se debe a eventos angiodependientes (Dogrul et al., 2010; Greene et al., 2003).

Se ha mencionado que el hígado cumple una gran variedad de funciones, muchas de las cuales están especializadas o son diferentes dependiendo de la zona del lobulillo hepático y que las mismas están determinadas por el aporte de oxígeno y de nutrientes (Jüngermann and Kietzmann, 1996). En cuanto a los parámetros de crecimiento como la ADNs, distintos trabajos describieron un patrón de distribución heterogéneo, por ejemplo en ratas, con valores de proliferación más altos en el área periportal y un gradiente decreciente en el sentido del drenaje venoso (Ohtake et al., 2004; Geisler et al., 1994; Reynaert et al., 2001). Sin embargo, también hay estudios que indican que la renovación celular ocurre al azar a lo largo del lobulillo (Fausto and Campbell, 2003). Al evaluar la ADNs y la expresión de VEGF de los ratones de 28 días se hace evidente que existe una distribución homogénea dentro del lobulillo hepático de ambas variables, al igual que de la fase $S$ de los hepatocitos de ratas adultas y destetadas (Wright and Alison, 1984; Grisham, 1969).

Los ratones hepatectomizados también poseen variaciones circadianas en la ADNs. Este resultado concuerda con lo hallado por Martin et al. (2000) y García et al. (2010). En este caso, la reducción en la masa hepática produce una respuesta regenerativa rápida tendiente a reemplazar la pérdida del tejido por medio de una hiperplasia compensatoria de los lóbulos remanentes (Alison, 1986). En los ratones jóvenes, dicha respuesta involucra un pico de actividad de la ADNs entre las 34-38 h posthepatectomía, coincidiendo con lo hallado por Fausto et al. (2006). Ellos, demostraron que la ADNs es una variable que no depende del reloj circadiano de las células, ocurriendo siempre $36 \mathrm{~h}$ después de la cirugía, independientemente de la hora en que se practique. Además, tras la 
hepatectomía parcial, el 95\% de los hepatocitos de los ratones jóvenes se dividen entre las 30 y $60 \mathrm{~h} \mathrm{PH}$ para compensar las demandas regenerativas y continuar el crecimiento normal (Fausto and Campbell, 2003).

Este ritmo en la proliferación, a su vez, se debe a las variaciones circadianas en los niveles de los corticoesteroides, que actúan a modo de sincronizador del crecimiento hepático a través de un control negativo (Barbason et al., 1987; Barbason et al., 1996; Barbason et al., 1989). De esta manera, cuando los valores de los corticoesteroides son elevados, ejercen un efecto inhibidor sobre el comienzo de la fase $\mathrm{S}$, a través de la inhibición de la actividad de la ADN polimerasa (Guzek, 1968; Henderson and Loeb, 1974). Al estudiar el ritmo circadiano de la ADNs de los ratones hepatectomizados, los picos para ambas zonas, quedan comprendidos dentro del período de actividad de los ratones, momento en que los valores de los corticoidesteroides son más bajos (Barbason et al., 2003).

Además de la influencia que pueden ejercer determinadas variables fisiológicas en el ritmo circadiano de la ADNs de los hepatocitos, la especie de roedor también puede ser decisiva. Por ejemplo, se ha demostrado que en ratas el pico ocurre a las $20 \mathrm{~h}$ siguientes de la HP mientras que en los ratones, de manera similar a lo obtenido para los ratones jóvenes, entre las 32-36 h posteriores (Weglartz and Sandgren, 2000). La entrada masiva, coordinada, en la fase $S$ dada por la presencia de un pico fuerte de incorporación de bromodeoxiuridina, difiere en la temporización entre especies como consecuencia de la variabilidad en la longitud de la fase G1 (Collin de l'Hortet et al., 2012).

Otro factor involucrado, sumado al interespecífico, que también puede introducir diferencias en cuanto al patrón de crecimiento hepático, es la edad de los animales. Así, en ratas la proliferación de los hepatocitos regenerantes jóvenes ocurre antes y en una fracción mayor que en el tejido hepático de los animales adultos (Bucher et al., 1964). Por otro lado, al comparar los resultados de los ratones jóvenes hepatectomizados con el de los adultos de García et al. (2010), se observa que la ADNs se retrasa en los primeros. Es decir, existen diferencias en la estructura temporal de la ADNs relacionadas con la especie, y con la edad dentro de la misma especie. 
Al tener en cuenta el tipo de tratamiento empleado en los experimentos para analizar la ADNs, dichos valores en los animales hepatectomizados es mayor para el hígado regenerante, respecto del de los ratones intactos. Esto tiene relación, con que el hígado posee una notable habilidad para regenerarse en respuesta a una remoción quirúrgica o una injuria química o viral, siendo que además, la magnitud de la respuesta depende de la severidad de la HP (Mangnall et al., 2003). La respuesta regenerativa se ve incrementada cuanto mayor sea la masa hepática extraída durante la cirugía, ya que cuando se extirpa el $90 \%$ del órgano la regeneración es más rápida que cuando se extrae el 70 \% (Bockhorn et al., 2008). Esto explicaría la mayor intensidad de la ADNs en los animales hepatectomizados respecto de los ratones intactos, debida a la remoción de tejido hepático como consecuencia de la HP.

La AM de los hepatocitos regenerantes también posee variaciones circadianas, siendo que la sincronización de su actividad aumenta desde el día 20 al 30 de vida posnatal (Barbason et al., 1987). El pico de actividad en los ratones jóvenes ocurre a las 08 h, coincidiendo con Russo y Echave Llanos (1964), quienes analizaron la $\mathrm{AM}$ en el hígado en regeneración de ratones adultos durante tres días consecutivos y encontraron que el pico de la misma siempre ocurría a las $08 \mathrm{~h}$, momento que representa el comienzo del período de reposo. A pesar de que existen algunas diferencias con estos autores en la metodolgía empleada, como la hora en que se realizó la cirugía, el pico de AM sigue ocurriendo a las $08 \mathrm{~h}$, como también lo demostara oportunamente Andrini et al. (2013) en ratones adultos. Fausto et al. (2006) indicaron que una vez que los hepatocitos replicaban su ADN, éstos ingresaban a la fase $\mathrm{M}$ siempre a la misma hora. Tal vez, la transición G2/M esté bajo un control circadiano, en el cual cobraría importancia la quinasa WEE1 (Fausto et al, 2006).

En trabajos previos se demostró que la expresión del VEGF presenta variaciones circadianas en los hepatocitos del hígado de ratones adultos $\mathrm{C} 3 \mathrm{H} / \mathrm{S}$ bajo distintas condiciones experimentales (Furnus et al., 2003; Fernández Blanco et al., 2011; Andrini et al., 2011). En el presente trabajo, la expresión del VEGF también presenta variaciones circadianas, con los valores máximos $34 \mathrm{~h}$ después de practicada la HP. Si se compara este resultado con el de ratones adultos (Andrini et al., 2011), es fácil advertir que éstos presentan el pico de expresión del VEGF $12 \mathrm{~h}$ 
después, lo cual podría atribuirse a un retraso de la angiogénesis dependiente de la edad, ya que las células maduras no responden con la misma rapidez (Sadoun and Reed, 2003; Rivard et al., 1999).

Se ha documentado la existencia de zonación hepática en la ADNs del hígado regenerante de ratas, con valores más altos en la zona periportal respecto de la zona perivenular (Reynaert et al., 2001; Ohtake et al., 2004). Coincidiendo parcialmente con estos investigadores, en el parénquima hepático de los ratones jóvenes hepatectomizados, la ADNs se encuentra distribuida de una manera homogénea a lo largo del eje periportal-perivenular durante las primeras $38 \mathrm{~h}$ siguientes a la HP. Entre las $42-46 \mathrm{~h}$ posteriores se manifiestan diferencias zonales, ya que los hepatocitos periportales poseen los valores de ADNs más altos. Esto podría deberse a que estos hepatocitos poseen más receptores para el EGF, lo cual explicaría por qué responden mejor al mismo, sintetizando más ADN que los hepatocitos perivenulares (Gebhardt, 1998; Gebhardt and Jonitza, 1991). Además, cuando se compara la ubicación temporal de los picos de ADNs entre los hepatocitos periportales y perivenulares, se observa que el de los hepatocitos periportales regenerantes ocurre $4 \mathrm{~h}$ antes. Probablemente, estos hepatocitos poseen una G1 más corta respecto de los de la zona mediozonal y perivenular, provocando así una activación diferencial de los hepatocitos por parte de las citoquinas y ciclinas (Gebhardt, 1992; Fausto and Campbell, 2009).

En cuanto a la distribución zonal de la expresión del VEGF y de la AM en los ratones hepatectomizados, los mismos poseen valores similares en ambas zonas, indicando que existe una distribución predominantemente homogénea de estas variables dentro del lobulillo hepático. Este patrón de distribución podría deberse a que como los hepatocitos periportales y perivenulares poseen la misma tasa de actividad mitótica, la demanda del estímulo angiogénico (VEGF) también sea similar para ambas zonas (Fernández-Blanco et al., 2014).

A partir de los resultados también es posible señalar, que en estos ratones el estímulo angiogénico, dado por la presencia del VEGF dentro del lobulillo hepático, existe mucho antes de que los hepatocitos se dividan, debido a que su valor máximo precede en $12 \mathrm{~h}$ al pico de AM. Esta idea concuerda con el hecho de que para cuando los hepatocitos experimentan mitosis ya podrían contar con una arquitectura de sinusoides hepáticos que aporten oxígeno y nutrientes a los hepatocitos que se 
están replicando (Taniguchi et al., 2001; Shimizu et al., 2005). El proceso de angiogénesis en los ratones hepatectomizados comienza cuando con la resección hepática del $70 \%$ hay un aumento del flujo portal en los lóbulos remanentes y de la cantidad de moléculas señal circulantes, como el HGF y EGF (Michalopoulos, 2010). La elevación de la presión venosa portal posterior a la HP provoca una esteatosis (venosa portal) y una consecuente hipoxia en la zona periportal, elevando los niveles del factor inductor de hipoxia 1-a (Yamamoto et al., 2010). Éste, induce la expresión de los receptores del VEGF en las células endoteliales, a los cuales luego podría unirse el VEGF generado por los hepatocitos (Bao et al., 2009). Posteriormente, las células endoteliales proliferan y liberan IL-6 y FGF desencadenando la angiogénesis para que se restablezca la microcirculación y tensión de oxígeno (LeCouter et al., 2003; Shimizu et al., 2001; Mochida et al., 1996).

Al analizar la relación temporal entre las distintas variables, es posible afirmar que en los hepatocitos perivenulares de los ratones jóvenes no portadores los valores máximos de expresión del VEGF aparecen antes del pico de la ADNs, por lo que hipotetizamos que se presentan en la fase G1/S. Finalmente, los hepatocitos se dividen.

Muchos años atrás, se mencionó que la portación de un tumor podía alterar los patrones metabólicos del hígado del huésped, induciendo cambios medibles de varios componentes y de la tasa mitótica de las células hepáticas (Annau et al., 1951; Medigreceanu, 1910; Yeakel and Farris, 1947; Yeakel, 1948). Sin embargo, no existen muchos trabajos que den cuenta del crecimiento regenerativo del hígado en animales portadores de tumor (Altun and Zalpan, 2004). Entre algunos de ellos podemos mencionar aquellos que describieron que cuando se injertaban determinados hepatomas en ratones machos hepatectomizados, se podía estimular la aparición de un pico de AM, el cual difería en su ubicación temporal de acuerdo con la edad del animal (Badrán et al., 1984; Barbeito et al., 2002; Theologides and Zaki, 1969). Recientemente, Andrini et al. (2013) encontraron que en los hepatocitos de los ratones adultos portadores no sólo se estimulaba la AM sino que además se producía un adelanto de su valor máximo.

En cuanto a la expresión del VEGF y de la ADNs de los hepatocitos bajo la condición de portación de tumor, se observa que existe una secuencia temporal 
entre estas variables, con los dos valores más altos de la síntesis de ADN (26 y $34 \mathrm{~h} \mathrm{PH}$ ), seguidos cada uno por un valor máximo de expresión del VEGF (30 y $46 \mathrm{~h} \mathrm{PH}$ ). Es decir, que los hepatocitos primero presentan valores más altos de ADNs y luego los del VEGF, con lo cual éste podría tener su máximo en la fase G2. Además, la repetición de estas secuencias de variables no descarta la posibilidad de estar ante la presencia de dos poblaciones de hepatocitos diferentes que se expresan también en momentos diferentes. Una de ellas estimulada a dividirse tempranamente, $26 \mathrm{~h}$ después de la HP, y otra $8 \mathrm{~h}$ después.

Al igual que lo que observamos en los ratones jóvenes portadores, Theologides and Kennedy (1967) y Tannuri et al. (2007) encontraron que la ADNs del hígado en regeneración posee valores máximos dentro de un periodo comprendido entre las 24 a $36 \mathrm{~h} \mathrm{PH}$.

La presencia de un tumor puede afectar significativamente el índice de ADNs en el hígado en regeneración de ratones $\mathrm{CH} 3 / \mathrm{S}$ de 6 a10 semanas de edad (Theologides and Kennedy, 1967). En los animales hepatectomizados de nuestro trabajo, el pico de la ADNs ocurre entre 34 a 38 h después de la cirugía y, si se los compara con la de los hepatocitos de los ratones portadoreshepatectomizados, se demuestra que en éstos la fase $S$ está adelantada. Por lo tanto, la temporalidad de la ADNs se modifica ante la presencia del tumor.

Respecto a la expresión del VEGF y de manera similar a lo que ocurre para la ADNs de los ratones portadores, el pico aparece tempranamente, a las $30 \mathrm{~h}$ poshepatectomía, coincidiendo de esta manera con lo hallado por Andrini et al. (2010) en ratones adultos. Se sabe que existe un aumento en la densidad de los vasos sanguíneos que precede al crecimiento rápido de un tumor (Ferrara et al., 2004). Es posible que la aparición más temprana de la proliferación hepatocítica, denotada por el máximo valor de ADNs a las $26 \mathrm{~h}$ posteriores a la hepatectomía, también sería acompañada por una vasculatura inducida a formarse más tempranamente, mediante la secreción de VEGF por los hepatocitos a las $30 \mathrm{~h}$, para abastecer de nutrientes y de oxígeno al tejido hepático en proliferación y/o para el crecimiento del tumor.

Previamente se ha demostrado que la AM de los hepatocitos de ratones adultos portadores del tumor ES12a (no hepatectomizados), no manifiestan 
variaciones circadianas (Barbeito, 1999). Sin embargo, los animales jóvenes hepatectomizados portadores y no portadores tienen variaciones circadianas de la $\mathrm{AM}$ con un pico a las $46 \mathrm{~h} \mathrm{PH}$. Este hecho sugiere que la presencia de un tumor por sí sola no modifica el ritmo circadiano de la AM, pudiendo entonces resultar fundamental la hepatectomía parcial o el estrés quirúrgico para la presencia de dicho pico en los dos grupos experimentales.

Considerando la distribución de las distintas variables dentro del lobulillo hepático en los animales portadores del tumor ES2, resulta evidente que sólo existen diferencias entre las zonas periportal y perivenular en la AM a las $46 \mathrm{~h} \mathrm{PH}$, con el valor más alto para los hepatocitos periportales. Será necesario muestrear puntos horarios posteriores, con el fin de analizar si las diferencias halladas entre las zonas se manifiestan tardíamente en la proliferación hepatocítica y si se mantienen, como consecuencia de un posible efecto ejercido por la portación del tumor.

Cuando se compara el promedio de síntesis de ADN entre todos los grupos, se destaca que los valores más altos pertenecen a los ratones portadores hepatectomizados y a los hepatectomizados. Tal vez, porque la hepatectomía parcial, mediante la liberación de diferentes moléculas y factores, puede inducir una hiperplasia compensatoria estimulándolos a crecer más. Al evaluar el promedio de la expresión del VEGF, los ratones portadores son los que presentan los valores más altos, como si se tratase de una sumatoria de efectos debida a la coexistencia de dos estímulos proliferativos. Es decir, que la presencia del tumor en el ratón hepatectomizado podría modificar la magnitud de la expresión de este factor de crecimiento provocando que sus valores sean mayores, así como también el adelanto de los valores máximos. Resultados concordantes fueron hallados con anterioridad por Andrini et al. (2013). En el mismo, la autora sugiere que el tumor ES2 podría estar estimulando a los hepatocitos para que aumenten su expresión de VEGF y así iniciar el proceso de angiogénesis, para el crecimiento o metástasis tumoral. Lee (1971) observó que un tumor implantado en animales hepatectomizados crecía más. Sin embargo, no es posible poder atribuirle al crecimiento del tumor dependiente de VEGF una única fuente de producción del mismo (Mochida et al., 1996; Tsuzuki et al., 2000). Por otra parte, una predicción del crecimiento tumoral en base sólo a los niveles de VEGF o de la 
angiogénesis resulta insuficiente, debiendo considerarse además, otros parámetros y moléculas involucradas en la proliferación y apoptosis de las células (Tsuzuki et al., 2000).

En el análisis de la influencia que podría estar ejerciendo el tumor en el huésped, no se descarta la posibilidad de que sean expresados ciertos factores de crecimiento por parte del tumor y la presencia de hormonas que modulen el crecimiento en los animales huésped (Masuhara et al., 1996; Pérez-Tomás et al., 1992; Echave Llanos et al., 1971b). Lo cierto es que la regeneración hepática también es un fenómeno muy complejo en el cual están involucrados numerosos factores de crecimiento, que incluso también podrían estar alterados en los animales portadores de neoplasias, tanto por ser sintetizados por el mismo tumor como por ser estimulada su síntesis por un efecto indirecto del tumor sobre las células normales del organismo (Barbeito et al., 2002).

Nuestros resultados también muestran que no existen diferencias entre las medias de la AM los ratones portadores y no portadores. Tal vez, exista un programa intrínseco en los hepatocitos que se encargue de regular el tamaño definitivo del órgano en cualquiera de los experimentos planteados o el intervalo de tiempo analizado no permita observar la existencia de cambios respecto de la media entre los grupos.

Ya se había mencionado que la edad podía influir en el comportamiento de las distintas variables. Por ejemplo, en las ratas jóvenes el pico de ADNs se presenta antes que en las ratas jóvenes adultas y en éstas, a su vez, antes que en las adultas (Bucher et al., 1964). Los valores máximos de ADNs de los ratones jóvenes portadores se presentan hasta $12 \mathrm{~h}$ antes respecto de los animales adultos (Andrini et al., 2013). Cuando se emplea la actividad mitótica como indicador de proliferación celular, se observa que conforme aumenta la edad, la AM va disminuyendo. Es decir, que la capacidad de regenerarse del hígado disminuye (Bucher et al., 1964). 


\section{CONCLUSIONES PARCIALES}

$\checkmark$ La expresión del VEGF, la ADNs y la AM presentan variaciones circadianas en los ratones jóvenes.

$\checkmark$ Los valores máximos de expresión del VEGF en los animales no portadores se presentan antes del pico de ADNs, mientras que en los portadores, después.

$\checkmark$ La portación del tumor modifica las curvas de expresión del VEGF y de la ADNs provocando el adelanto de sus valores máximos. Además, se produce un aumento del pico de expresión del VEGF.

$\checkmark$ La hepatectomía parcial condiciona la hora y magnitud del pico de AM, tanto en los ratones portadores o no portadores de tumor.

$\checkmark$ Los animales hepatectomizados portadores o no portadores presentan valores mayores de ADNs.

$\checkmark$ Existe una distribución predominantemente homogénea en la expresión de VEGF, la ADNs y la AM dentro del lobulillo hepático. 


\section{CONCLUSIÓN GENERAL}

La cronobiología de los eventos de la proliferación celular en los ratones intactos y hepatectomizados sitúa los valores más altos de expresión de VEGF antes del pico de la ADNs. Sin embargo, al coexistir un tumor maligno en los ratones hepatectomizados, dicha cronobiología se ve alterada de modo tal que primero se manifiesta el pico de ADNs, luego el de expresión del VEGF y finalmente, el de AM. 


\section{REFERENCIA BIBLIOGRÁFICA}

Achen MG, Williams RA, Minekus MP, Thornton GE, Stenvers K, Rogers PA, et al. Localization of vascular endothelial growthfactor-D in malignant melanoma suggests a role in tumor angiogenesis. J Pathol. 2001;193:147-54.

Akoulitchev S, Chuikov S, Reinberg D. TFIIH is negatively regulated by cdk8containing mediator complexes. Nature. 2000;407:102-6.

Alberts B, Bray D, Hopkin K, Johnoson A, Lewis J, Raff M, Roberts K, et al. Introducción a la Biología Celular. 2a ed. New York: Garland; 2006.

Albrecht JH, Hu MY, Cerra FB. Distinct patterns of cyclin D1 regulations in models of liver regeneration and human liver. Biochem Biophys Res Commun. 1995;209:648-55.

Alison MR. Regulation of Hepatic Growth. Physiol Rev. 1986;66:499-541.

Alitalo K, Carmeliet P. Molecular mechanisms of lymphangiogenesis in health and disease. Cancer Cell. 2002;1:219-27.

Alitalo K, Tammela T, Petrova TV. Lymphangiogenesis in development and human disease. Nature. 2005;438:946-53.

Altun S, Zalpan A. Interactive regeneration of liver and growth of Ehrlich ascites tumor in mice. Biologia. 2004;59:375-82.

An W, Liu XJ, Lei TG, Dai J, Du GG. Growth induction of hepatic stimulator substance in hepatocytes through its regulation on EGF receptors. Cell Res. 1999; 9:37-42. 
Andrini L, Blanco AF, Inda A, García M, Garcia A, Errecalde A. VEGF expression in hepatectomized tumor-bearing mice. J Immunoassay Immunochem. 2011;32: 318-25.

Andrini L, García M, Barbeito C, Errecalde A, Badrán A. Estudio de la síntesis de ADN de los enterocitos de las criptas del intestino grueso de ratones hepatectomizados. Ciencias Morfológicas. 1999;6:5-10.

Andrini L, García M, Inda AM, Errecalde AL. Circadian rhythm of VEGF expression in the liver of hepatectomized tumor bearing mice. Biol Rhythm Res. 2010;41:5762.

Andrini L, García M, Inda AM, Errecalde AL. Study of DNA synthesis and mitotic activity of hepatocytes and its relation to angiogenesis in hepatectomised tumour bearing mice. Cell Biol Int. 2013;37:1233-7.

Ángeles-Castellanos M, Rodríguez $\mathrm{K}$, Salgado $\mathrm{R}$, Escobar C. Fisiología y fisiopatología de los ritmos biológicos. Monografía de Cronobiología médica. Rev Fac Med UNAM. 2007;6:238-41.

Annau E, Manginelli A, Roth A. Increased weight and mitotic activity in the liver of tumor-bearing rats and mice. Cancer Res. 1951;11:304-6.

Asaga $T$, Suzuki $K$, Umeda $M$, Sugimasa $Y$, Takemiya $S$, Okamoto $T$. The enhancement of tumor growth after partial hepatectomy and the effect of sera obtained from hepatectomized rats on tumor cell growth. Jpn J Surg. 1991;21:66975.

Asahara T, Murohara T, Sullivan A, Silver M, van der Zee R, Li T, Witzenbichler B, Schatteman G. Isolation of putative progenitor endotelial cells for angiogenesis. Science. 1997;275:964-67. 
Badrán AF, Moreno F, Echave Llanos JM. Liver regeneration in mice bearing a trasplanted hepatoma. Rev Esp de Oncología. 1984;31:591-600.

Badrán AF, Moreno FR, Echave Llanos JM. Development of the effect an indifferentiated tumour extracto in sinusoid litoral cells of young growing liver. Microsc electron biol cell. 1985b;9:13-21.

Badrán AF, Moreno FR, Echave Llanos JM. Effect of tumour extracts on liver growth: hepatocarcinomas SS1H and SS1K. Comunicaciones Biológicas. 1985a; 4:143-9.

Bao P, Kodra A, Tomic-Canic M, Golinko MS, Ehrlich HP, Brem H. The role of Vascular Endothelial Growth Factor in wound healing. J Surg Res. 2009;153:34758.

Barbason H, Bouzahzah B, Herens C, Marchandise J, Sulon J, Van Cantfort J. Circadian synchronization of liver regeneration in adult rats: the role played by adrenal hormones. Cell Tissue Kinet. 1989;22:451-60.

Barbason H, Fourré F, Focan C. Effet synchroniseur du rythme circadien de la corticostérone sur la vitesse de synthèse du DNA dans le foie du jeune rat. Pathologie Biologie. 2003;51:210-1.

Barbason H, Herens CH, Mormont C, Bouzahzah B. Circadian synchronization of hepatocyte proliferation in young rats: the role played by adrenal hormones. Cell Tissue Kinet. 1987;20:57-67.

Barbason H, Laloux I, Gustin JF, Milis G, Kaouass M. Chronotolérance de la corticostérone sur la synthèse du DNA chez le jeune rat en croissance. Path Biol. 1996;44:212-5.

Barbason H, Van Cantfort J, Houbrechts N. Correlation between tissular and division functions in the liver of young rats. Cell Tissue Kinet. 1974;7:319-26. 
Barbeito CG. Hepatectomía del portador de tumor: análisis de la evolución de la actividad mitótica normal y neoplásica [Tesis doctoral]. La Plata: Universidad Nacional de La Plata. Facultad de Ciencias Veterinarias; 1999.

Barbeito CG. Desde Prometeo hasta la proteómica, una breve historia de las ideas sobre el crecimiento tisular. RAAB. 2010;12:3-14.

Barbeito CG, Flamini MA, Garcia MN, Andrés Laube PF, Andrini LB, Badrán AF. Development of compensatory hepatic hyperplasia in mice carrying the hepatocellular carcinoma ES12a. J Exp Clin Cancer Res. 2002;21:397-400.

Barik D, Baumann WT, Paul MR, Novak B, Tyson JJ. A model of yeast cell-cycle regulation based on multisite phosphorylation. Mol Syst Biol. 2010; 6:1-5.

Bates O. Vascular endothelial growth factors and vascular permeability. Cardiovasc Res. 2010;87:262-71.

Benjamin LE, Golijanin D, Itin A, Pode D, Keshet E. Selective ablation of immature blood vessels in established human tumors follows vascular endothelial growth factor withdrawal. J Clin Invest. 1999;103:159- 65.

Bockhorn M, Benkö T, Optiz B, Sheu S-Y, Sotirpoulos GC, Schlaak JF, Broelsch $\mathrm{CE}$, et al. Impact of hepatic vein deprivation on liver regeneration and function after major hepatectomy. Langenbecks Arch Surg. 2008;393:527-33.

Bottinger EP, Factor VM, Tsang ML., Weatherbee JA., Kopp JB, Qian SW, et al. The recombinant proregion of transforming growth factor beta1 inhibits active transforming growth factor beta 1 in transgenic mice. Proc Natl Acad Sci. 1996;93:5877-82.

Braeuning A, Ittrich C, Köhle C, Buchmann A, Schwarz M. Zonal gene expression in mouse liver resembles expression patterns of $\mathrm{Ha}$-ras and $\beta$-Catenin mutated hepatomas. Drug Metab Dispos. 2007;35:503-7. 
Braeuning A, Ittrich C, Kohle C, Hailfinger S, Bonin M, Buchmann A, et al. Differential gene expression in periportal and perivenous mouse hepatocytes. FEBS J. 2006;273:5051-61.

Brues A, Drury D, Brues M. A quantitative study of cell growth in regenerating liver. Arch Pathol. 1936;22:658-73.

Brüel A, Christensen El, Tranum-Jensen J, Qvortup K, Geneser F. Geneser Histología. 4a ed. Méjico (DF): Editorial Médica Panamericana; 2014.

Bucher NL, Swaffield MN, Ditroia JF. The influence of age upon the incorporation of thymidine-2-C14 into the DNA of regenerating rat liver. Cancer Res. 1964; 24:509-12.

Burkhardt S, Bahnemann R, Failing K, Reinacher. Zonal Distribution of Cell Proliferation in the Liver of Untreated B6C3F1 and C57BL Mice. Toxicol Pathol. 2004;32:100-5.

Carmeliet P. Angiogenesis in health and disease. Nat Med. 2003;9:653-60.

Carmeliet P, Collen D. Molecular basis of angiogenesis. Role of VEGF and VEcadherin. Ann N Y Acad Sci. 2000;902:249-62.

Cascales Angosto M. Bases celulares y moleculares de la regeneración hepática. 15a ed. Madrid: Instituto de España; 2009.

Chung AS, Ferrara N. The extracellular matrix and angiogenesis. Pathways. 2010;11:3-5.

Cienfuegos JA, Fernando Rotellar F, Baixauli J, Martínez Regueira F, Pardo F, Hernández Lizoáin JL. Regeneración hepática; el secreto mejor guardado. Una forma de respuesta al daño tisular. Rev Esp Enferm Dig. 2014;106:171-194. 
Clapp C, Thebault S, Jeziorski MC, Martínez de la Escalera G. Peptide Hormone Regulation of Angiogenesis. Physiol Rev. 2009;89:1177-1215.

Collin de l'Hortet A, Gilgenkrantz H, Guidotti J-E. EGFR: A Master Piece in G1/S Phase Transition of Liver Regeneration. Int J Hepatol. 2012;2012:1-9.

Colnot S, Perret C. Liver zonation. In: Molecular Pathology of Liver Diseaes. Monga SPS, editor. New York (USA): Springer; 2011. p. 7-16.

Cook MJ. The anatomy of the laboratory mouse. Cook MJ, editor. London: Elsevier; 1965. p. 1-143.

Cross M, Dexter M. Growth factors in development transformation and tumorogenesis. Cell. 1991;64:271-80.

De Boer L, Oakes V, Beamish H, Giles N, Stevens F, Somodevilla-Torres M, et al. Cyclin A/cdk2 coordinates centrosomal and nuclear mitotic events. Oncogene. 2008;27:4261-68.

Delahunty TJ, Rubinstein D. Accumulation and release of triglycerides by rat liver following partial hepatectomy. J Lipid Res. 1970;11:536-43.

Diallo A, Prigent C. The serine/threonine kinases that control cell cycle progression as therapeutic targets. Bull Cancer. 2011;98:1335-45.

Dobles M, Liberal V, Scott M, Benezra R, Sorger PK. Chromosome missegregation and apoptosis in mice lacking the mitotic checkpoint protein Mad2. Cell. 2000;101:635-45.

Dogrul AB, Colakoglu T, Kosemehmetoglu K, Birben E, Yaman E, Gedikoglu G et al. Antiangiogenic response after $70 \%$ hepatectomy and its relationship with hepatic regeneration and angiogenesis in rats. Surgey. 2010;147:288-94. 
Drixler TA, Vogten MJ, Ritchie ED, van Vroonhoven TJ, Gebbink MF, Voest EE, Borel Rinkes IH. Liver regeneration is an angiogenesis-associated phenomenon. Ann Surg. 2002;236:703-11.

Duronio RJ, Xiong Y. Signaling Pathways that Control Cell Proliferation. Cold Spring Harb Perspect Biol. 2013;5:a008904.

Echave Llanos J. Experimental sources of variations in the study of liver regeneration. Epatologia. 1967;13:117-32.

Echave Llanos J. Importancia del ritmo circadiano en el estudio de los factores tisulares del crecimiento durante la regeneración hepática. Rev Soc argent Biol. 1963;39:256-79.

Echave Llanos J, Sadnik I. Preparation of liver tissue for the evaluation of mitótica activity. Stain Technol. 1964;39:289-94.

Echave Llanos JM, Aloisso MD, Souto M, Balduzzi R, Surur JM. Circadian variations and DNA synthesis, mitotic activity, and cell size of hepatocyte population in young immature male mouse growing liver. Virchows Arch Abt B Zellpath. 1971a;8:309-17.

Echave Llanos JM, Bade E, Bordin C. Standarization for periodicity analysis and scatter of values in the study of hepatic regeneration. Acta Physiol Lat Am. 1963;13:385-7.

Echave Llanos JM, Badrán AF, Moreno FR. Inhibiting effect of a hepatoma extracto $\mathrm{n}$ the mitotic rate of regenerating liver. Virchows Arch Cell Pathol. 1986; 51:17-27.

Echave Llanos JM, Gómez Dumm CL, Nessi AC. Ultraestructure of STH cells of the pars distalis of the hypophysis of hepatectomized mice. Z Zellforsch. 1971b; 113:29-38. 
Errecalde AL. Especificidad de población celular de las variaciones de la actividad mitótica ante la acción de factores tisulares y plasmáticos [Tesis doctoral]. La Plata: Universidad Nacional de La Plata. Facultad de Ciencias Médicas; 1994.

Escobar C, Martínez-Merlos MT, Ángeles M, Mendoza JY. El alimento como sincronizador de los ritmos biológicos: su relevancia para la identificación de un oscilador circadiano. Rev Fac Med UNAM. 2001;44:58-62.

Eynard AR, Valentich MA, Rovasio RA. Histología y Embriología del ser humano: bases celulares y moleculares. 4a. ed. Buenos Aires: Médica Panamericana; 2008.

Fantin A, Herzog B, Mahmoud M, Yamaji M, Plein A, Denti L, et al. Neuropilin 1 (NRP1) hypomorphism combined with defective VEGF-A binding reveals novel roles for NRP1 in developmental and pathological angiogenesis. Development. 2014;141:556-62.

Fausto N. Liver regeneration. J Hepathol. 2000;32:19-31.

Fausto N. Liver regeneration: from laboratory to clinic. Liver Transplant. 2001;7: 835-44.

Fausto N, Campbell J, Riehle K. Liver regeneration. Hepatology. 2006; 2:545-53.

Fausto N, Campell JS. The role of hepatocytes and oval cells in liver regeneration and repopulation. Mech Dev. 2003;120:117-30.

Fausto N, Campbell JS. Liver Regeneration. In: The Liver: Biology and Pathobiology. Arias IM, Boyer JL, Chisari FV, Fausto N, Schachter D, Shafritz DA, editors. 4th ed. Philadelphia: John Wiley \& Sons; 2009. p. 591-610. 
Fernández Blanco A, Inda AM, Errecalde AL. Distribución zonal homogénea del Factor de Crecimiento del Endotelio Vascular (VEGF) dentro del lobulillo hepático de ratones en crecimiento hepatectomizados. Tercera Época. 2014; 2(2):1-1.

Fernández Blanco A, García AL, Inda AM, Errecalde AL. Vascular endothelial growth factor expression along a circadian time span in intact adult mice liver. Biol Rhythm Res. 2011;42:141-6.

Ferrara N. Vascular endothelial growth factor: basic science and clinical progress. Endoc Rev. 2004;25:581-611.

Ferrara N, Davis-Smyth T. The biology of vascular endothelial growth factor. Endocr Rev. 1997;18:4-25.

Ferrara N, Gerber HP, LeCouter J. The biology of VEGF and its receptors. Nat Med. 2003;9:669-76.

Ferrara N, Henzel WJ. Pituitary follicular cells secrete a novel heparing-binding growth factor specific for vascular endothelial cells. Biochem Res Commun. 1989; 161:851-8.

Ferrara N, Hillan KJ, Gerber HP, Novotny W. Discovery and development of bevacizumab, an anti-VEGF antibody for treating cancer. Nature Reviews Drug Discovery. 2004;391-400.

Fisher D, Krasinska L, Coudreuse D, Novák B. Phosphorylation network dynamics in the control of cell cycle transitions. J Cell Sci. 2012;15:4703-11.

Folkman J. Clinical applications of research on angiogenesis. N Engl J Med. 1995; 333:1757-63. 
Folkman J. What is the evidence that tumors are angiogenesis dependent? J Natl Cancer Inst. 1990;82:4-6.

Francavilla A, Zeng Q, Polimeno L, Francavilla A, Zeng Q, Polimeno L, et al. Small-for-size liver transplanted into larger recipient: a model of hepatic regeneration. Hepatology. 1994;19:210-6.

Furnus C, Inda A, Andrini L, García M, García A, Badrán A, et al. Chronobiology of the proliferative events related to angiogenesis in mice liver regeneration after partial hepatectomy. Cell Biol Int. 2003;27:383- 6.

García M, Inda A, García A, Furnus C, Andrini L, Badrán A, et al. Estudio de la proliferación hepatocítica durante la regeneración hepática. Ciencias Morfológicas. 2001;5:49-54.

García MN, Andrini LB, Errecalde AL, Cerutti R, Barbeito GC. Changes in DNA synthesis circadian rhythms in a hepatocelular carcinoma after hepatectomy. Biol Rhythm Res. 2009;40:325-35.

García MN, Andrini LB, Inda AM, Ronderos JR, Hijano JC, Errecalde AL. Changes in VEGF expression and DNA synthesis in hepatocytes from hepatectomized and tumour-bearing mice. Cell Biol Int. 2010;34:283-6.

Gatfield D, Schibler U. Circadian glucose homeostasis requires compensatory interference between brain and liver clocks. PNAS. 2008;105:14753-4.

Gebhardt R. Metabolic zonation of the liver: regulation and implications for liver function. Pharmacol Ther. 1992;53:275-354.

Gebhardt R. Isolation of periportal and pericentral hepatocytes. Methods Mol Biol. 1998;107:319-28. 
Gebhardt R, Jonitza D. Different proliferative responses of periportal and perivenous hepatocytes to EGF. Biochem Biophys Res Commun. 1991;181:12017.

Geisler A, Stiller K, Machnik G. The cellular reproduction in physiological and reparative liver regeneration. Exp Toxicol. 1994;46:247-50.

Gerber HP, Hillan KJ, Ryan AM, Kowalski J, Keller GA, Rangell L, et al. VEGF is required for growth and survival in neonatal mice. Development. 1999;126:114959.

Gerber HP, Dixit V, Ferrara N. Vascular endothelial growth factor induces expression of the antiapoptotic proteins $\mathrm{Bcl}-2$ and $\mathrm{A} 1$ in vascular endothelial cells. J Biol Chem. 1998; 273:13313-16.

Gopinathan L, Ratnacaram CK, Kaldis P. Established and novel Cdk/cyclin complexes regulating the cell cycle and development. Results Probl Cell Differ. 2011;53:365-89.

Golias $\mathrm{CH}$, Charalabopoulos A, Charalabopoulos K. Review. Cell proliferation and cell cycle control: a mini review. Int J Clin Pract. 2004;58:1134-41.

Golombek D. Cronobiología humana: ritmos, relojes biológicos en la salud y en la enfermedad. 2a ed. Bernal: Universidad Nacional de Quilmes; 2007.

Greene AK, Wiener S, Puder M, Yoshida A, Shi B, Perez-Atayde AR, et al. Endothelial-directed hepatic regeneration after partial hepatectomy. Ann Surg. 2003;237:530-5.

Grisham JW. Cellular proliferation in the liver. In: Fry RJ, editor. Cancer Res. 1969; pp 28-43. 
Grisham JW. Morphologic study of deoxyribonucleic acid synthesis and cell proliferation in regenerating rat liver; Autoradiography with Thymidine- $\mathrm{H}$. Cancer Res. 1962;22:842-9.

Guzek JW. Effect of corticotrophin and corticosterone on the incorporation of $3 \mathrm{H}$ thymidine into deoxyribonucleic acids (DNA) of regenerating liver in the white rat. Actu Endocrinol. 1968;59:10-22.

Halberg F, Barnum CP, Silber RH, Bittner JJ. 24 hour rhythm at several levels of integration in mice of different lighting regimens. Proc Soc Exp Biol. 1958;97:897900.

Henderson C, Loeb JN. Hormone-induced changes in liver DNA synthesis: effects of glucocorticoids and growth hormone on liver growth and DNA polymerase activity. Endocrinology. 1974;94:1637-43.

Herens C, Bouzahzah B, Barbason H. Mitotic circadian control in rat hepatocarcinogenesis: the genetic effects. In: Touitou Y, editor. Biological clocks. Mechanisms and applications. International Congress Series; Biological Clocks: Mechanisms And Applications; 1998; pp. 511-4.

Hichklin DJ, Lee ME. Role of the vascular endothelial growth factor. Pathway in tumor growth and angiogenesis. J Clin Oncol. 2005;23:1011-27.

Hochegger H, Dejsuphong D, Sonoda E, Saberi A, Rajendra E, Kirk J et al. An essential role for Cdk1 in $S$ phase control is revealed via chemical genetics in vertebrate cells. J Cell Biol. 2007;178:257-68.

Hochegger H, Takeda S, Hunt T. Cyclin-dependent kinases and cell-cycle transitions: does one fit all? Nat Rev Mol Cell Biol. 2008;9:910-16.

Holmes DI, Zachary I. The vascular endothelial growth factor (VEGF) family: angiogenic factors in health and disease. Genome Biol. 2005;6:209. 
Hummel KP, Richardson FL, Fekete E. Anatomy. In: Green EL, editor. Biology of the laboratory mouse. New York: MacGraw-Hill; 1966.

Jeltsch M, Kaipainen A, Joukov V, Meng X, Lakso M, Rauvala H, Swartz M, Fukumura D, Jain RK, Alitalo K. Hyperplasis of lymphatic vessels in VEGF-C transgenic mice. Science. 1997;276:1423-5.

Jeremy JY, Dashwood MR. Microvascular repair. In: Shepro D, editor. Encyclopaedia of the Microvasculature. New York: Elsevier; 2006; p. 903-11.

Jüngermann K. Zonation and metabolism and gene expression in liver. Histochemistry. 1995;103:81-91.

Jüngermann K, Kietzmann T. Role of oxygen in the zonation of carbohydrate metabolism and gene expression in liver. Kidney Int. 1997;51:402-12.

Jüngermann K, Kietzmann T. Zonation of parenchymal and non parenchymal metabolism in liver. Annu Rev Nutr. 1996;16:179-203.

Jüngermann K, Kietzmann T. Oxygen: Modulator of Metabolic zonation and disease of the liver. Hepatology. 2000;31:255-60.

Karamysheva AF. Mechanisms of angiogenesis. Biochemistry. 2008;73:751-62.

Karkkainen MJ, Haiko P, Sainio K, Partanen J, Taipale J, Petrova TV, et al. Vascular endothelial growth factor $\mathrm{C}$ is required for sprouting of the first lymphatic vessels from embryonic veins. Nat Immunol. 2004;5:74-80.

Kempf CN. Charakterisierung von Knochenmark-Generierten Makrophagen unter der Einwirkung von Vascular Endothelial Growth Factor. [Tesis doctoral]. Freiburg: Albert-Ludwigs-Universität; 2004. 
Kiernan F. The anatomy and physiology of the liver. Philos Trans R Soc Lond B Biol Sci Biol. 1833;123:711-70.

Klagsbrun M, Takashima S, Mamluk R. The role of neuropilin in vascular and tumor biology. Adv Exp Med Biol. 2002;515:33-48.

Kojima I, Nagasawa M. TRPV2: A Calcium-Permeable Cation Channel Regulated by Insulin-Like Growth Factors. In: Liedtke WB, Heller S, editors. TRP Ion Channel Function in Sensory Transduction and Cellular Signaling Cascades. Boca Raton (FL): CRC Press; 2007. Chapter 7.

Kountouas J, Boura P, Lygidakis NJ. Liver regeneration after hepatectomy. Hepatogastroenterology. 2001;48:556-62.

Krasinska L, Besnard E, Cot E, Dohet C, Méchali M, Lemaitre JM, et al. Cdk1 and Cdk2 activity levels determine the efficiency of replication origin firing in Xenopus. EMBO J. 2008;27:758-69.

Kroll J, Waltenberger J. A novel function of VEGF receptor-2 (KDR), rapid release of nitic oxide in response to VEGF-A stimulation in endothelial cells. Biochem Biophys Res. 1999;265:636-99.

Lane DP. p53, Guardian of the genome. Nature. 1992;358:15-16.

Lebel M, de Souza-Pinto NC, Bohr VA. Metabolism, Genomics, and DNA Repair in the Mouse Aging Liver. Current Gerontol Geriatr Res. 2011;2011:1-15.

LeCouter J, Moritz DR, Li B, Phillips GL, Lang XH, Gerber HP, et al. Angiogenesis-Independent Endothelial Protection of Liver: Role of VEGFR-1. Sciene. 2003;299:890-3.

Lee S, Chen TT, Barber CL, Jordan MC, Murdock J, Desai S, et al. Autocrine VEGF signaling is required for vascular homeostasis. Cell. 2010;130:691-703. 
Lee JC. Effects of partial hepatectomy in rats on two transplantable hepatomas. Am J Pathol. 1971;65: 347-56.

Lee TH, Seng S, Sekine M, Hinton C, Fu Y, Avraham HK, et al. Vascular endothelial growth factor mediates intracrine survival in human breast carcinoma cells through internally expressed VEGFR1/FLT1. PLoS Med. 2007;4:e186.

Leung DW, Cachianes G, Kuang WJ, Goeddel DV, Ferrara N. Vascular endothelial growth factor is a secreted angiogenic mitogen. Science. 1989;246: 1306-9.

Lieckens S, De Clercq E, Neyts J. Angiogenesis: regulators and clinical applications. Biochem Pharmacol. 2001;61:253-70.

Lim S, Kaldis P. Cdks, cyclins and CKIs: roles beyond cell cycle regulation. Development. 2013;140:3079-93.

Liskay RM. Absence of a measurable G2 phase in two Chinese hamster cell lines. Proceedings of the National Academy of Science of the United States of America $1977 ; 74: 1622-5$.

Lodish H, Berk A, Matsudaira P, Kaiser CA, Krieger M, Scott MP, et al. Biología Celular y Molecular. 5a ed. Buenos Aires: Médica Panamericana; 2005.

Loyer P, Cariou S, Glaise D, Bilodeau M, Baffet G, Guguen-Guillouzo C. Growth factor dependence of progression though $G_{1}$ and $S$ phases of adult rat hepatocytes in vitro. J Biol Chem. 1996;271:11484-92.

Lupu F, Terwilliger JD, Lee K, Segre GV. Roles of growth hormone and insulin-like growth factor 1 in mouse postnatal growth. Dev Biol. 2001;229:141-62. 
Lyttle DJ, Fraser KM, Fleming SB, Mercer AA, Robinson AJ. Homologs of vascular endothelial growth factor are encoded by the poxvirus orf virus. J Virol. 1994;68: 84-92.

Madrahimov N, Dirsh O, Broelsch C, Dahmen U. Marginal hepatectomy in the rat: from anatomy to surgery. Ann Surg. 2006;244: 89-98.

Malumbres M, Barbacid M. Mammalian cyclin-dependent kinases. Trends Biochem Sci. 2005;30:630-41.

Malumbres M, Harlow E, Hunt T, Hunter T, Lahti JM, Manning G, et al. Cyclindependent kinases: a family portrait. Nat Cell Biol. 2009;11:1275-76.

Malumbres M, Barbacid M. To cycle or not to cycle: a critical decisión in cáncer. Nat Rev Cancer. 2001;1:222-31.

Mall FP. A study of the structural unit of the liver. Am J Anat. 1906;5:227-308.

Mangnall D, Bird NC, Majeed AW. The molecular physiology of liver regeneration following partial hepatectomy. Liver Int. 2003;23:124-38.

Mars WM, Kim TH, Stolz DB, Liu ML, Michalopoulos GK. Presence of urokinase in serum-free rimary rat hepatocytes cultures and its role in activating hepatocytes growth factor. Cancer Res. 1996;56:2837-43.

Martín CA, Surur J, García M, Badrán A. DNA synthesis and nucleolar organizer regions circadian rhythm in mouse regenerating liver hepatocytes. Biocell. 2000; 24:151-5.

Martins P, Theruvath TP, Neuhaus P. Rodent models of partial hepatectomies. Liver Int. 2008;28:3-11.

Massague J. G1 cell-cycle control and cancer. Nature. 2004;432:298- 306. 
Masuhara M, Yasunaga M, Tanigawa K, Tamura F, Yamashita S, Sakaida I, Okita K. Expression of hepatocyte growth factor, transforming growth factor alpha, and transforming growth factor beta 1 messenger RNA in various human liver diseases and correlation with hepatocyte proliferation. Hepatology. 1996;2:323-9.

Matsumoto T, Claesson-Welsh L. VEGF receptor signal transduction. Sci STKE. 2001;112:21.

Matsuo T, Yamaguchi S, Mitsui S, Emi A, Shimoda F, Okamura H. Control mechanism of the circadian clock for timing of cell division in Vivo. Science. 2003; 302:255-9.

McCaffrey TA, Falcone DJ. Evidence for an age-related dysfunction in the antiproliferative response to transforming growth factor- $\beta$ in vascular smooth muscle cells. Mol Biol Cell. 1993;4:315- 22.

McCuskey RS, Ekataksin W, LeBouton AV, Nishida J, McCuskey MK, McDonnell et al. Hepatic microvascular development in relation to the morphogenesis of hepatocellular plates in neonatal rats. The anatomical record Part A 2003; 275A:1019-30.

Medigreceanu F. On the relative size of the organs of rats and mice bearing malignant new growths. Proc Roy Soc. 1910;82:286-91.

Mehendale HM. Role of hepatocellular regeneration and hepatolobular healing in the final outcome of liver injury. Biochem Pharmacol. 1991;42:1155-62.

Michalopoulos GK. Liver regeneration after partial hepatectomy. Critical analysis of mechanistic dilemmas. Am J Pathol. 2010;176:2-13.

Michalopoulos GK. Liver regeneration: alternative epithelial pathways. Int $\mathrm{J}$ Biochem Cell Biol. 2011;43:173-9. 
Michalopoulos GK, Khan Z. Liver regeneration, growth factors, and amphiregulin. Gastroenterology. 2005;128:503-6.

Michalopoulus G, DeFrances M. Liver regeneration. Science. 1997;276:60-87.

Mochida S, Ishikawa K, Inao M, Shibuya M, Fujiwara K. Increased expression of vascular endothelial growth factor and its receptors, flt-1 and KDR/flk-1, in regenerating rat liver. Biochem Biophys Res Commun. 1996;226:176-9.

Moeller SJ, Sheaff RJ. G1 phase: components, conundrums, context. Results Probl Cell Differ. 2006;42:1-29.

Mogford JE, Tawil N, Chen A, Gies D, Xia Y, Mustoe TA. Effect of age and hypoxia on TGF beta 1 receptor expression and signal transduction in human dermal fibroblasts: impact on cell migration. J Cell Physiol. 2002;190:259-65.

Moreno FR. Ensayo de efectos promotores e inhibidores con extractos totales de hepatomas injertados sobre el crecimiento del hígado [Tesis doctoral]. La Plata: Universidad Nacional de La Plata. Facultad de Ciencias Médicas; 1984.

Morgan DL. The cell cycle: principles of control. London: New Science Press and Oxford University Press; 2007.

Morgan W, Cameron IL. Effect of fast-growing transplantable hepatoma on cell proliferation in host tissue of the mouse. Cancer Res. 1973;33:441-8.

Murray A, Hunt T. The Cell Cycle. An Introduction. New York: WH Freeman; 1993.

Nagy P, Teramoto T, Factor VM, Sanchez A, Schnur J, Paku S, Thorgeirsson SS. Reconstitution of liver mass via cellular hypertrophy in the rat. Hepatology. 2001; 339-45. 
Nihikawa Y, Wang M, Carr Bl. Changes in TGF-beta receptor of rat hepatocytes during primary culture and liver regeneration: increased expression of TGF-beta receptors associated with increased sensitivity to TGF-beta mediated growth inhibition. J Cell Physiol. 1998;176:612-7.

Novo E, Cannito S, Zamara E, Valfré di Bonzo L, Caligiuri A, Cravanzola C, et al. Proangiogenic cytokines as hipoxia-dependent factors stimulating migration of human hepatic stellate cells. Am J Pathol. 2007;170:1942- 53.

O'Farrell P. Quiescense: early evolutionary origins and universality do not imply uniformity: Phil Trans R Soc B. 2011;366:3498-3507.

Oki T, Nishimura K, Kitaura J, Togami K, Maehara A, Izawa K, et al. A novel cellcycle-indicator, mVenus-p27K2, identifies quiescent cells and visualizes G0-G1 transition. Sci Rep. 2014;4:4012.

Ohtake Y, Maruko A, Kojima S, Ono T, Nagashima T, Fukumoto M et al. Zonal differences in DNA synthesis and in transglutaminase activity between perivenous versus periportal regions of regenerating rat liver. Biol Pharm Bull 2004;27:175862.

Pardee AB. $G_{1}$ events and regulation of cell proliferation. Science. 1989;246:6039.

Paschkis KE, Cantarow A, Stasney J, Hobbs JH. Tumor growth in partially hepatectomized rats. Cancer Res. 1955;15:579-82.

Patan S. Vasculogenesis and angiogenesis. Cancer Treat Res. 2004;117:3-32.

Peirce SM, Skalak TC. Microvascular remodeling: a complex continuum spanning angiogenesis to arteriogenesis. Microcirculation. 2003;10:99-111. 
Pérez de Castro I, de Cárcer G, Malumbres M. A census of mitotic cancer genes: new insights into tumor cell biology and cancer therapy. Carcinogenesis. 2007;28: 899-912.

Pérez-Tomás R, Mayol X, Culleré X, Díaz Ruiz C, Domingo J. Transforming growth factor-alpha expression in rat experimental hepatocarcinogenesis. Histol Histopath. 1992;7:457-62.

Pfeuty B, David-Pfeuty T, Kaneko K. Underlying principles of cell fate determination during G1 phase of the mammalian cell cycle. Cell Cycle. 2008; 7:3246-57.

Plouet J, Schilling J, Gospodarowics D. Isolation and characterization of a newly identified endothelial cell mitogen produced by AtT-20 cells. EMBO J. 1989;8: 3801-6.

Post J, Hoffman J. Multiplicación celular hepática durante el crecimiento y la regeneración hepática. Patología Hepática. 1967;2:171-81.

Rappaport A. The structural and functional unit in the human liver (liver acinus). Anat Rec. 1954;130:673-89.

Reed SM, Quelle DE. p53 Acetylation: Regulation and Consequences. Cancers. 2015;7:30-69.

Reed MJ, Corsa AC, Kudravi SA, McCormick RS, Arthur WT. A deficit in collagenase activity contributes to impaired migration of aged microvascular endothelial cells. J Cell Biochem. 2000;77:116-26.

Reed MJ, Ferarra N, Vernon R. Impaired migration, integrin function, and actin cytoskeletal organization in dermal fibroblasts from a subset of aged human donors. Mech Ageing Dev. 2001;122:1203-20. 
Reuber M. Histopathology of transplantable hepatic carcinomas induced by chemical carcinogens in rats. Gann Monographs. 1966;1:43-54.

Reynaert H, Chavez M, Geerts A. Vascular endothelial growth factor and liver regeneration. J Hepatol. 2001;34:759-61.

Ribatti D. The crucial role of vascular permeability factor/vascular endothelial growth factor in angiogenesis: a historical review. Br J Haematol. 2004;128:303-9.

Rivard A, Fabre JE, Silver M, Chen D, Murohara T, Kearney M, et al. Agedependent impairment of angiogenesis. Circulation. 1999;99:111-20.

Ross MA, Sander CM, Kleeb TB, Watkins SC, Stolz DB. Spatiotemporal expression of angiogenesis growth factor receptors during the revascularization of regenerating liver. Hepatology. 2001;34:1135-48.

Roy $\mathrm{H}$, Bhardwaj S, Babu M, Jauhiainen S, Herzig $\mathrm{KH}$, Bellu AR, et al. Adenovirus-mediated gene transfer of placental growth factor to perivascular tissue induces angiogenesis via up regulation of the expression of endogenous vascular endothelial growth factor-A. Human Gene Ther. 2005;16:1422-28.

Roy H, Bhardwaj S, Ylä-Herttuala S. Biology of vascular endothelial growth factors. FEBS Letters. 2006;580:2879-87.

Russo J, Echave Llanos JM. Twenty-four-hour rhythm in the mitotic activity and in the water and dry matter content of regenerating liver. Z Zellforsch Mikrosk Anat. 1964;61:824-8.

Sadoun E, Reed MJ. Impaired Angiogenesis in Aging Is Associated with Alterations in Vessel Density, Matrix Composition, Inflammatory Response, and Growth Factor Expression. J Histochem Cytochem. 2003;51:1119-30. 
Santamaría D, Barrière C, Cerqueira A, Hunt S, Tardy C, Newton K, et al. Cdk1 is sufficient to drive the mammalian cell cycle. Nature. 2007;448:811-5.

Sato T, El-Assal ON, Ono T, Yamanoi A, Dhar DK, Nagasue N. Sinusoidal endotelial cell proliferation and expression of angiopoietin/Tie family in regenerating liver. J Hepatol. 2001;34:690-8.

Schaper W, Scholz D, Clauss M, Pipp F, Issbrucker K, Weich H, et al. Factors regulating arteriogenesis. Arterioscler Thromb Vasc Biol. 2003;23:1143-51.

Shankland SJ, Wolf G. Cell cycle regulatory proteins in renal desease: role in hypertrophy, proliferation, and apoptosis. Am J Physiol renal Physiol. 2000;278: 515-29.

Sheikh-Bahaei S, Maher JJ, Anthony Hunt C. Computational experiments reveal plausible mechanisms for changing patterns of hepatic zonation of xenobiotic clearance and hepatotoxicity. J Theor Biol. 2009;265:718-33.

Sherr CJ. Cancer cell cycles. Science. 1996;274:1672-7.

Sherr CJ, Roberts JM. Inhibitors of mammalian G1 cyclin dependent kinases. Genes Dev. 1995;9:1149-63.

Shibuya M. Differential roles of vascular endotelial growth factor receptor-1 and receptor-2 in angiogenesis. J Biochem Molecular Biology. 2006;39:469-78.

Shibuya M, Claesson-Welsh L. Signal transduction by VEGF receptors in regulation of angiogenesis and lymphangiogenesis. Exp Cell Res. 2006;312:54960.

Shimizu H, Mitsuhashi N, Ohtsuka M, Ito H, Kimura F, Ambiru S, et al. Vascular endothelial growth factor and angiopoietins regulate sinusoidal regeneration and 
remodeling after partial hepatectomy in rats. World J Gastroenterol. 2005;11: 7254-60.

Shimizu H, Miyazaki M, Wakabayashi Y, Mitsuhashi N, Kato A, Ito $\mathrm{H}$. et al. Vascular endothelial growth factor secreted by replicating hepatocytes induces sinusoidal endothelial cell proliferation during regeneration after partial hepatectomy in rats. J Hepatol. 2001;34:683-9.

Senger DR, Galli SJ, Dvorak AM, Perruzzi CA, Harvey VS, Dvorak HF. Tumour cells secrete a vascular permeability factor that promotes accumulation of ascites fluid. Science. 1983;219:983-5.

Soker S, Takashima S, Miao HQ, Neufeld G., Klagsbrun M. Neuropilin-1 is expressed by endothelial and tumor cells as an isoform-specific receptor for vascular endothelial growth factor. Cell. 1998;92:735-45.

Stacker SA, Caesar C, Baldwin ME, Thornton GE, Williams RA, Prevo R, et al. VEGF-D promotes the metastatic spread of tumor cells via the lymphatics. Nat Med. 2001;7:186-91.

Stamatakos M, Palla V, Karaiskos I, Xiromeritis K, Alexiou I, Pateras I, et al. Cell cyclins: triggering elements of cancer or not?. World J Surg Oncol. 2010; 8:111.

Stefanini MO, Wu TH, Mac Gabhann F, Popel AS. A compartment model of VEGF distribution in blood, healthy and diseased tissues. BMC Syst Biol. 2008;2:77.

Sugiyama Y, Takabe Y, Nakakura T, Tanaka S, Koike T, Shiojiri N. Sinusoid development and morphogenesis may be stimulated by VEGF-Flk-1 signaling during fetal mouse liver development. Dev Dyn. 2010;239:386-97.

Sun J, Toshinori I, Zhang P. Enhancement of tumor growth after partial hepatectomy and blood transfusion. Zhonghua Zhong Liu Za Zhi. 1996;18:113-5. 
Sun Y, Hao Z, Sui Y, Zhao L, Gao G. Study on the changes of IGF-1 mRNA expression levels in the developmental muscles of the Geese. J Anim Vet Adv. 2012;11:3023-26.

Surur JM, Moreno FR, Badrán A, Echave Llanos JM. Variations in DNA synthesis and mitotic indices in hepatocytes and sinusoid litoral cells of adult intact male mouse along a circadian time span. Chronobiol Int. 1985;2:161-8.

Suto K, Yamazaki Y, Morita T, Mizuno H. Crystal Structures of Novel Vascular Endothelial Growth Factors (VEGF) from Snake Venoms. J Biol Chem. 2005;3: 2126-31.

Taniguchi E, Sakisaka S, Matsuo K, Tanikawa K, Sata M. Expression and role of vascular endothelial growth factor in liver regeneration after partial hepatectomy in rats. J Histochem Cytochem. 2001;49:121-9.

Tanikawa K, Ueno T. Liver diseases and hepatic sinusoidal cells. 1st ed. Tokyo; 1999. [electrónico].

Tannuri AC, Tannuri U, Coelho MC, dos Santos NA, Mello ES. Experimental models of hepatectomy and liver regeneration using newborn and weaning rats. Clinics. 2007;62:757-62.

Tarla M, Ramalho F, Ramalho L, Silva T, Brandao D, Ferreira J. A molecular view of liver regeneration. Acta Cir Bras. 2006;58-62.

Tarn WY, Lai MC. Translational control of cyclins. Cell Division. 2011;6:5.

Theologides A, Kennedy BJ. Nucleic acid and phospholipid synthesis in the regenerating liver of tumor-bearing mice. Cancer Res. 1967;27:1270-7.

Theologides A, Zaki GF. Mitotic index in the regenerating liver of tumor-bearing mice. Cancer Res. 1969;29:1913-5. 
Tomiya T, Hayashi S, Yanase M, Umeda N, Tani M, Yamdada S, et al. Serum transforming growth factor-alpha level can be parameters for evaluating liver regeneration alter partial hepatectomy in patients with liver cancer. Semin Oncol. 1997;18:304-8.

Torre C, Perret C, Colnot S. Molecular determinants of liver zonation. In: Kaestner $\mathrm{K}$, editor. Development, differentation and dissease of the para-alimentary tract. 1st ed. London: Elsevier; 2010; p. 127-45.

Touitou Y. Biological clocks. Mechanisms and applications. International Congress of Chronobiology. Paris: Elsevier Publishing Company; 1997.

Tsuzuki Y, Fukumura D, Oosthuyse B, Koike C, Carmeliet P, Jain RK. Vascular endothelial growth factor (VEGF) modulation targeting hypoxia inducible factor$1 \alpha \rightarrow$ hypoxia response element $\rightarrow$ VEGF cascade differentially regulates vascular response and growth rate in tumors. Cancer Res. 2000;60:6248-52.

Tyson JJ, Csikasz-Nagy A, Novak B. The dynamics of cell cycle regulation. BioEssays. 2002;24:1095-1109.

Uhlmann F, Bouchoux C, López-Avilés S. A quantitative model for cyclindependent kinase control of the cell cycle: revisited. Phil Trans R Soc B. 2011; 366:3572-83.

Van Cantfort J, Barbason $\mathrm{H}$. Relation between the circadian rhythms of mitotic rate and cholesterol-7a-hydroxylaes activity in the regenerating liver. Cell Tissue Kinet. 1972;5:325-30.

van den Heuvel S. Cell-cycle regulation (September, 2005), 21:1-16. WormBook, ed. The C. elegans Research Community, WormBook, doi/10.1895/wormbook.1.7.1, http://www.wormbook.org. 
van der Bilt JD, Borel Rinkes IH. Surgey and angiogenesis. Biochim Biophys Acta. 2004;1654:95-104.

Van Thiel DH, Gavaler J, Kam I, Francavilla A, Polimeno L, Schade RR, et al. Rapid growth of an intact human liver transplanted into a recipient larger than the donor. Gastroenterology. 1987;93:1414-9.

Vasa M, Breitschopf K, Zeiher AM, Dimmeler S. Nitric oxide activates telomerase and delays endothelial cell senescence. Circ Res. 2000;87:540-2.

Viallard JF, Lacombe F, Belloc F, Pellegrin JL, Reiffers J. Mécanismes moléculaires contrôlant le cycle cellulaire: aspects fondamentaux et implications en cancérologie. Cancer/Radiother. 2001;5:109-29.

Virag JA, Lust RM. Circadian influences on myocardial infarction. Front Physiol. 2014;30;5:1-10.

Vousden KH, Prives C. Blinded by the Light: The Growing Complexity of p53. Cell. 2009;137:413-31.

Webber EM, Wu JC, Wang L, Merlino G, Fausto N. Overexpression of transforming growth factor-alpha causes liver enlargement and increased hepatocytes proliferation in transgenic mice. Am J Pathol. 1994;101:10608-13.

Weglartz C, Sandgren EP. Timing of hepatocytes entry into DNA synthesis after partial hepatectomy is cell autonomous. Proc Natl Acad Sci. 2000;97:12595-600.

Williams DP, Shipley R, Ellis MJ, Webb S, Ward J, Gardner L, et al. Novel in vitro and mathematical models for the prediction of chemical toxicity. Toxicol Res. 2013;2:40-59.

Winick M, Noble A. Quantitative changes in DNA, RNA, and protein during prenatal and postnatal growth in the rat. Develop Biol. 1965;12:451. 
Wolpert L, Tickle C. Historia y conceptos básicos (traducción). En: Wolpert L, Tickle C, editores. Principles of Development. 4rd.edition. New York: Oxford University Press; 2011; p. 1-29.

Wood O, Hrushesky W. Circadian timing of cancer chemotherapy. In: Stein GS, Stein JL, Lian JB, editors. Critical reviews in eukaryotic gene expression. 2d. ed. Baltimore: Willims and Wilkins; 1996. p. 177-202.

Woolard J, Bevan HS, Harper SJ, Bates DO. Molecular diversity of VEGF-A as a regulator of its biological activity. Microcirculation. 2009;16:572-92.

Wright N, Alison M. The liver. In: Wright N, Alison M, editors. The Biology of Epithelial Cell Populations. Oxford: Clarendon Press; 1984.

Wright NA, Appleton DR. The metaphase arrest technique. A critical review. Cell Tissue Kinet. 1980;13:643-63.

Xue W, Zender L, Miething C, Dickins RA, Hernando E, Krizhanovsky V, et al. Senescence and tumour clearance is triggered by p53 restoration in murine liver carcinomas. Nature. 2007;445:656-60.

Yamamoto C, Yagi S, Hori T, lida T, Taniguchi K, Isaji S, et al. Significance of portal venous VEGF during liver regeneration after hepatectomy. J Surg Res. 2010;159:e37-43.

Yamazaki Y, Takani K, Atoda H, Morita T. Snake venom vascular endothelial growth factors (VEGFs) exhibit potent activity through their specific recognition of KDR (VEGF receptor 2). J Biol Chem. 2003;278 51985-8.

Yamazaki Y, Matsunaga Y, Tokunaga Y, Obayashi S, Saito M, Morita T. Snake Venom Vascular Endothelial Growth Factors (VEGF-Fs) Exclusively Vary Their Structures and Functions among Species. J Biol Chem. 2009;284:9885-91. 
Yamazaki Y, Morita T. Molecular and functional diversity of vascular endothelial growth factors. Mol Divers. 2006;10:515-27.

Yeakel EH, Farris EJ. Changes with age in the weight of the liver in Wistar Albino rats. Cancer Res. 1947;97:377-8.

Yeakel EH. Increased with induced and transplanted tumors. Cancer Res. 1948;8: 392-6.

Zachary I. VEGF signaling: integration and multi-tasking in endothelial cell biology. Biochem Soc Trans. 2003;31:1171-7.

Zou Y, Bao Q, Kumar S, Hu M, Wang G-Y, Dai G. Four waves of hepatocyte proliferation linked with three waves of hepatic fat accumulation during partial hepatectomy-induced liver regeneration. PLOS ONE. 2012;7:1-8. 


\section{TABLAS}

\section{Zona perivenular}

TABLA 1. Síntesis de ADN y de expresión del VEGF en ratones intactos a lo largo de un periodo circadiano en la zona perivenular.

\begin{tabular}{|c|c|c|}
\hline HD & VEGF & ADNs \\
\hline 12 & $2,65 \pm 0,60(4)$ & $2,21 \pm 0,32(6)$ \\
\hline 16 & $1,09 \pm 0,39(5)$ & $0,71 \pm 0,18(7)$ \\
\hline 20 & $2,21 \pm 1,09(5)$ & $1,06 \pm 0,18(6)$ \\
\hline 00 & $3,68 \pm 1,03(6)$ & $0,66 \pm 0,12(6)$ \\
\hline 04 & $0,48 \pm 0,25(5)$ & $1,26 \pm 0,18(7)$ \\
\hline 08 & $0,71 \pm 0,18(3)$ & $2,12 \pm 0,40(5)$ \\
\hline$X d \pm \operatorname{ESM}(n)$ & $1,92 \pm 0,37(28)$ & $1,30 \pm 0,13(37)$ \\
\hline $\mathbf{P}$ & $<0,05$ & $<0,0001$ \\
\hline Postest & ns & $\begin{array}{l}12-00, p<0,001 \\
08-16, p<0,01 \\
12-16, p<0,001\end{array}$ \\
\hline
\end{tabular}

$\mathrm{HD}$, hora del día; Xd \pm ESM (n), media diaria \pm error estándar de la media (tamaño de la muestra); $p$, probabilidad; ns: diferencias no significativas. 
TABLA 2. Expresión del VEGF, de la síntesis de ADN y de la actividad mitótica en ratones hepatectomizados a diferentes horas posthepatectomía en la zona perivenular.

\begin{tabular}{llll}
\hline $\mathrm{X} \pm \mathrm{ESM}(\mathrm{n})$ & & & \\
\hline HD/HPH & VEGF & ADNs & AM \\
\hline $12 / 26$ & $1,58 \pm 1,17(7)$ & $1,89 \pm 0,56(6)$ & $0,23 \pm 0,05(6)$ \\
$16 / 30$ & $2,40 \pm 1,90(5)$ & $1,06 \pm 0,39(7)$ & $0,77 \pm 0,31(5)$ \\
$20 / 34$ & $2,76 \pm 2,08(6)$ & $11,9 \pm 7,11(4)$ & $0,16 \pm 0,08(6)$ \\
$00 / 38$ & $0,014 \pm 0,01(5)$ & $13,30 \pm 4,06(4)$ & $0,76 \pm 0,45(6)$ \\
$04 / 42$ & $0,95 \pm 0,88(5)$ & $7,86 \pm 1,20(5)$ & $0,76 \pm 0,31(5)$ \\
$08 / 46$ & $0,06 \pm 0,04(5)$ & $2,10 \pm 0,19(6)$ & $3,35 \pm 0,67(6)$ \\
\hline Xd \pm ESM (n) & $1,36 \pm 0,54(33)$ & $5,36 \pm 1,26(32)$ & $1,02 \pm 0,24(34)$ \\
\hline $\mathbf{p}$ & $\mathrm{ns}$ & $<0,01$ & $<0,0001$ \\
& & $00-12, \mathrm{p}<0,05$ & $08-12, \mathrm{p}<0,001$ \\
& & $00-16, p<0,05$ & $08-16, \mathrm{p}<0,001$ \\
Postest & $n$ & & $08-20, \mathrm{p}<0,001$ \\
& & & $08-00, \mathrm{p}<0,001$ \\
& & &
\end{tabular}

HD, hora del día; Xd \pm ESM (n), Media diaria \pm error estándar de la media (tamaño de la muestra); p, probabilidad; ns: diferencias no significativas; AM, actividad mitótica. 
TABLA 3. Expresión del VEGF, de la síntesis de ADN y de la actividad mitótica en ratones portadores-hepatectomizados a diferentes horas posthepatectomía en la zona perivenular.

\begin{tabular}{|c|c|c|c|}
\hline \multicolumn{4}{|l|}{$X \pm \operatorname{ESM}(n)$} \\
\hline HD/HPH & VEGF & ADNs & AM \\
\hline $12 / 26$ & $5,66 \pm 4,1(6)$ & 14. $64 \pm 5,96(6)$ & $0,018 \pm 0,018(6)$ \\
\hline $16 / 30$ & $22,96 \pm 9,14(5)$ & $4,04 \pm 1,95(5)$ & $0,10 \pm 0,06(4)$ \\
\hline $20 / 34$ & $1,35 \pm 1,28(5)$ & $11,44 \pm 3,01(5)$ & $0,72 \pm 0,50$ \\
\hline $00 / 38$ & $1,76 \pm 0,65(4)$ & $7,72 \pm 3,75(6)$ & $0,20 \pm 0,07(4)$ \\
\hline $04 / 42$ & $15,54 \pm 9,10(4)$ & $8,74 \pm 2,63(4)$ & $0,49 \pm 0,18(6)$ \\
\hline $08 / 46$ & $25,94 \pm 5,39(5)$ & $5,30 \pm 1,10(6)$ & $3,50 \pm 0,73(6)$ \\
\hline$X d \pm \operatorname{ESM}(n)$ & $12,22 \pm 2,86(29)$ & $8,7 \pm 1,52(32)$ & $0,93 \pm 0,28(31)$ \\
\hline $\mathbf{p}$ & $<0,02$ & ns & $<0,0001$ \\
\hline Postest & ns & ns & $\begin{array}{l}08-12, p<0,001 \\
08-16, p<0,001 \\
08-20, p<0,001 \\
08-00, p<0,001 \\
08-04, p<0,001\end{array}$ \\
\hline
\end{tabular}

HD, hora del día; Xd \pm ESM (n), Media diaria \pm Error Stándar de la Muestra (tamaño de la muestra); p: probabilidad; ns: diferencias no significativas; AM, actividad mitótica. 


\section{Zona periportal}

TABLA 4. Expresión del VEGF y de la síntesis de ADN en ratones intactos en la zona periportal.

\begin{tabular}{lll}
\hline$X \pm E S M(n)$ & VEGF & ADNs \\
\hline HD & $6,25 \pm 1,73(4)$ & $1,89 \pm 0,39(6)$ \\
12 & $2,94 \pm 0,95(7)$ & $1,02 \pm 0,33(7)$ \\
16 & $6,13 \pm 1,46(4)$ & $1,39 \pm 0,23(5)$ \\
00 & $3,27 \pm 1,32(5)$ & $0,79 \pm 0,23(6)$ \\
04 & $5,46 \pm 1,18(4)$ & $1,48 \pm 0,26(7)$ \\
08 & $1,4 \pm 0,39(5)$ & $2,79 \pm 0.98(5)$ \\
\hline Xd \pm ESM (n) & $3,99 \pm 0,55(29)$ & $1,44 \pm 0,2(36)$ \\
\hline p & $<0,05$ & $<0,05$ \\
Postest & $n s$ & $08-00, p<0,05$ \\
\hline
\end{tabular}

$H D$, hora del día; Xd \pm ESM (n), Media diaria \pm Error Stándar de la Muestra (tamaño de la muestra); p: probabilidad; ns: diferencias no significativas. 
TABLA 5. Expresión del VEGF, de la síntesis de ADN y de la actividad mitótica en ratones hepatectomizados a diferentes horas posthepatectomía en la zona periportal.

\begin{tabular}{llll}
\hline $\mathrm{X} \pm \mathrm{ESM}(\mathrm{n})$ & & & \\
\hline HD/HPH & VEGF & ADNs & AM \\
\hline $12 / 26$ & $0,2 \pm 0,13(6)$ & $2,69 \pm 1,28(6)$ & $0,51 \pm 0,13(6)$ \\
$16 / 30$ & $0,6 \pm 0,43(5)$ & $1,42 \pm 0,43(7)$ & $1,50 \pm 0,54(5)$ \\
$20 / 34$ & $1,46 \pm 0,41(5)$ & $16,19 \pm 6,03(5)$ & $0,70 \pm 0,22(6)$ \\
$00 / 38$ & $0,015 \pm 0,015(5)$ & $11,39 \pm 4,03(5)$ & $0,61 \pm 0,24(6)$ \\
$04 / 42$ & $0,31 \pm 0,26(5)$ & $12,58 \pm 1,56(5)$ & $1,52 \pm 0,22(5)$ \\
$08 / 46$ & $0,23 \pm 0,12(5)$ & $4,09 \pm 0,31(6)$ & $5,27 \pm 0,94(7)$ \\
\hline Xd \pm ESM (n) & $0,46 \pm 0,13(31)$ & $7,39 \pm 1,4(34)$ & $1,8 \pm 0,36(35)$ \\
\hline p & $<0,01$ & $<0,01$ & $<0,0001$ \\
& $20-12, p<0.05$ & $20-12, p<0,05$ & $08-12, p<0,001$ \\
& $20-00, p<0.05$ & $20-16, p<0,01$ & $08-20, p<0,001$ \\
Postest & $20-08, p<0.05$ & $20-08, p<0,05$ & $08-00, p<0,001$ \\
& & & $08-04, p<0,001$ \\
\hline
\end{tabular}

HD, hora del día; Xd \pm ESM (n), Media diaria \pm Error Stándar de la Muestra (tamaño de la muestra); p: probabilidad; ns: diferencias no significativas; AM, actividad mitótica. 
TABLA 6. Expresión del VEGF, de la síntesis de ADN y de la actividad mitótica en ratones portadores-hepatectomizados a diferentes horas posthepatectomía en la zona periportal.

$$
X \pm \operatorname{ESM}(n)
$$

\begin{tabular}{llll}
\hline HD/HPH & \multicolumn{1}{l}{ VEGF } & \multicolumn{1}{l}{ ADNs } & \multicolumn{1}{l}{ AM } \\
\hline $12 / 26$ & $8,05 \pm 4,9(6)$ & $15,86 \pm 6,31(6)$ & $0,18 \pm 0,16(6)$ \\
$16 / 30$ & $24,87 \pm 7,67(5)$ & $3,18 \pm 1,51(5)$ & $0,96 \pm 0,48(4)$ \\
$20 / 34$ & $2,89 \pm 2,77(5)$ & $14,06 \pm 2,76(5)$ & $0,79 \pm 0,36(5)$ \\
$00 / 38$ & $2,92 \pm 1,46(4)$ & $10,22 \pm 5,10(6)$ & $0,60 \pm 0,24(4)$ \\
$04 / 42$ & $13,59 \pm 10,27(4)$ & $7,96 \pm 1,31(4)$ & $0,72 \pm 0,21(6)$ \\
$08 / 46$ & $27,63 \pm 4,30(5)$ & $5,64 \pm 0,64(6)$ & $10,37 \pm 1,05(6)$ \\
Xd \pm ESM (n) & $13,35 \pm 2,84(29)$ & $9,63 \pm 1,7(32)$ & $2,51 \pm 0,73(31)$ \\
\hline $\mathbf{p}$ & $<0,02$ & $\mathrm{~ns}$ & $<0,0001$ \\
& & & $08-12, \mathrm{p}<0,001$ \\
& & $\mathrm{~ns}$ & $08-16, \mathrm{p}<0,001$ \\
Postest & $\mathrm{ns}$ & & $08-20, \mathrm{p}<0,001$ \\
& & & $08-04, \mathrm{p}<0,0001$ \\
\hline
\end{tabular}

HD, hora del día; Xs \pm ESM (n), Media diaria \pm Error Stándar de la Muestra (tamaño de la muestra); p: probabilidad; ns: diferencia no significativas. 


\section{OTRAS TABLAS}

TABLA 7. Comparación de los valores promedio de la expresión del VEGF entre las zonas periportal y perivenular en los animales intactos.

\begin{tabular}{llll}
\hline \multicolumn{4}{l}{ X ESM (n) } \\
\hline HD & periportal & perivenular & p \\
\hline 00 & $3,27 \pm 1,32(5)$ & $3,68 \pm 1,03(6)$ & ns \\
04 & $5,46 \pm 1,18(4)$ & $0,48 \pm 0,25(5)$ & ns \\
08 & $1,4 \pm 0,39(5)$ & $0,71 \pm 0,18(3)$ & ns \\
12 & $6,25 \pm 1,73(4)$ & $2,65 \pm 0,60(4)$ & ns \\
16 & $2,94 \pm 0,95(7)$ & $1,09 \pm 0,39(5)$ & ns \\
20 & $6,13 \pm 1,46(4)$ & $2,21 \pm 1,09(5)$ & ns \\
\hline & & & \\
p & $<0,05$ & $<0,05$ & \\
Postest & ns & ns & \\
\hline
\end{tabular}

Xd $\pm \operatorname{ESM}(n)$, media diaria \pm erros estándar de la media (tamaño de la muestra); HD, hora del día; $p$, probabilidad; ns, diferencia no significativa. 
TABLA 8. Comparación de los valores promedio de la síntesis de ADN entre las zonas periportal y perivenular en los animales intactos.

\begin{tabular}{llll}
\hline \multicolumn{4}{l}{ X ESM (n) } \\
\hline HD & periportal & Perivenular & p \\
\hline 00 & $0,79 \pm 0,23(6)$ & $0,66 \pm 0,12(6)$ & $n s$ \\
04 & $1,48 \pm 0,26(7)$ & $1,26 \pm 0,18(7)$ & $n s$ \\
08 & $2,79 \pm 0.98(5)$ & $2,12 \pm 0,40(5)$ & $n s$ \\
12 & $1,89 \pm 0,39(6)$ & $2,21 \pm 0,32(6)$ & $n s$ \\
16 & $1,02 \pm 0,33(7)$ & $0,71 \pm 0,18(7)$ & $n s$ \\
20 & $1,39 \pm 0,23(5)$ & $1,06 \pm 0,18(6)$ & $n s$ \\
& & & \\
& & $<0,0001$ & \\
Postest & $08-00, p<0,05$ & $08-16, p<0,01$ & \\
& & $12-16, p<0,001$ & \\
\hline
\end{tabular}

$X d \pm \operatorname{ESM}(n)$, media diaria \pm erros estándar de la media (tamaño de la muestra); HD, hora del día; $p$, probabilidad; ns, diferencia no significativa. 
TABLA 9. Comparación de los valores promedio de expresión del VEGF entre las zonas periportal y perivenular en los animales hepatectomizados.

\begin{tabular}{|c|c|c|c|}
\hline & $\mathrm{X} \pm \operatorname{ESM}(\mathrm{n})$ & & \\
\hline $\mathrm{HD} / \mathrm{HPH}$ & periportal & perivenular & $\mathbf{p}$ \\
\hline $12 / 26$ & $0,2 \pm 0,13(6)$ & $1,58 \pm 1,17(7)$ & ns \\
\hline $16 / 30$ & $0,6 \pm 0,43(5)$ & $2,40 \pm 1,90(5)$ & ns \\
\hline 20/34 & $1,46 \pm 0,41(5)$ & $2,76 \pm 2,08(6)$ & ns \\
\hline $00 / 38$ & $0,015 \pm 0,015(5)$ & $0,014 \pm 0,01(5)$ & ns \\
\hline 04/42 & $0,31 \pm 0,26(5)$ & $0,95 \pm 0,88(5)$ & ns \\
\hline $08 / 46$ & $0,23 \pm 0,12(5)$ & $0,06 \pm 0,04(5)$ & ns \\
\hline $\mathbf{p}$ & $<0,01$ & ns & \\
\hline Postest & $\begin{array}{l}20-12, p<0.05 \\
20-00, p<0.05 \\
20-08, p<0.05\end{array}$ & & \\
\hline
\end{tabular}

$\mathrm{HD} / \mathrm{HPH}$, hora del día/hora posthepatectomía; Xd \pm ESM (n), media diaria \pm erros estándar de la media (tamaño de la muestra); $p$, probabilidad; ns, diferencia no significativa. 
TABLA 10. Comparación de los valores promedio de la síntesis de ADN entre las zonas periportal y perivenular en los animales hepatectomizados.

\begin{tabular}{|c|c|c|c|}
\hline & $\mathrm{X} \pm \operatorname{ESM}(\mathrm{n})$ & & \\
\hline HD/HPH & periportal & perivenular & $p$ \\
\hline $12 / 26$ & $2,69 \pm 1,28(6)$ & $1,89 \pm 0,56(6)$ & ns \\
\hline $16 / 30$ & $1,42 \pm 0,43(7)$ & $1,06 \pm 0,39(7)$ & ns \\
\hline $20 / 34$ & $16,19 \pm 6,03(5)$ & $11,9 \pm 7,11(4)$ & ns \\
\hline $00 / 38$ & $11,39 \pm 4,03(5)$ & $13,30 \pm 4,06(4)$ & ns \\
\hline $04 / 42$ & $12,58 \pm 1,56(5)$ & $7,86 \pm 1,20(5)$ & $<0,05$ \\
\hline $08 / 46$ & $4,09 \pm 0,31(6)$ & $2,10 \pm 0,19(6)$ & $<0,001$ \\
\hline $\mathbf{p}$ & $<0,01$ & $<0,01$ & \\
\hline Postest & $\begin{array}{l}20-12, p<0,05 \\
20-16, p<0,01 \\
20-08, p<0,05\end{array}$ & $\begin{array}{l}00-12, p<0,05 \\
00-16, p<0,05\end{array}$ & \\
\hline
\end{tabular}

$\mathrm{HD} / \mathrm{HPH}$, hora del día/hora posthepatectomía; Xd $\pm \operatorname{ESM}(\mathrm{n})$, media diaria \pm erros estándar de la media (tamaño de la muestra); $\mathrm{p}$, probabilidad; ns, diferencia no significativa. 
TABLA 11. Comparación de los valores promedio de la actividad mitótica entre las zonas periportal y perivenular en animales hepatectomizados.

\begin{tabular}{|c|c|c|c|}
\hline & $\mathrm{X} \pm \operatorname{ESM}(\mathrm{n})$ & & \\
\hline HD/HPH & periportal & perivenular & $\mathbf{p}$ \\
\hline $12 / 26$ & $0,51 \pm 0,13(6)$ & $0,23 \pm 0,05(6)$ & ns \\
\hline $16 / 30$ & $1,50 \pm 0,54(5)$ & $0,77 \pm 0,31(5)$ & ns \\
\hline $20 / 34$ & $0,70 \pm 0,22(6)$ & $0,16 \pm 0,08(6)$ & $<0,05$ \\
\hline $00 / 38$ & $0,61 \pm 0,24(6)$ & $0,76 \pm 0,45(6)$ & ns \\
\hline $04 / 42$ & $1,52 \pm 0,22(5)$ & $0,76 \pm 0,31(5)$ & ns \\
\hline 08/46 & $5,27 \pm 0,94(7)$ & $3,35 \pm 0,67(6)$ & ns \\
\hline$p$ & $<0,0001$ & $<0,0001$ & \\
\hline Postest & $\begin{array}{l}08-12, p<0,001 \\
08-16, p<0,001 \\
08-20, p<0,001 \\
08-00, p<0,001 \\
08-04, p<0,001\end{array}$ & & \\
\hline
\end{tabular}

$\mathrm{HD} / \mathrm{HPH}$, hora del día/hora posthepatectomía; Xd $\pm \mathrm{ESM}(\mathrm{n})$, media diaria \pm erros estándar de la media (tamaño de la muestra); $p$, probabilidad; ns, diferencia no significativa. 
TABLA 12. Comparación de los valores promedio de expresión del VEGF entre las zonas periportal y perivenular en los animales portadores de tumor.

\begin{tabular}{|c|c|c|c|}
\hline & $X \pm \operatorname{ESM}(n)$ & & \\
\hline HD/HPH & periportal & perivenular & $\mathbf{p}$ \\
\hline $12 / 26$ & $8,05 \pm 4,9(6)$ & $5,66 \pm 4,1(6)$ & ns \\
\hline $16 / 30$ & $24,87 \pm 7,67(5)$ & $22,96 \pm 9,14(5)$ & ns \\
\hline $20 / 34$ & $2,89 \pm 2,77(5)$ & $1,35 \pm 1,28(5)$ & ns \\
\hline $00 / 38$ & $2,92 \pm 1,46(4)$ & $1,76 \pm 0,65(4)$ & ns \\
\hline $04 / 42$ & $13,59 \pm 10,27(4)$ & $15,54 \pm 9,10(4)$ & ns \\
\hline $08 / 46$ & $27,63 \pm 4,30(5)$ & $25,94 \pm 5,39(5)$ & ns \\
\hline p & $<0,02$ & $p<0,02$ & ns \\
\hline Postest & ns & ns & \\
\hline
\end{tabular}

$\mathrm{HD} / \mathrm{HPH}$, hora del día/hora posthepatectomía; Xd $\pm \operatorname{ESM}(\mathrm{n})$, media diaria \pm erros estándar de la media (tamaño de la muestra); p, probabilidad; ns, diferencia no significativa. 
TABLA 13. Comparación de los valores promedio de la síntesis de ADN entre las zonas periportal y perivenular en los animales portadores de tumor.

\begin{tabular}{llll}
\hline \multicolumn{5}{l}{ X \pm ESM $(\mathrm{n})$} & \\
\hline HD/HPH & periportal & perivenular & $\mathbf{p}$ \\
$12 / 26$ & $15,86 \pm 6,31(6)$ & $14.64 \pm 5,96(6)$ & $\mathrm{ns}$ \\
$16 / 30$ & $3,18 \pm 1,51(5)$ & $4,04 \pm 1,95(5)$ & $\mathrm{ns}$ \\
$20 / 34$ & $14,06 \pm 2,76(5)$ & $11,44 \pm 3,01(5)$ & $\mathrm{ns}$ \\
$00 / 38$ & $10,22 \pm 5,10(6)$ & $7,72 \pm 3,75(6)$ & $\mathrm{ns}$ \\
$04 / 42$ & $7,96 \pm 1,31(4)$ & $8,74 \pm 2,63(4)$ & $\mathrm{ns}$ \\
$08 / 46$ & $5,64 \pm 0,64(6)$ & $5,30 \pm 1,10(6)$ & $\mathrm{ns}$ \\
\hline & & & \\
$\mathbf{P}$ & $\mathrm{ns}$ & $\mathrm{ns}$ & \\
\hline
\end{tabular}

$\mathrm{HD} / \mathrm{HPH}$, hora del día/hora posthepatectomía; Xd $\pm \operatorname{ESM}(\mathrm{n})$, media diaria \pm erros estándar de la media (tamaño de la muestra); p, probabilidad; ns, diferencia no significativa. 
TABLA 14. Comparación de los valores promedio de la actividad mitótica entre las zonas periportal y perivenular en los animales portadores de tumor.

\begin{tabular}{|c|c|c|c|}
\hline & $\mathrm{X} \pm \operatorname{ESM}(\mathrm{n})$ & & \\
\hline HD/HPH & periportal & perivenular & $p$ \\
\hline $12 / 26$ & $0,18 \pm 0,16(6)$ & $0,018 \pm 0,018(6)$ & ns \\
\hline $16 / 30$ & $0,96 \pm 0,48(4)$ & $0,10 \pm 0,06(4)$ & ns \\
\hline $20 / 34$ & $0,79 \pm 0,36(5)$ & $0,72 \pm 0,50(5)$ & ns \\
\hline $00 / 38$ & $0,60 \pm 0,24(4)$ & $0,20 \pm 0,07(4)$ & ns \\
\hline $04 / 42$ & $0,72 \pm 0,21(6)$ & $0,49 \pm 0,18(6)$ & ns \\
\hline $08 / 46$ & $10,37 \pm 1,05(6)$ & $3,50 \pm 0,73(6)$ & $<0,001$ \\
\hline $\mathbf{P}$ & $<0,0001$ & $<0,0001$ & \\
\hline Postest & $\begin{array}{l}08-12, p<0,001 \\
08-16, p<0,001 \\
08-20, p<0,001 \\
08-00, p<0,001 \\
08-04, p<0,001\end{array}$ & & \\
\hline
\end{tabular}

$\mathrm{HD} / \mathrm{HPH}$, hora del día/hora posthepatectomía; Xd $\pm \operatorname{ESM}(\mathrm{n})$, media diaria \pm erros estándar de la media (tamaño de la muestra); p, probabilidad; ns, diferencia no significativa. 
TABLA 15. Comparación de los valores promedio diarios de la síntesis de ADN entre los ratones intactos, hepatectomizados y portadores-hepatectomizados de las zonas periportal y perivenular.

\begin{tabular}{|c|c|c|c|}
\hline & \multicolumn{3}{|l|}{$\mathrm{Xd} \pm \operatorname{ESM}(\mathrm{n})$} \\
\hline & periportal & perivenular & $p$ \\
\hline Int & $1,44 \pm 0,2(36)$ & $1,30 \pm 0,13(37)$ & ns \\
\hline Hep & $7,39 \pm 1,4(34)$ & $5,36 \pm 1,26(32)$ & ns \\
\hline PortHep & $9,63 \pm 1,7(32)$ & $8,7 \pm 1,52(32)$ & ns \\
\hline \multirow{2}{*}{ Postest } & \multicolumn{3}{|l|}{ Int-Hep, $p<0,01$} \\
\hline & \multicolumn{3}{|c|}{ Int-PortHep, $p<0,001$} \\
\hline
\end{tabular}

Int, animales intactos; Hep, animales hepatectomizados; PortHep, animales portadoreshepatectomizados; $\mathrm{Xd}$, media diaria; $\mathrm{p}$, probabilidad; ns, diferencia no significativa. 
TABLA 16. Comparación de los valores promedio diarios de la expresión del VEGF entre los ratones intactos, hepatectomizados y portadoreshepatectomizados de las zonas periportal y perivenular.

\begin{tabular}{|c|c|c|c|}
\hline & \multicolumn{3}{|l|}{$X d \pm \operatorname{ESM}(n)$} \\
\hline & periportal & perivenular & $\mathbf{p}$ \\
\hline Int & $3,99 \pm 0,55(29)$ & $1,92 \pm 0,37(28)$ & $<0,001$ \\
\hline Hep & $0,46 \pm 0,13(31)$ & $1,36 \pm 0,54(33)$ & ns \\
\hline PortHep & $13,35 \pm 2,84(29)$ & $12,22 \pm 2,86(29)$ & ns \\
\hline Postest & \multicolumn{3}{|c|}{ PortHep-Int, $p<0,001$} \\
\hline & \multicolumn{3}{|c|}{ PortHep-Hep, $p<0,01$} \\
\hline
\end{tabular}

Int, animales intactos; Hep, animales hepatectomizados; PortHep, animales portadoreshepatectomizados; $\mathrm{Xd}$, media diaria; $\mathrm{p}$, probabilidad; ns, diferencia no significativa. 
TABLA 17. Comparación de los valores promedio diarios de la actividad mitótica entre los ratones intactos, hepatectomizados y portadores-hepatectomizados de las zonas periportal y perivenular.

\begin{tabular}{llll}
\hline & Xd $\pm \operatorname{ESM}(\mathrm{n})$ & & \\
\hline & periportal & perivenular & p \\
\hline Hep & $1,8 \pm 0,36(35)$ & $1,02 \pm 0,24(34)$ & ns \\
PortHep & $2,51 \pm 0,73(31)$ & $0,93 \pm 0,28(31)$ & $<0,05$ \\
\hline Postest & ns & ns & \\
\hline
\end{tabular}

Int, animales intactos; Hep, animales hepatectomizados; PortHep, animales portadoreshepatectomizados; Xd, media diaria; $p$, probabilidad; ns, diferencia no significativa. 


\section{BECAS Y FINANCIAMIENTO}

- Esta Tesis Doctoral ha sido desarrollada durante el transcuro de las Becas de Perfeccionamiento a la Investigación y de Formación Superior, otorgadas por la Universidad Nacional de La Plata, durante el periodo 2008-2012.

- La fuente de financiamiento para la realización de la presente Tesis Doctoral surgió de los proyectos acreditados por el Ministerio de Educación de la Nación, dentro del marco del Plan de Incentivos para docentes investigadores:

- Estudio de la proliferación celular y la angiogénesis en diferentes poblaciones celulares normales y tumorales (Proyecto № $M / 129$ ), con la dirección de la Prof. Dra. Ana Lía Errecalde y bajo la codirección de la Prof. Dra. Ana María Inda, desde el 01/01/08 al $31 / 21 / 11$.

- Estudio de la proliferación celular y la angiogénesis en diferentes poblaciones celulares normales y tumorales. Parte II (Proyecto № M/160), con la dirección de la Prof. Dra. Ana Lía Errecalde y bajo la co-dirección de la Prof. Dra. Ana María Inda, desde el 01/01/12 al $31 / 21 / 15$. 


\section{PUBLICACIONES}

Fernández-Blanco A, Inda AM, Errecalde AL. DNA synthesis in periportal and perivenous hepatocytes of intact and hepatectomized young mice. J Immunoassay Immunohistochem. 2015; 36:456-63.

Andrini L, Fernández Blanco A, Inda AM, García M, García A, Errecalde A. VEGF expression in hepatectomized tumour-bearing mice. J Immunoassay Immunochem. 2011; 32:318-25. 